Utah State University

DigitalCommons@USU

$12-2008$

\title{
The Evaluation of Synchronous Online Tutoring for Students At- Risk of Reading Failure
}

Eleazar Vasquez III

Utah State University

Follow this and additional works at: https://digitalcommons.usu.edu/etd

Part of the Special Education and Teaching Commons

\section{Recommended Citation}

Vasquez III, Eleazar, "The Evaluation of Synchronous Online Tutoring for Students At-Risk of Reading Failure" (2008). All Graduate Theses and Dissertations. 285.

https://digitalcommons.usu.edu/etd/285

This Dissertation is brought to you for free and open access by the Graduate Studies at DigitalCommons@USU. It has been accepted for inclusion in All Graduate Theses and Dissertations by an authorized administrator of DigitalCommons@USU. For more information, please contact digitalcommons@usu.edu.

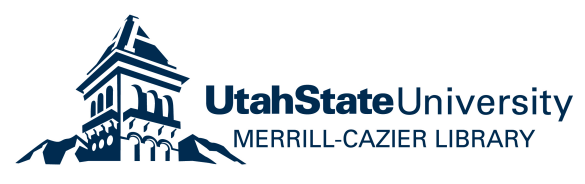


THE EVALUATION OF SYNCHRONOUS ONLINE TUTORING FOR STUDENTS

AT RISK OF READING FAILURE

by

Eleazar Vasquez III

A dissertation submitted in partial fulfillment

of the requirements for the degree

of

DOCTOR OF PHILOSOPHY

in

Disability Disciplines

Approved:

Timothy A. Slocum

Major Professor

Robert L. Morgan

Committee Member

Benjamin Lignugaris/Kraft

Committee Member
David E. Forbush

Committee Member
Brian Belland
Committee Member

Byron R. Burnham

Dean of Graduate Studies

UTAH STATE UNIVERSITY

Logan, Utah

2009 
Copyright (c) Eleazar Vasquez III 2009

All Rights Reserved 
ABSTRACT

The Evaluation of Synchronous Online Tutoring for Students

At-Risk of Reading Failure

by

Eleazar Vasquez III, Doctor of Philosophy

Utah State University, 2009

Major Professor: Dr. Timothy A. Slocum

Department: Special Education and Rehabilitation Counseling

Both legislative mandates such as those of No Child Left Behind (NCLB), and developments in the provision of reading instruction such as Response to Intervention (RTI), increase the demand for high quality tutoring services. However, the U.S.

Department of Education and state officials report that access to intensive supplemental tutoring may be limited in rural and urban areas due to limited availability of qualified providers. Online tutoring may be one way to provide supplemental reading instruction to students identified as at-risk of reading failure.

Researchers have focused on distance education since the 1920s. The authors of recent meta-analyses report near zero effect sizes between distance education and traditional face-to-face instruction for adults, paraprofessionals, postsecondary, and K-12 students. Relatively little information is available about the effects of distance education on $\mathrm{K}-12$ students at-risk of reading failure. To update and narrow the search of previous reviews, we systematically reviewed literature on distance education for at-risk K-12 
students. We found 39 articles that met our search criterion. None of the 39 articles provided empirical evidence on the effects of distance education for at-risk K-12 students.

The purpose of this study was to examine the effects of online reading instruction for at-risk fourth-grade students in Utah and Philadelphia. A multiple baseline design was used to assess the extent to which at-risk fourth-grade students increase their oral reading rate given systematic supplemental online reading instruction. Tutoring consisted of four sessions per week with 50-minute lessons of direct instruction delivered over a webbased synchronous two-way audiovisual system. Analysis of the multiple baseline across participants revealed gains in oral reading fluency for all participants when placed into the synchronous online tutoring program. Additionally, all participants made standard score gains on basic reading skills as assessed by the Woodcock Johnson Test of Achievement and Dynamic Indicators of Basic Early Literacy Skills (DIBELS) benchmark assessments. Participating students and tutors reported an awareness of increased reading skills and value of synchronous online instruction. Finally, teachers and parents generally reported that students demonstrated increased reading skills after receiving instruction. 
This dissertation is the end result of a journey and dream to become a humble scholar in the field of special education. I would like to thank my major professor, Dr. Timothy Slocum, for his patience, diligence, and most importantly, his friendship while working with me during my program. He has modeled devotion to scholarship and excellence while shaping me into a teacher educator. Thanks Tim for helping me to "see the edge of the cliff without falling." I also extend my deep appreciation to Dr. David Forbush for the numerous discussions and initiation of the project, and allowing me to contribute to its outcome. I would also like to thank Dr. Benjamin Lignugaris/Kraft for his feedback and direction on the data analysis. Finally, I would like to thank Drs. Robert Morgan, David Wiley, Brian Belland, and Charles Salzberg for their feedback and contribution to this work.

I am indebted and thankful for my wife, Melissa, who willingly moved to the distant land of Utah without question to allow me to pursue and complete this goal. You supported and encouraged me to complete my studies despite living with a doctoral student and his mistress "grad school." Melissa, I couldn't have done it without you. You are my blessing and love of my life. I am extremely thankful for my parents, Eleazar and Bertha, who freely game themselves to invest in me and who believed in me, even while I was in high school. In addition, I would like to dedicate this study to my grandparents Ermelinda Pacheco, and Eleasar and Beatrice Vasquez. They were models of love, strength, wisdom, and understanding. Most importantly they set the tempo of our family values and stressed the importance of education. 
I would like to express my appreciation for my fellow graduate students and colleagues, especially Drs. Donald Stenhoff, Lee Mason, Brian Davey, and Michael Orosco, for their friendship and encouragement. To my good friend George Wooton, thank you for the words of encouragement, daily racquetball games, sampling of "good tequila" and sharing family stories. Finally, to Co, Tammy, Kris, and Jill, I appreciate your dedication to the department. Your support enabled me to finish. 
ABSTRACT iii

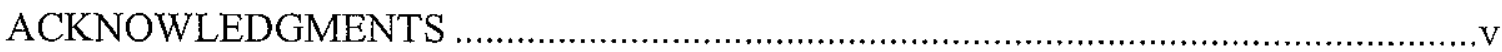

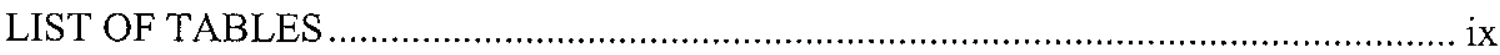

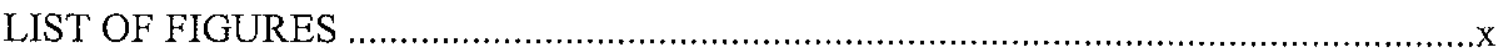

\section{CHAPTER}

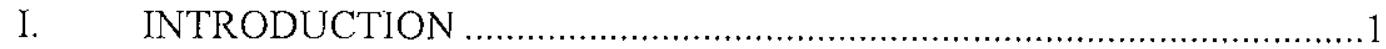

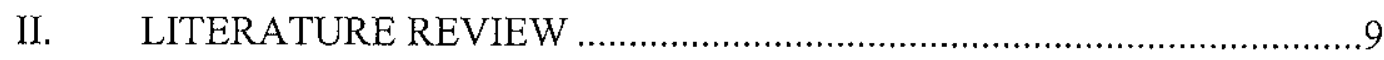

Significant Historical Factors ........................................................... 9

Review of Distance Education Effectiveness Research...........................12

Independent Review of Distance Education Literature on At-Risk Students .................................................................20

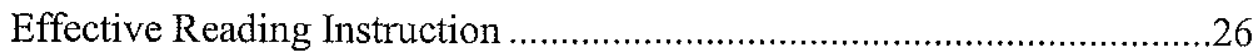

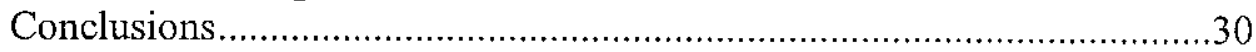

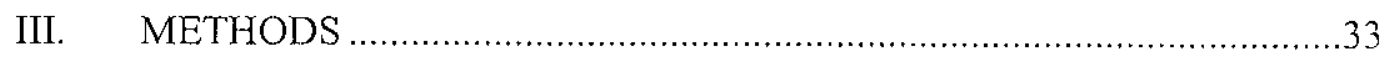

Participants and Settings ......................................................................33

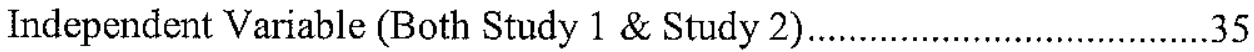

Tutor Training (Both Study $1 \&$ Study 2) ..............................................4 40

Measures (Both Study 1 \& Study 2) ...................................................4 42

Procedures, Experimental Design, and Conditions (Both Study 1

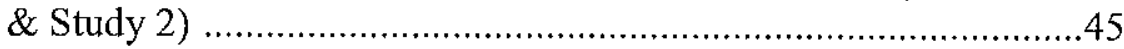

Data Analysis (Both Study 1 \& Study 2) .........................................47

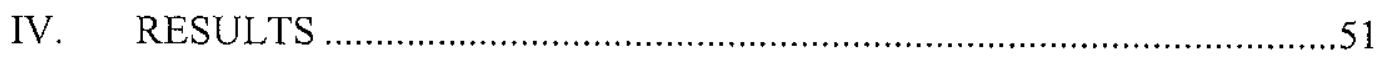

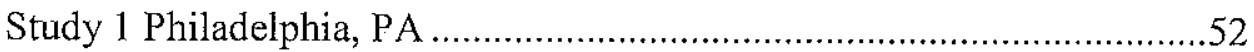

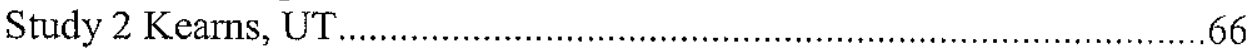

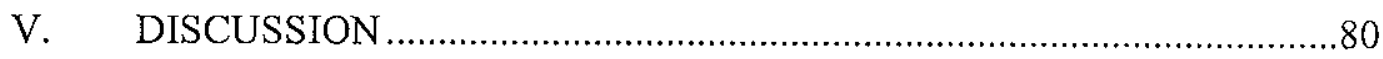

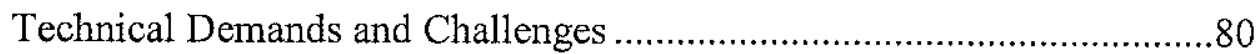




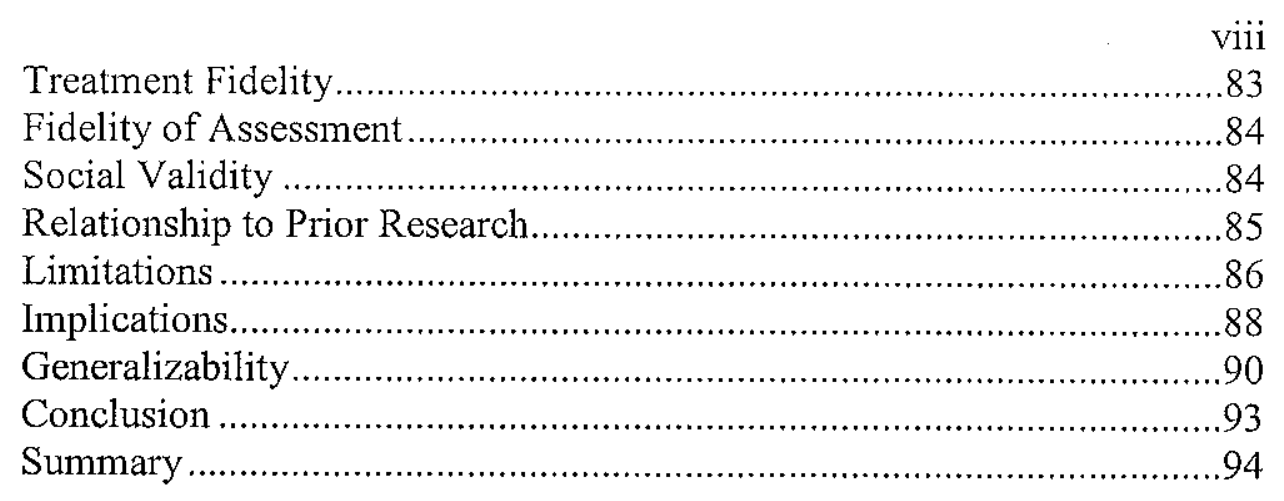

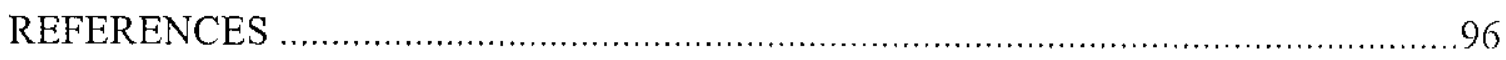

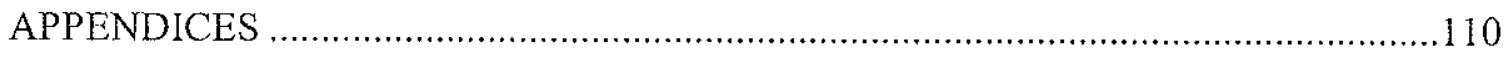

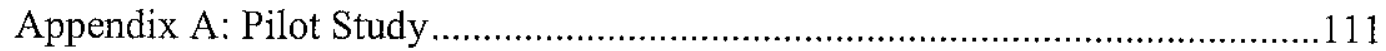

Appendix B: Direct Instruction Supervision System..........................................114

Appendix C: Dynamic Indicator Battery of Early Literacy Skills

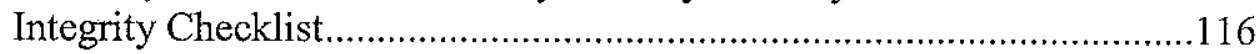

Appendix D: Woodcock Johnson-III Test of Academic Achievement

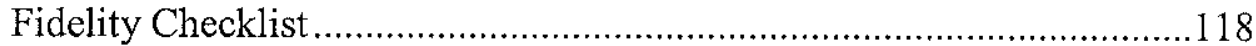

Appendix E: Social Validity Questionnaire .......................................................120

Appendix F: Informed Consent ......................................................................124

Appendix G: Permission to Use Adobe Connect Screen Shot ...........................137

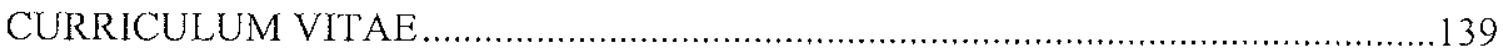


1 Number of Articles Identified by Type of Technology and Participant ...............24

2 Interobserver Agreement for All Dependent Measures in Philadelphia ...............52

3 Assessment of Treatment Fidelity (Direct Instruction Observation Form) ......... 54

$4 \quad$ Fidelity of Assessment Delivery For Pre and Posttest Measures .........................55

5 Comparison of expected ORF Gains Compared to Actual Gain Scores for

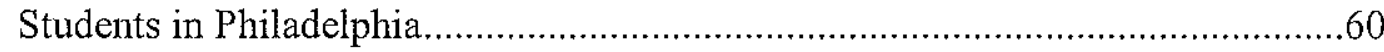

6 Social Validity Outcomes for Participants in Philadelphia................................63

7 Interobserver Agreement for Dependent Measures in Kearns.............................66

8 Assessment of Treatment Fidelity (Direct Instruction Observation Form) ..........67

$9 \quad$ Assessment of Fidelity for Pre/Posttest Measures ..........................................68

10 Comparison of Expected ORF Gains Compared to Actual Gain Scores for Students in Kearns ......................................................................................... 75

11 Social Validity Outcomes for Participants in Kearns .......................................77

12 Possible Generalization of Research Findings................................................. 91 
LIST OF FIGURES

Figure

1 Screen shot of synchronous online tutoring delivered over Adobe Connect system 38

2 Results of online tutoring for students in Philadelphia. Data represent median number of words read correctly per min in a multiple baseline across participants design

3 DIBELS benchmark pre- and posttest scores in words read correct per minute for students in Philadelphia. .58

4 Woodcock Johnson III reading cluster scores .59

5 Results from individual Woodcock Johnson III reading subtests. 61

6 Results of supplemental online instruction to students in Kearns, UT .70

7 DIBELS oral reading fluency benchmark pre and posttest results 72

8 Woodcock Johnson III reading cluster scores .73

9 Results from individual Woodcock Johnson III reading subtests. .74 


\section{CHAPTER I}

\section{INTRODUCTION}

The ability to read accurately and fluently is a highly valued skill in any literate society. Upon entering school, many children learn to read without great difficulty; however, each year a proportion of children experience significant problems learning to read (Catts, Fey, Tomblin, \& Zhang, 2002). Authors of the 2005 National Academy of Science's report on Preventing Reading Difficulties in Young Children state, "current difficulties in reading largely originate from rising demands for literacy, not from declining absolute literacy levels. "In a technological society, the demands for higher literacy are ever increasing, creating more grievous consequences for those who fall short" (Snow, Burns, \& Griffen, 1998, p. 1). Clearly, reading is essential to success in modern American society. Reading is required to execute critical tasks (e.g., reading instructions, reading magazines and newspapers, gaining access to literature, completing tax forms and paying bills, and accessing the internet) within school, home, and community environments. Lack of reading skills produces immediate functional deficits in response to environmental demands (e.g., driving, shopping, reading warning signs, etc.), and also produces long-term limitations for individuals in future, more complex and technical, environments (e.g., working with computers, internet banking, reading news feeds, etc.).

Educators, the public, and politicians have long recognized the social importance of literacy development. As part of his vision of a Great Society, President Johnson authorized the Elementary and Secondary Education Act (ESEA, 1965) to address the growing concern about student achievement, and more specifically, to make educational opportunities available to the poor. American politicians continue to promote literacy 
through legislation such as the Improving America's Schools Act of 1994, and the No Child Left Behind Act (NCLB, 2001). Under NCLB provisions, states must set specific performance standards in reading and math, and describe how they will ensure that all students, including disadvantaged students, will achieve these academic proficiency standards. States must produce annual state and school district report cards informing parents and communities about school performance. Schools consistently failing to achieve adequate yearly progress (AYP) are subject to sanctions, increasing in cumulative fashion for five consecutive years (United States Department of Education [USDOE], 2002).

In spite of decades of attention by educators and lawmakers, many students still struggle with reading. For example, the College Board recently released SAT test scores for the class of 2007, which reaffirmed the need for more support for our students. The class of 2007 SAT test-takers was the largest and most diverse to date. However, there was a decline in reading and math scores for the second consecutive year (Spellings, 2007). In 2007 the National Assessment of Educational Progress (NAEP) released the Nation's Report Card indicating mixed results in reading performance. Despite recent attention to reading instruction; nationally, fourth graders' average score in 2007 was only one point higher than 2005 (218 to 219 on a 500 point scale) (NAEP, 2007). While recent aggregated NAEP scores show minimal positive growth, disaggregated data continue to show substantial performance differences across genders, ethnic/racial groups, and social classes (SES levels). For example, in 2007 NAEP scores for Caucasian and Asian students in the fourth grade averaged 26.7 points higher than American Indian, Hispanic, and Black students. Fourth-grade students eligible for free and reduced lunch score, on 
average, 27 points lower on reading assessments than students who do not qualify for free and reduced lunch. These outcomes are alarming in light of data suggesting that students who are not proficient readers by fourth grade are not likely to become proficient adult readers (Campbell, Hombo, \& Mazzeo, 2000).

Many reading researchers (e.g., Blackman 1996, 1997; Felton, 1993; Fletcher \& Lyon, 1998; Torgesen, 1997) argued the vast majority of reading problems can be prevented through early identification and high quality research-based instruction. Lyon (2001) estimates that through appropriate, explicit, comprehensive, and intensive early instruction, we can decrease the number of children experiencing reading failure by approximately two-thirds. Through an extensive review of thousands of research studies, the National Reading Panel (NRP, 2000), identified five critical elements of reading (i.e., phonemic awareness, phonics, fluency, vocabulary, reading comprehension) that, if attended to instructionally, may result in skill improvements for many children.

One NCLB mandate is the requirement that public schools failing to achieve AYP for three consecutive years and identified as in need of improvement must provide low SES students' parents with a list of supplemental service providers to provide tutoring services at the schools expense (United States Department of Education [USDOE], 2002). Supplemental educational service is additional academic instruction designed to increase the academic achievement of students in schools in need of improvement. NCLB defines supplemental services as "tutoring, remediation and other educational interventions, provided that such approaches are consistent with the content and instruction used by the local educational agency (LEA) and are aligned with the State's academic content standards" (USDOE, 2005, p. 1). According to NCLB regulations, supplemental 
educational services must be high quality, research-based, and specifically designed to increase student academic achievement (USDOE, 2002). The State Education Agency (SEA) must identify providers, maintain a list of providers, and monitor services (USDOE, 2005). Specifically, the SEA must: (a) Consult with parents, teachers, LEA's, and interested members of the public to promote maximum participation by providers to ensure, to the extent practicable, that parents have as many choices as possible; (b) provide and disseminate broadly, through an annual notice to potential providers, the process for obtaining approval to be a provider of supplemental educational services; (c) develop and apply objective criteria for approving potential providers; (d) maintain an updated list of approved providers, across the State, by school district, from which parents may select; (e) develop, implement, and publicly report on standards and techniques for monitoring the quality and effectiveness of services offered by approved supplemental educational services providers, and for withdrawing approval from providers that fail, for two consecutive years, to contribute to increasing the academic proficiency of students served by the providers (USDOE, 2005). Thus, NCLB has mandated that states establish an elaborate system for promoting access to these supplemental tutoring services. This might be expected to dramatically increase demand for these services. In fact, in the state of Utah, there are currently 15-registered supplemental service providers. Services range in price from $\$ 17.35 \mathrm{hr}$ to $\$ 2000$ per student per month (Utah State Office of Education, n.d.). All service providers are required to be research based; however, little to no information is available regarding empirical validation of these services.

Similar to NCLB, the reauthorized Individuals with Disabilities Education Improvement Act (IDEIA) $(1997,2004)$ requirements provide individualized instruction 
for students with disabilities. In updating IDEIA, Congress found that the education of students with disabilities has been impeded by "low expectations and an insufficient focus on applying replicable research on proven methods of teaching and learning" (PL 108446, p. 4). Significant changes to IDEIA as well as a close alignment to NCLB are designed to provide students with disabilities access to high expectations and to the general education curriculum in the regular classroom, to the maximum extent possible in order to "meet developmental goals and, to the extent possible, the challenging expectations that have been established for all children" (PL 108-446, p.6).

To meet the NCLB and IDEIA standards and mandates many schools have turned to Response to Intervention models (RTI). RTI is the practice of providing high-quality instruction and intervention matched to student need, monitoring progress frequently to make decisions about change in instruction or goals, and applying child performance data to decisions about level of services for students (NASDSE, 2005). The most common RTI models employ three tiers of increasingly intense interventions, with the second and third tiers including intensive instruction delivered to small groups (i.e., $<3$ students per group) and in some cases individual tutoring (Fuchs, Mock, Morgan, \& Young, 2003; McCook, 2006). Thus, RTI is another source of demand for individual tutoring in reading using research-based curricula.

Ensuring access to these research-based and intensive Tier II and III services or mandated supplemental education/tutoring services for students with reading skill deficits will be difficult. Numerous researchers document the disparities in educational funding between and within districts (Elliott, 1998; Hanushek, 1994; NRC, 1999; Reeves, 2003). Elliott analyzed National Education Longitudinal Study (NELS) data from the early 1990s 
and found that money impacts achievement gains, suggesting that more money allows districts to hire better-trained teachers who use more effective instructional strategies and high quality supplemental services. Thus, under-funded schools would be expected to have the greatest need for intensive Tier II and III instruction within RTI models, and would be most likely to fall under NCLB sanctions that require provision of supplemental services; at the same time, these are the schools with the most limited funds to support these services. Unfortunately the existing funding disparities make it difficult for administrators to find and pay for federally mandated supplemental services.

As some rural and inner city school districts attempt to provide a list of state approved service providers to parents of students in schools "in need of improvement" several significant challenges have arisen concerning the provision of services in those geographic areas. First, service providers do not have to agree to provide their services to every school district in the state (Reeves, 2003). Therefore suburban schools have a distinct advantage in attracting supplemental services in that they may be a more lucrative market for providers. Both rural and inner city locations lack economic resources to attract companies that provide these services (Clark \& Gorski, 2002; Reeves). Second, many of the companies applying to provide services simply do not operate facilities in rural areas (Reeves). Though mandated, the USDOE estimates that during the 2003-2004 school year, 2 million students qualified for supplemental tutoring services, but only 226,000 (8.85\%) actually received them (USDOE, 2005). Richard (2005) surveyed state officials in rural and urban areas and found that these services were frequently unavailable. She identified several factors reducing rural students' access to supplemental services. These include a lack of well-qualified tutors, inadequate transportation for eligible students, and 
reluctance of for-profit companies to serve areas where few students qualify. Limited access to supplemental services for students at-risk of academic failure functionally denies them the NCLB-mandated high quality research-based instruction that could prevent or remediate skill deficits in reading.

In addition, it is unclear who regulates or monitors the effects of these services on children. According to USDOE (2005), states must develop and apply objective criteria for evaluating providers and monitor the quality of services. It is unclear whether supplemental service providers use research-based curriculum and to what extent the states monitor these services (Anderson \& Laguarda, 2005). When supplemental service providers do use research-based curriculum it is unclear how the curriculum was empirically evaluated. For example, the Utah State Office of Education website provides a description of the state approved supplemental service providers. Of the 15 state approved programs only 2 provide information in the category "research based curriculum" the other 13 providers just indicate "yes" (Utah State Office of Education, n.d.).

One way to meet students' needs in locations in which high quality tutoring is not available is to supplement classroom instruction with synchronous online tutoring that provides systematic, comprehensive, and explicit instruction. Synchronous online tutoring refers to $1: 1$ tutoring taking place in real time in which the tutor is physically distant from the student. Synchronous online tutoring may offer important advantages including: (a) access to skilled tutors beyond students' geographic boundaries; (b) online tutoring can be made available during school or outside of school hours; (c) online tutoring can be accessed from home, school, or other locations, (d) online tutoring in the home may increase parent involvement by providing frequent updates and debriefing of each tutoring 
session, and (e) online tutoring over a synchronous technology may allow tutors to provide immediate feedback and error correction.

Branzburg (2004) identified seven for-profit companies that use synchronous and/or asynchronous online technology to deliver instruction. Reportedly, each of these businesses provides some homework assistance (e.g., daily independent practice of math facts or reading assistance) and two programs provide tutoring services (e.g., use of company created curriculum). None of the companies offer synchronous audio/video curriculum delivery with individualized instruction (Branzburg). None of the companies report use of a research-based curriculum or provide empirical evidence to support their claims that they are highly effective (Branzburg). In fact, all seven companies rely on client testimonials as the basis for making their claims. In addition, schools or parents incur a substantial cost to purchase these services - cost ranges from $\$ 35$ to $\$ 140$ per hour (Branzburg). Thus, it appears that there is a need for additional research and development of systems to provide research-based online tutoring that is accessible and affordable.

Given NCLB mandates along with recent national test results, there is a clear need for broad access to high quality supplemental reading instruction including individual tutoring. The lack of instructional resources in rural and inner city, suggest that there is a strong need to examine alternative practices for providing supplemental reading services. Synchronous online tutoring is one promising method for increasing access to these services. This dissertation evaluates the effectiveness of synchronous online tutoring for students at-risk of reading failure. 
CHAPTER II

\section{LITERATURE REVIEW}

\section{Significant Historical Factors}

Distance education holds tremendous promise, offering viable and attractive options for advancing student skills, increasing access, and potentially lowering the cost of educational services. For some, the term distance education may still call up old images of educational television or other such dated methods. However, the media used in distance education have undergone remarkable changes over the years. A comprehensive definition of distance education must be broad because it encompasses so many different learning environments. Greenberg (1998) defined contemporary distance education as "a planned teaching/learning experience that uses a wide spectrum of technologies to reach learners at a distance and is designed to encourage learner interaction and increases in learning" (p. 36). Teaster and Blieszner (1999) indicated that distance learning may be applied to many instructional methods: "however, its primary distinction is that the teacher and the learner are separate in space and possibly time" (p. 741). Keegan (1996) provides a thorough definition, one that is frequently cited by researchers. He stated that distance education and training result from the technological separation of teacher and learner which frees the student from the necessity of traveling to "a fixed place, at a fixed time, to meet a fixed person, in order to be trained" (p. 7). Keegan's definition of distance education involves five qualities that distinguish it from other forms of instruction: (a) the quasi permanent separation of teacher and learner; (b) the influence of an educational organization in planning, preparation, and provision of student support; (c) the use of 
technical media; (d) the provision of two-way communication; and (e) the quasi permanent absence of learning groups.

A great deal of research on distance education focuses on comparing media. New media are typically compared to traditional face-to-face instruction to determine whether the new media is more, less, or similarly effective relative to traditional instruction. Clark $(1983,1994)$ ignited a debate on the relevance of such media comparison studies. Clark begins the debate by stating that, "media do not influence learning under any conditions." He states that media are "mere vehicles that deliver instruction but do not influence student achievement anymore than the truck that delivers out groceries causes changes in our nutrition" (1983). Clark updated his analogy in 1994, comparing the various methods of pharmaceutical delivery methods (pills, suppositories, IV, and injections) with their effectiveness. He indicated that the delivery method does not increase the patients' health; rather, improvement in health outcomes is the result of active chemical ingredients (1994). At the core of Clark's argument is the dichotomy between two components of instruction: (a) the instructional design (the information given to the student, the responses the student makes, the feedback the student is given, and so on); and (b) the media that delivers this instruction (live interaction, paper and pencil, computer delivered, etc.). He argued that most media comparison studies confound these two kinds of variables. That is, when two media are compared, the programs offered over the competing media also differ in their instructional design. If one program has a more effective instructional design, we would expect it to be more successful, and its success could not be attributed to the delivery medium. Only if the instructional design were identical across media could a valid comparison be made. But if instructional design were equated, then by definition, there 
would be no differences in relevant learning experiences for the student. Thus, according to Clark, media per se is neutral. Media simply deliver the instruction; it is the instruction that is responsible for learning.

Several researchers (Kozma, 1994; Morrison, 1994; Tennyson, 1994; Ullmer, 1994) rebut Clark's $(1983,1994)$ position. Kozma's main argument is that both media and methods are part of the instructional design. "Media must be designed to give us powerful new methods, and our methods must take appropriate advantage of media's capabilities" (p. 16). Further, Kozma suggested that recent media uses involve highly interactive sets of events that occur between learners and teachers, among learners (e.g., collaborative learning), and even between learners and nonhuman agents or tools; so considering media and instruction to be discrete variables no longer makes sense. Kozma has claimed that these interactive media are not neutral carriers of content, but allow for specific kinds of instructional interactions and therefore are potentially active elements of instruction. That is, new media offer options for instructional interactions that are simply not possible in other media. Thus, holding instructional features constant removes critical and potentially powerful features of various media. According to this view, the point of developing new media is to enable instructional interactions that were not possible (or were difficult) with previously available media.

Both arguments contain valid points. As Clark $(1983,1994)$ noted, media, instruction, and curriculum are frequently confounded and disentangling them is difficult at best. Further, if instruction and curriculum are equated, then media comparisons become trivial. However, media can certainly hinder the delivery of instruction and thereby impact student outcomes. For example, if one attempts to teach reading over the 
radio, it would be very difficult to present specific written words and point out specific letters within the words. In addition, providing proper error correction would be impossible. In this example, the technology simply does not afford the necessary modality to present visual stimuli nor the interactive capabilities to provide the necessary discriminated feedback on student responses. However, with a computer conferencing system that can afford real time two-way audio and video, reading instruction is much less hindered by the technology. If media can hinder instruction (relative to face-to-face), there may be ways that media may afford instructional opportunities not available in face-toface instruction. The ways that media may enhance or hinder instruction may be subtle; therefore, any new form of technology used to deliver instruction should be empirically validated in order to make claims of effectiveness. Unfortunately, little validation research of this type is available.

\section{Review of Distance Education Effectiveness Research}

The logical implication of Clark's $(1983,1994)$ position is that when instructional and content factors are reasonably well controlled, comparative research should find no differences between media; and when differences are found, media is likely confounded with substantial instructional and content differences. We can examine the comparative distance education research literature to see whether this pattern is present.

Numerous narrative reviews, meta-analyses of the media comparison, and distance education literatures are available and results of these reviews have not always agreed. One of the most widely cited reviews is Russell's (1999) annotated bibliography of 335 papers and articles that show no significant difference between traditional and 
technologically delivered instruction. This work is often cited as empirical support for Clark's $(1983,1994)$ argument. Russell declared that there was no compelling evidence to refute Clark's original 1983 claim that a delivery medium contributes little if anything to the outcomes of planned instruction and that technology-delivered distance education confers no advantages in terms of educational outcomes. However, according to Russell, "I did not use any scientific sampling method but instead listed every study found that showed no significant difference.... The point remains that...studies [showing a significant difference] are practically nonexistent and the very few that do exist are offset by a like number which show negative results for the technology based instruction" ( $\mathrm{p}$. xiii). Essentially, Russell selected studies based on their outcomes, cited those that showed no significant difference in the annotated bibliography, and excluded articles which showed a significant difference. For these reasons, numerous researchers (e.g., Bernard et al., 2004; Diaz \& Cartnal 1999; Ehrmann, 1995; Kozma, 1994; Moore \& Thompson, 1997; Saba, 1999) question the validity of Russell's claims. To address other researchers' questions, Russell developed a website that now accepts both significant and nonsignificant articles into a database (Russell, 2008).

Bernard et al. (2004) argued that there are several problems with Russell's (1999) approach. First, not all studies are of equal quality and rigor, and to include them all, without qualification or description, renders conclusions and generalizations difficult. Second, Bernard argued that an accepted null hypothesis is not strong evidence that there is no difference between the treatments; it only means that any differences were not large enough to exceed the critical value of the statistical significance test. This is particularly important in small-sample studies where the power to reject the null hypothesis is not 
high. Third, the different sample sizes of individual studies make it impossible to aggregate the results of different studies solely on the basis of their test statistics. Thus, Bernard concluded that Russell's work represents neither a sufficient overall test of the hypothesis of no difference nor an adequate estimate of the magnitude of effects attributable to distance education.

Phipps and Merisotis (1999), in another widely cited report prepared for the American Federation of Teachers (1999) and the National Education Association (2004), reviewed articles published from 1990 to 1999 that addressed two-way interactive video, one-way prerecorded video, two-way audio/one-way video, and computer mediated learning in college-level courses. Phipps and Merisotis identified only 12 articles on this topic and did not provide a quantitative synthesis of results such as an average effect size. Rather, they describe different types of distance education research (i.e., descriptive research, case studies, correlation and experimental research). The authors suggest that design flaws in distance education research make the results inconclusive, noting, "most of the studies do not use randomly selected subjects" (p. 20). However, "... achievement [in distance education treatments] compares favorably [with face-to-face instruction] across a variety of age and content levels. User satisfaction is higher than in traditional instruction regardless of the technology used" (p.21).

Bernard et al. (2004) criticized the Phipps and Merisotis (1999) review for lack of clear inclusion and exclusion criteria. This lack of clear and objective criteria for which studies are included in a review raises a potential selection bias. The reviewer may select research, to make a point rather than accurately characterizing the state of research literature around a given question. Bernard argued that Phipps and Merisotis' finding of 
the "high user satisfaction" based on a select sample of studies is no more credible than Russell's claim of non-significance based on everything that has ever been published.

Seven quantitative syntheses specifically related to distance education and face-toface academic instructions were published recently (Allen, Bourhis, Burrell, \& Mabry, 2002; Bernard et al., 2004; Cavanaugh, 2001; Cavanaugh, Gillan, Kromrey, Hess, \& Blomeyer, 2004; Machtmes \& Asher, 2000; Shachar \& Newmann, 2003; Ungerleider \& Burns, 2003). Shachar and Newmann's research compared university students' final grades in distance education with those in traditional classes. Their meta-analysis of 86 studies between 1990 and 2002 resulted in a statistically significant overall effect size of 0.37 favoring distance education programs.

In another recent study, Ungerleider and Burns (2003) conducted a systematic review for the Council of Ministers of Education of Canada including a quantitative metaanalysis of the literature on networked and online learning for secondary and post secondary students. They found poor methodological quality from a sample of 25 articles, to the extent that only 12 achievement and 4 satisfaction outcomes were of sufficient quality to be analyzed. They found an overall effect size of zero for achievement and an effect size of -0.509 for satisfaction. Both findings were significantly heterogeneous - that is, the set of studies showed a wide range of results. They concluded that there was a need for more systematic research on the effect of networked and on-line technologies, particularly with a focus on children and adolescents, women/girls, and people from marginalized populations (Ungerleider \& Burns).

In the most recent meta-analysis, Bernard et al. (2004) reviewed 232 studies on distance education published between 1985 and 2003. Bernard et al. identified articles that 
compared traditional instruction to distance education instruction. They included all educational levels including $\mathrm{K}-12$, post secondary, professional adult training and military training. None of the articles selected included studies in K-6 settings; however, in 11 articles researchers compared secondary-level students in science, computer applications, math (statistics, calculus, and algebra), and geography. Bernard et al. found a near zero overall effect size (.0128) for student achievement. The split between synchronous and asynchronous distance education resulted in a small negative mean effect size for synchronous of - 0.102 (92 studies) that was statistically significant. The mean effect size for asynchronous articles was statistically significant favoring distance education, but very small (.0527 based on 174 studies) (Bernard et al.). Bernard et al. concluded that overall, classroom instruction and distance education are comparable; however, the wide variability present in all outcome measures (e.g., achievement, attitude, and retention) precludes any firm declarations.

Given the frequent outcome of 'no significant difference' between groups in distance education research, interpretation of this kind of outcome becomes very important. The problem is that "'no significant difference' is an inconclusive result. A finding of 'no significance difference' between face-to-face instruction and distancedelivered instruction does not mean they're equally good or bad" (Lockee, Moore, \& Burton, 2001, p. 62). Some researchers have interpreted no significant difference as the use of technology to deliver courses does no harm- that is; face to face learning has no inherent advantage to students over learning at a distance (Conger, 2005). A more precise way of reporting results is to use effect sizes bounded by confidence intervals (Altman, 1996; Shadish, Cook, \& Campbell, 2002). Because effect sizes are standardized, they can 
be directly compared (Gall, Gall, \& Borg, 1999). Thus, reporting the effect size and confidence intervals provides more insight into the rejection or acceptance of the null hypothesis (Creswell, 2002).

From this set of reviews of the literature, it appears the effect sizes for comparison studies of distance education and traditional face-to-face instruction are near zero. However, neither this conclusion nor Clark's $(1983,1994)$ argument against media comparisons should be construed to imply that a particular distance education application would be as effective as a corresponding face-to-face experience. Many factors can influence relative effectiveness. For example participant characteristics, instructional methods, and media attributes are all variables that can influence the relative effectiveness of educational practices. Thus, it is important to empirically verify the effectiveness of a distance education application, especially when we attempt to provide instruction for a new population (e.g., students at-risk of academic failure) or extend previous research findings. Overall, one could argue that Bernard and colleagues' (2004) results are in agreement with Russell (1999) and Clark. Although Bernard et al. found statistically significant differences, the effect sizes were so small that his results strengthen the argument that there is no educationally important difference between face-to-face and distance education. Unfortunately, the above meta-analyses provided only meager and indirect information on distance education in the K-12 context. Their focuses were either very broad (including all student populations) or specific to higher education. In fact, Bernard et al. found only 12 articles on distance education in the $\mathrm{K}-12$ context and all of these focused on high school AP courses (e.g., Calculus, Biology, Literature, Computer Science, etc.). 
Distance Education in the K-12 Context

Distance learning programs in K-12 education have seen large growth over the last decade. Much of the appeal of distance education is that it provides a means for giving students access to broader educational opportunities (such as specialized coursework) than are otherwise available (Cavanaugh et al., 2004). In 2005, the U.S. Department of Education issued the first comprehensive examination of distance education in the $\mathrm{K}-12$ schools (Setzer \& Lewis, 2005). The authors report that $36 \%$ of public school districts and $9 \%$ of public schools had students enrolled in distance education courses in 2002-2003. They found that a greater proportion of districts located in rural areas than in suburban or urban areas indicated that they had students enrolled in distance education courses (46\% compared with $28 \%$ and $23 \%$, respectively). Schools that served upper grade levels were far more likely to offer distance education than those serving lower grades. Overall, $38 \%$ of high schools offered distance education courses, compared to $4 \%$ of middle or junior high schools, and less than $1 \%$ of elementary schools. Finally, advanced placement and college-level courses were the most common types of courses to be delivered through distance education in 2002-2003.

In 2004, Cavanaugh et al. reported results of a meta-analysis examining interactive (i.e., videoconferencing and telecommunications) distance education technologies in $\mathrm{K}$ 12. They selected studies that: (a) focused on interactive distance education technology; (b) were published between 1999 and 2004; (c) included quantitative outcomes from which effect sizes could be extracted; and (d) were free from obvious methodological flaws. In 19 studies (total of 929 participants) meeting these criteria, results indicated a near zero overall effect size of .015 (in favor of distance education conditions) based on a 
significantly heterogeneous sample. Subsequent investigation of moderator variables

revealed no additional findings of consequence. Cavanaugh et al. concluded that students could experience similar levels of academic success whether courses use

telecommunications or traditional classroom settings. However, $74 \%$ of the studies were conducted in the secondary grades (6-12), and none of the studies identified participants as lower performing, at-risk, or receiving special education services. Only $26 \%$ of the studies were on elementary level reading. Thus, further research is needed to determine whether similar technologies can be used with younger students at risk of academic failure

\section{Distance Education with At-Risk Students K-12}

In a comprehensive literature review, Kinash, Crichton, and Kim-Rupnow (2004) found 43 publications released between 2000-2003 intersecting online learning and disability. Unfortunately, the authors did not give any rationale for excluding articles conducted earlier than 2000 . Of the 43 identified publications, $22(51 \%)$ presented guidelines and how-to information in regard to topics including accessibility, communication tools, instructional design, pedagogy, policy, teaching strategies, and universal design. Descriptions of products and or educational programs accounted for 13 $(30 \%)$ of the papers. Finally, research was described in five $(12 \%)$ of the articles. Two of the five research articles were unpublished conference presentations by Kinash (2002, 2003) and the other "research articles" were actually editorials or opinion pieces. Thus, we found no published empirical research on online instruction for students with disabilities. The fact that this systematic review yielded no published empirical research on academic outcomes for students with disabilities further strengthens the need for such research. 
K-12 Online Tutoring

While several years of research supports the use of tutoring as an effective practice to teach reading (e.g., Gunn, Smolkowski, Biglan, \& Black, 2002; Haisley, Tell, \& Andrews, 1981; Kamps et al., 2008; VanNorman \& Wood, 2008), and in some cases, this kind of instruction is federally mandated, numerous barriers described above can severely limit access to high quality tutoring services, especially in urban and rural areas. Real time two-way audio-visual technology provides one possible means for making high quality tutoring more widely available. There are numerous similarities between this online technology and face-to-face tutoring. For example, when using this online format tutors can be flexible in their instruction including their use of materials (i.e., having text, white board overlays, video, and audio in one location with one click of the mouse) similarly to face-to-face instruction (chalkboard, print materials, etc.) (Beth-Marom, Saporta, \& Caspi, 2005). Online distance tutoring that closely approximates face-to-face instruction may bolster the argument Clark (1983, 1994) and Russell (1999) make of "no significant difference." Unfortunately, previous reviews of literature have found very little evidence on the use of synchronous online reading instruction being delivered to students at-risk of reading failure.

\section{Independent Review of Distance Education Literature on At-Risk Students}

The purpose of this literature review is three-fold. First, to establish the relevance of this study and identify recent changes in the literature within the distance education literature, articles were reviewed that addressed the need for supplemental reading instruction at the K-12 level. Second, to assist in the design of this study articles were 
reviewed that described supplemental reading interventions implemented over synchronous technology. Finally, to determine if the existing research base is sufficient to assist educators in the development of effective reading programs utilizing synchronous technology, empirical studies of implemented interventions were identified, described and analyzed. Specifically, we wanted to find and analyze the current literature base on distance education in the K-12 context for students at risk of reading failure.

\section{Article Selection}

Articles selected for inclusion in this review were located by: (a) an informal search for information related to synchronous tutoring, online tutoring, distance tutoring, telecommunication, and video conferencing; (b) a formal search of ERIC, EBSCO Host, and Educator Full Text indexes; and (c) exploration of websites of various federal agencies (e.g., Department of Education, Federal Government Distance Learning Association, and international Centre for Distance Learning), and private educational organizations that provide supplemental instruction over technology (e.g., Sylvan, Lightspan Inc., Brainfuse, and Tutor.com). The formal search included search terms to define:

1. The mode of instruction: (a) distance education, (b) internet learning, (c) webbased instruction, (d) online instruction, (e) telecommunication, (f) video conferencing

2. The population: (a) at-risk, (b) special education, (c) elementary, (d) K-12 and

3. The content area: (a) reading, (b) reading instruction, and (c) remedial reading. 
The purpose of using this broad array of search terms was to capture any use of technology to teach remedial reading skills at the $K-12$ level to at risk students. Articles were included in the study only if they had participants in the K-12 range and used technology to deliver instruction. More specifically, the broad search terms defining media (i.e., distance education or internet learning or web-based instruction or online instruction or telecommunication) were crossed with those defining the grade level (elementary or K-12) to establish the set distance education articles concerned with $\mathrm{K}-12$ education. This search yielded 457 articles. To further refine our search, we added search terms that defined the content area (reading or reading instruction or remedial reading); this reduced the number of articles from 457 to 122 .

\section{Coding Variables}

We organized the 122 articles into categories using specific coding variables. First, type of technology used to deliver instruction was coded either as synchronous or asynchronous. Synchronous was defined as the transfer of information without delay. Traditional teaching was considered synchronous. Distance education examples of synchronous instruction include audio and video transmitted "live" between instructors and students via TV, Internet or radio. Asynchronous was defined as two-way communication with a substantial delay between when a message is sent (or recorded) and when it is received. Distance education examples of asynchronous communication include static text on websites, email, voicemail, discussion boards and so forth. Second, participant grade level was coded as elementary or above elementary. Studies in which participants were above elementary were dropped from the analysis. Additionally, studies in which teachers, administrators and other school-related staff were the main participants 
$(n=83)$ were coded as such and not included in the final analysis. Third, instructional content in the study was coded as reading, math, or language arts. Fourth, participants' academic functioning was coded as high, low, or both. High academic participants are participants in the general education, honors, and advanced placement courses. Low academic participants are students at risk of academic failure or identified as needing special education services. Finally, methodological characteristics were coded to identify the outcome measures for each article. Specifically, we wanted to identify if the article reported student performance outcomes.

\section{Independent Literature Review Results}

A total of 39 articles were identified that met the selection criteria (distance education and reading and elementary level students). Interestingly, 34 of the 39 identified articles were also referenced in the three meta-analyses reviewed earlier (i.e., Bernard et al., 2004; Cavanaugh, 2001; Kinash et al., 2004). The five new articles were opinion papers, rejoinders, and pilot suggestions for future research in distance education; none reported empirical research. The results of coding these articles are displayed in Table 1. Twenty-three articles were found in which researchers used asynchronous technology. Of the 23 studies 13 were with high-achieving and eight were with lowachieving participants. The asynchronous technology ranged from web sites to CDROMs, and content of instruction included reading, writing, and math skills. Twelve studies were found in which researchers used synchronous technology. Six of the articles were found in which researchers investigated synchronous technology with high performing participants. The most common subjects taught for the high performing 
Table 1

Number of Articles Identified by Type of Technology and Participant

\begin{tabular}{lcccc} 
& \multicolumn{4}{c}{ Type of technology } \\
Achievement & 13 & Synchronous & Mixed & Total \\
\cline { 2 - 5 } & Asynchronous & 6 & 3 & 22 \\
Low & 8 & 4 & 0 & 12 \\
Mixed & 2 & 2 & 1 & 5 \\
Total & 23 & 12 & 4 & 39 \\
\hline
\end{tabular}

group were language arts/technology, advanced math, and reading. Synchronous technology used to deliver instruction ranged from interactive radio to modern telecommunications programs such as Net meeting, Polycom, and Dwyco.

Of the 39 identified articles only four investigated synchronous instruction implemented at the elementary grade level with low academic students. Cooper and Nichols (2007) described the use of a Mountbatten Pro Braille reader for 20 kindergarteners, first, and second graders on their writing and reading skills. Cooper and Nichols utilized both qualitative and quantitative measures to determine the extent to which the use of the Brailler increased students' reading skills assessed by the Texas Primary Reading Inventory. Writing was measured by observation and writing samples from the Brailler. The project reportedly had a positive impact on the students' writing and reading skills as well as in participation in instruction and social interaction. However, the authors provided data on percent correct without reporting means and 
standard deviations for their outcome measure from the Texas Primary Reading Inventory so effect sizes could not be calculated.

Sax (2002) published a description of online teaching assistance (peer tutors) to facilitate discussion and model the role of successful online instruction. Unfortunately, a clear limitation of Sax's article is that she did not empirically determine the effectiveness of online instruction. Instead she provided information on student perceptions and desirability of instruction over the online system. Kornhauser and Brooke (1968) provided math instruction through a radio broadcast for pre-kindergarten through $12^{\text {th }}$ graders. They report increased student math skills as measured by researcher-developed curriculumbased assessments.

Gutknecht and Gutknecht (2001) reported a plan to implement instruction very similar to that proposed for this dissertation. Their goal was to provide one-on-one reading instruction to fourth-grade students over a video conferencing and internet-based interactive program. However, the authors never completed the study due to technical difficulties and suggested further improvement in technology prior to attempting such a project.

From our search it is apparent that the extant research on distance education with K-12 students predominantly focuses on higher performing students and asynchronous technology. It is also clear that, whether working with asynchronous or synchronous technology, very little attention is devoted to the use of distance education technology with low functioning students (12 of 39 studies). Further, of the 12 articles with low functioning students only four articles report direct measures of achievement associated with distance education (Cole \& Hilliard, 2006; Cooper \& Nichols 2007; Englert, Zhao, 
Collings, \& Romig, 2005; Meyer, Brezinski, Middlemiss, \& McDougall, 2002). Of the four articles with direct measures of achievement, only Cooper and Nichols focused on elementary aged students. This literature does not provide a basis for predicting the effectiveness of online reading tutoring for lower-performing students at the elementary grade level. Given the common finding of no statistically significant difference between distance education and face-to-face instruction; these technologies may be a viable means to deliver high quality reading instruction; however, there is no direct evidence of this, nor is there closely related indirect evidence. Clearly, one critical variable in the effectiveness of distance delivery of reading instruction is the quality of the reading curriculum and the reading instruction. I will now turn to curricular and instructional factors that appear to be important for successful reading instruction in any media.

\section{Effective Reading Instruction}

Historically, large numbers of students have struggled in reading and contentious debates rage over how best to teach reading. In 1997 Congress mandated the formation of the National Reading Panel (NRP, 2000) to review and evaluate scientific literature on effective reading instruction and to summarize the results. Over 100,000 studies related to reading instruction were examined. The NRP report found five areas of instruction critical to the success of beginning readers and those in need of remediation. These areas include (a) phonemic awareness - the ability to identify and manipulate individual sounds in spoken words; (b) phonics - the relationship between letters in written words and sounds; (c) fluency - ability to read quickly, accurately and with expression; (d) vocabulary - the 
meaning of words; and (e) comprehension - the interaction between reader and text in which readers draw on background knowledge to understand what they read.

In addition, the NRP (2000) found that reading skills in grades $\mathrm{K}$ through 4 should be taught systematically and explicitly (NRP). Systematic instruction is defined as "the plan of instruction that includes a carefully selected set of letter-sound relationships that are organized into a logical sequence" (Armbruster, Lehr, \& Osborn, 2003, p.19). Explicit instruction pertains to "a systematic method of teaching with emphasis on proceeding in small steps, checking for student understanding, and achieving active and successful participation by all students" (Rosenshine, 1987, p. 34). When reading instruction in the key areas identified by the NRP is systematic and explicit, reading skills are acquired at higher levels (Armbruster et al.).

One instructional approach that systematically and explicitly teaches reading skills is Direct Instruction (DI). The design of the DI programs incorporates five main elements: (a) analysis of the content including identification of generalizable strategies that help students learn more efficiently, (b) instructional design to minimize vagueness for students, (c) structured dialogue between the teacher, (d) skills taught in a sequential manner, and (e) instructional objectives organized to allow for systematic skill development throughout the programs (Watkins \& Slocum, 2004). These elements of the DI model along with the specific DI reading curriculum align with the recommendations of the NRP.

DI has been widely studied with the most comprehensive evaluation being conducted as part of Project Follow Through (Watkins \& Slocum, 2004). This massive, federally funded project evaluated the effectiveness of nine models of compensatory 
education. Each model was implemented at multiple sites and each site was matched to a local comparison site. Outcomes included multiple measures in three domains: basic skills, complex cognitive skills, and affective outcomes. Results indicated that DI was more effective than any of the other models in all three domains.

In addition to Project Follow Through, many smaller-scale evaluations show strong positive effects of DI in reading. Adams and Engelmann (1996) conducted a metaanalysis of research on DI. They reviewed 350 research studies, 37 of which met their criterion for analysis. The studies were divided into four groups: (a) regular education, (b) special education, (c) Project Follow Through, and (d) follow-up studies (Adams \& Engelmann). Overall, they found that students taught with DI programs exceeded comparison groups by an average effect size of .87. Examining results in specific subject areas, they found 15 reading studies with an average effect size of .69; 7 language studies with an effect size of .49, and 3 spelling studies showing an average effect size of 1.33 .

Several DI reading programs are available; each addresses the needs of a different population of students. Corrective Reading (CR) is designed to address the needs of remedial readers who are at risk of reading failure. $C R$ is characterized as a systematic, explicit remedial phonics program containing four levels (A, B1, B2, and C) that provides hierarchical skill development in reading for students in grades three through twelve (Engelmann, Carnine, \& Johnson, 1999; Engelmann, Meyer, Carnine, et al., 1999; Engelmann, Meyer, Johnson, \& Carnine, 1999). Researchers have documented the effectiveness of the Corrective Reading-Decoding series with remedial readers (Campbell, 1988; Gregory, Hackney, \& Gregory, 1982), non-categorical poor readers (Holdsworth, 1984-85; Kasendorf \& McQuaid, 1987), and special education students (Thompson, 1992; 
Thorne, 1978). Gunn, Biglan, Smolkowski, and Ary (2000) investigated the use of the CR program as a supplemental instructional intervention for 256 students in kindergarten through second grade. In both the original article and later in a follow up study (Gunn et al., 2002), students' reading skills were statistically significantly better on measures of word attack, word identification, oral reading fluency, vocabulary, and reading comprehension when compared to a control group. Malmgren and Leone (2000) conducted a study in which CR was implemented as a significant component of an intensive 6-week reading intervention with a group of 45 incarcerated adolescents with reading deficits. Analysis of the results of pre- and posttest standardized assessments (GORT -3$)$ revealed that significant gains were noted in the area of oral reading combined (GORT-3 subtest: (a) oral reading rate, (b) accuracy of oral reading, (c) rate and accuracy combined, and (d) comprehension). No marked improvement was exhibited on the comprehension subtest, indicating that more intervention time may be warranted to produce change in this particular area. Nonetheless, this study demonstrated the efficacy of $C R$ in increasing reading fluency of students with reading problems.

In addition to the CR program, researchers have shown that a repeated reading technique improves students reading performance (e.g., Daly, Martens, Dool, \& Hintze, 1998; Homan, Klesius, \& Hite, 1993; Sindelar, Monda, \& O’Shea, 1990; Stoddard, Valcante, Sindelar, O'Shea, \& Algozzine, 1993; Weinstein \& Cooke, 1992). Repeated readings is the process of reading a short, meaningful passage several times until students meet a specified fluency criterion (rate and accuracy) (Samuels, 1978). Stoddard et al. indicated that when the speed at which an individual reads a passage increased, their comprehension also increased. Along these lines, Sprick and Howard (1995-1997) stated, 
"although fluency alone is not sufficient for reading with understanding, it is clear that it is a necessary prerequisite for understanding, interpreting, and responding to print" (p. 25). Because of the strong evidence of the efficacy of repeated reading, Dowhower (1994) argued that it should be included in daily literacy instruction, as subsequent readings lead to higher levels of recall, deeper processing of words in text, and generalized fluency abilities to new passages. Given the large number of students who experience reading failure, further studies on means of increasing access to the CR program with repeated reading instruction are in order.

\section{Conclusions}

Given the need for greater access to intensive, high quality interventions for students at risk of reading failure, this literature review explored whether distance education might be a viable means of providing these interventions. Analysis of the literature indicates that many distance education applications appear to produce outcomes comparable to face-to-face instruction. In three meta-analyses on distance education researchers reported that on average, results from distance education are comparable to similar instruction delivered face-to-face; however, these reviewers also reported heterogeneous results suggesting that although distance education can produce strong results, it does not always do so. This suggests that although distance education is a viable mode for delivering instruction, individual applications must be carefully considered and empirically validated. Importantly, few low functioning students are represented in the empirical literature. In fact, no study has been found with synchronous interactive online tutoring being delivered at a distance to students at risk of reading failure. This gap in the literature adds to the uncertainty regarding effectiveness of distance education instruction 
for at risk readers and strengthens the importance of evaluating remedial reading instruction delivered via distance education.

As Clark, the NRP, and many others have argued, technology is not a curriculum nor does it imply specific instructional practices; thus this review also briefly explored research on effective reading curriculum and instruction. Researchers have identified content and teaching methods that should be incorporated into reading instruction. Research based curricula such as the CR program clearly align with the critical curriculum elements that have been outlined by the NRP and other researchers. Thus, CR may be an effective curriculum for online tutoring of students who struggle in reading. In addition, repeated readings are an effective method of producing increases in reading skills. Combining both the $\mathrm{CR}$ program and repeated readings may produce a more powerful intervention for students at risk of reading failure.

The purpose of this research project was to evaluate the effectiveness of an on-line system for delivering remedial reading instruction to students at a distance. Specific research questions focus on various aspects of effectiveness (measures of reading skills), as well as tutors', students', teachers' and administrators' perceptions of usability and satisfaction. Specific questions are as follows: (a) To what extent will synchronous supplemental reading instruction delivered online increase the oral reading fluency for students at risk of reading failure? (b) To what extent will synchronous supplemental reading instruction delivered online increase overall reading skills as measured by the Woodcock Johnson III Tests of Academic Achievement reading battery (Letter Word ID, Word Attack, Reading Fluency, and Passage Comprehension) for students at risk of 
reading failure? (c) What are students', tutors', parents', and teachers' perceptions of the effectiveness and desirability of the online tutoring? 
CHAPTER III

\section{METHODS}

We conducted two studies to determine the effects of supplemental online instruction. The first study was conducted in a public school in Philadelphia, PA and the second was a systematic replication in Kearns, UT. The purpose for running two studies was to determine if similar outcomes could be obtained given the same independent variable with new participants and setting.

\section{Participants and Setting}

This study included eight fourth-grade students, four tutors, four teachers, and parents of each fourth-grade student (see Appendix F for IRB consent forms). To be included in the study, student participants met two criteria. First, student participants were identified by their teachers as scoring below the $20^{\text {th }}$ percentile on a reading achievement test and in need of supplemental instruction. Second, participants would place into Corrective Decoding Level B1 according to the program's placement test. The requirement of placing into the program ensured that all students were relatively homogeneous in instructional needs. Study 1 included four students attending M. Stanton Hall Elementary school located in Philadelphia, PA. All participants in Philadelphia were African American, three were male and one was female. All received free or reduced lunch. These participants all received 60 minutes of reading instruction daily from their general education program using a district developed curriculum. None of the student participants received additional reading instruction during the school day. Students selected for participation were administered five pretests from the Woodcock Johnson 
Test of Academic Achievement. The average percentile rank for students on subtests Letter Word Identification, Reading Fluency, Picture Vocabulary, Word Attack and Picture Vocabulary was 19.72 (range 10.85-30.75). During the intervention phase of the study, students were pulled out of homeroom and elective classes to receive 50 minutes of supplemental online tutoring. M. Stanton Hall Elementary school was classified as a 90/90/90 school, where $90 \%$ of the students were eligible for free or reduced lunch, $90 \%$ of the students were members of ethnic minority groups, and $90 \%$ or more of the students met the district or state academic standards in reading and math. Although the instruction, interventions and support in place at this school are highly effective for most of the students, $10 \%$ of the students still did not meet state standards. Student participants did not miss any core instructional time (i.e. reading, math, and science) while participating in this study. The computer lab was equipped with Internet connected Macintosh computers (iMac $2.5 \mathrm{GHz}$ Intel processor).

In Study 2, four student participants were located at Western Hills Elementary in Kearns, UT. Just as in the primary study, teachers identified students as needing supplemental instruction. Students needed to score below the $20^{\text {th }}$ percentile on a reading achievement test and place into Corrective Decoding Level B1. The four participants all received free or reduced lunch. There were two male (one Hispanic and one African American) and two female participants (one Caucasian and one Hispanic). Students in Study 2 were also given a pretest from the WJ-III prior to the intervention. These students average percentile rank for the same five subtests was 25.03 (range 15.5-36.25). All four students received 50 minutes of reading instruction daily from their general education classes using the Imagine IT Reading program. During the intervention phase 
supplemental online tutoring was delivered before school; the student participants did not miss any regular instructional time. The school in Kearns was classified as a Title 1 school with $62 \%$ of the students receiving either free or reduced lunch. The ethnic distribution for this school was 58\% Caucasian, 35\% Hispanic, $1 \%$ African American, and $6 \%$ other. Students received instruction in the computer lab at Western Hills Elementary equipped with Internet connected Dell computers (P3 1.0 GHz Intel processors).

In both Study 1 and Study 2 the school principal identified teacher participants. The two teacher participants in Philadelphia (two male, one Caucasian, and one African American) helped identify potential student participants and helped setup technology. Similarly, two teacher participants in Kearns (two female, one Caucasian, and one Hispanic) helped identify student participants. Tutors were four female Caucasian preservice teachers recruited from Utah State University (USU) undergraduate programs. Tutors were located on the USU campus. Tutoring was delivered from the USU distancetutoring lab equipped with Internet connected Dell computers (P4 $2.3 \mathrm{GHz}$ Intel processors).

Independent Variable (Both Study $1 \&$ Study 2)

The independent variable included two main components - Online Tutoring System and Reading Curriculum. The independent variable was delivered as a treatment package and no attempt was made to analyze the contribution of the separate components. 
Online Tutoring System

The hardware required to deliver synchronous online tutoring included a Macintosh or PC computer with a web camera, and an audio connection with either binaural headset with microphone or a telephone headset (also binaural). The Adobe Connect program (formerly known as Breeze) was loaded onto the computers to create a virtual classroom environment. Adobe Connect provides both a dedicated Web meeting room at a fixed web address and telephone conferencing for up to 15 participants. It supports webcams and works with Macs as well as PCs (Adobe Acrobat, 2008). Adobe Connects' capabilities include real-time communication (i.e., audio, video, text, and graphics), and document sharing within a virtual tutoring room. The Adobe Connect environment allows tutors and students to see and interact with each other simultaneously (Adobe Acrobat, 2005).

For some of the students, the audio signals were carried over the Adobe Connect system and for others audio made use of a separate Voice Over Internet Protocol (VOIP) system. The combination of video, audio, and shared documents through Adobe Connect often exceed the computers' processing capabilities resulting in dropped information packets. Based on the results of the pilot study (see Appendix A) the preferred method of sending audio was the VOIP system. VOIP alleviated the computer processing restriction by splitting the computer processing demands onto two systems (i.e., audio via VOIP, and video and document sharing via PC). However, the VOIP required a phone line near the computer tutoring station. The Pennsylvania distance site only had one phone line in their computer lab and the Utah distance site did not have any phone lines in the 
computer lab so audio was primarily carried over the Adobe Connect system and we used the one VOIP line in Pennsylvania.

The USU distance-tutoring lab was equipped with broadband Internet capabilities, and two PC computer-tutoring stations each equipped with a web camera, noise canceling binaural headsets, and VOIP phone. The Philadelphia distance site used Macintosh computers while the Utah elementary school utilized PC computers. Both the Philadelphia school and the Utah school were equipped with broadband Internet capabilities and each tutoring station was equipped with a web camera and electronic writing board. In addition, Philadelphia had one phone with binaural headset and regular phone connection for VOIP calls. Kearns had a prepaid cell phone for initial setup of tutoring sessions. The distance sites had only one relevant difference in hardware when compared to the USU tutoring lab.

A writing board was used at the distance sites to allow students to write responses and complete workbook activities without the use of a mouse or keyboard. All computers had the following software installed to run the Adobe Connect program: (a) an Internet browser (e.g., Explorer, Safari, Fire Fox, etc.), (b) Macromedia Flash Player, (c) Quickcam drivers, and (d) Adobe Acrobat PDF reader. Figure 1 displays an example of the Adobe Connect online tutoring environment. In the upper left of the screen, Adobe Connect displays the video pod that allowed students and tutors to see each other. To the right of the screen, the reading lesson or assessment is displayed to both participants. Below the "video pod" is a white board overlay. We used this area to play a "you/me game" to shape and maintain student behavior. 


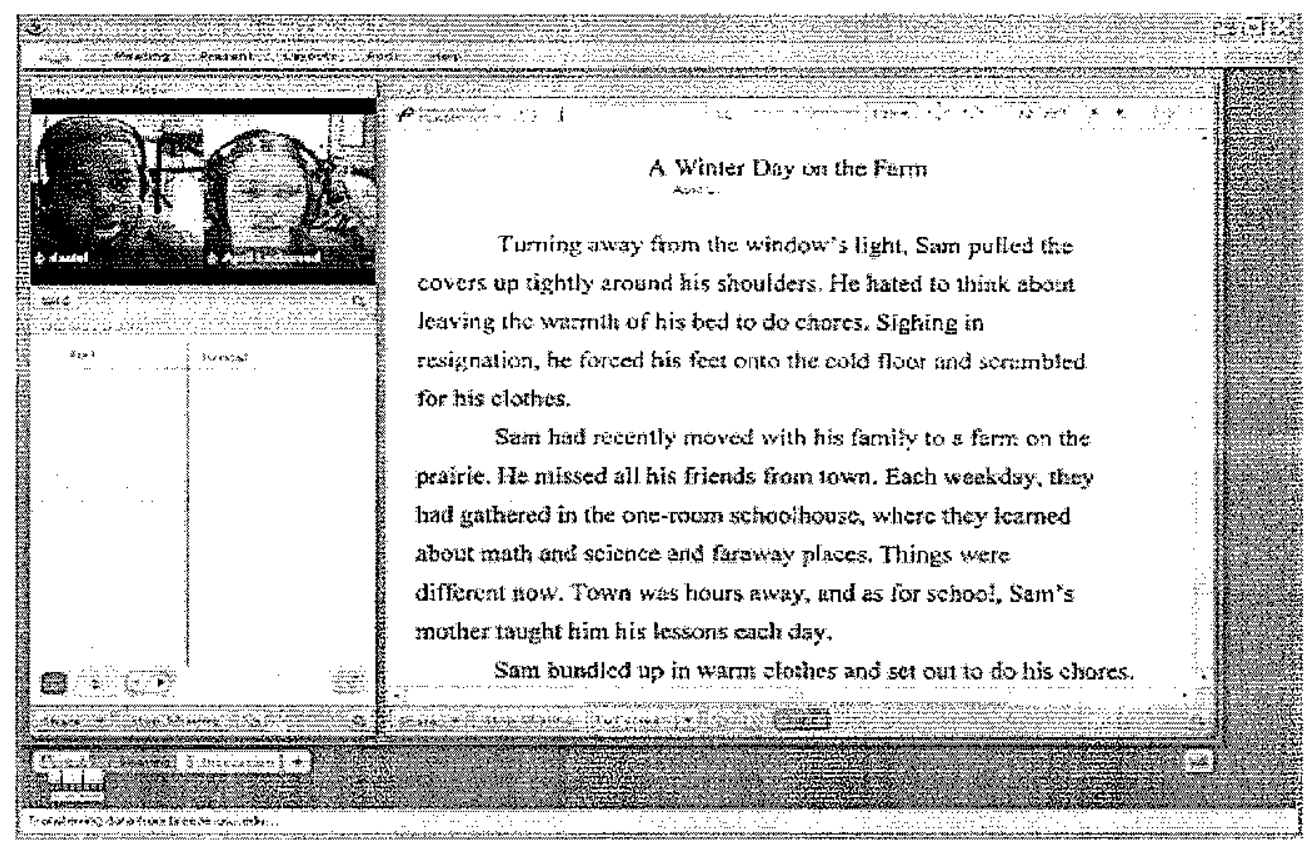

Figure 1. Screen shot of synchronous online tutoring delivered over the Adobe Connect system (see Appendix G for copyright approval).

\section{Reading Instruction}

The Direct Instruction program Corrective Reading-Decoding was delivered over the online tutoring system described above. The Corrective Reading Decoding program is appropriate for students who have trouble identifying words, understanding how the arrangement of letters in a word relate to pronunciation, and whose reading rate is inadequate. The lesson format incorporates word-attack practice, group reading, individual reading checkouts, and workbook exercises. In this study we delivered 45 minutes of the Corrective Reading Decoding Level B1 in each tutoring session. In addition to the reading lesson, each student also received 5 minutes of repeated reading practice to build oral reading fluency. Repeated reading passages came from the Corrective Reading Decoding Level B1 previous day's lesson. 
Delivery of the CR program over the Adobe Connect system required several adaptations. First, all student materials, teacher presentation materials and assessments were digitized by scanning documents, saving files in PDF format, then converting them to SWF using Acrobat Flash Paper. The purpose of converting the files to SWF was to generate a fast-opening, web-ready Flash document. Flash documents load on the Adobe Connect system virtually instantly so there was no need to download, install, and wait for a separate reader application to display documents. The second adaptation needed to deliver instruction was to utilize the "display mouse pointer" option within Adobe Connect. The "display mouse pointer" allowed both tutors and students to see the other's mouse pointer. In a traditional face-to-face lesson, teachers point to a specific word or letter and ask for a response from the student. When delivering a lesson via Adobe Connect, the tutor used the mouse pointer to identify the appropriate stimulus. Third, traditional delivery of Corrective Reading requires changing word endings or sound blends on a chalkboard. Rather than using a chalkboard, tutors used the "white board overlay" to make these interactive changes during the lesson. Finally, to maintain or shape student behavior I used the "white board overlay" to play a "you/me game." This game is commonly used by DI teachers to manage behavior. Using this game, the teacher tells the student that if they respond on signal, for example, they will earn a point. If they do not respond on signal, teacher earns the point. The teacher keeps track of the points on the board, labeled with $m e$ (the teacher) and you (the student). The teacher marks points in either category, pairing them with praise, or an error correction. 
Tutor Training (Both Study 1 \& Study 2)

Four undergraduate preservice teachers were trained to deliver the CR program. Two tutors who previously participated in the pilot study (see Appendix A), and two new tutors were trained to participate in this project. Training consisted of first, reading a onepage summary of the goals and expectations for delivering CR and repeated reading procedures. Second, tutors were given 20-minute video models of the CR program and procedures. Third, tutors were asked to deliver a simulated online lesson with the researcher and an assistant to determine whether or not the tutor met criterion. Specifically, tutors were expected to obtain seven to nine responses per minute as well as provide the correct error correction procedure (i.e., model, test, and retest) for incorrect responses. Further, tutors were required to deliver praise for correct responses at least 5 times per minute with a combination of specific and general praise statements. Finally, tutors were instructed to deliver 5 minutes of repeated reading practice on the previous day's lesson passage.

Tutors were also taught to administer both the DIBELS oral reading fluency probes, benchmarks, and Woodcock Johnson Tests of Academic Achievement III (WJIII) reading subtests. Training consisted of reading the procedures for each assessment and watching a model of appropriate test administration. Tutors were then required to deliver a simulated assessment online with high fidelity (i.e., deliver questions and score items correctly as per assessment directions) before they had access to student participants. 
Assessment of Treatment Integrity (Both Study $1 \&$ Study 2)

All distance tutoring and testing sessions were electronically archived for purposes of monitoring and documenting treatment integrity. Tutors' delivery of the CR program was evaluated utilizing the Direct Instruction Supervision System to determine the extent to which tutors delivered instruction. The Direct Instruction Supervision System (Lignugaris/Kraft \& Marchand-Martella, 1993; see Appendix B) targets critical Direct Instruction teaching behaviors including (a) presentation of tasks, (b) error correction, (c) praise statements, and (d) pacing. Data collected from treatment integrity checks allowed researchers to provide feedback to tutors on details of their instructional delivery, and also to document the fidelity of implementation. Importantly, tutors did not teach research participants until they met the criterion listed above in tutorial with the researcher (i.e., 7-9 responses per min, providing correct error correction procedure, and reinforcing student responses on average of 5 per min).

Thirty percent of all archived distance-tutoring sessions were observed and scored to assess treatment integrity. Additionally, $30 \%$ of treatment integrity observations included a second observer to establish inter-observer agreement (IOA) on the Direct Instruction Supervision System. Two observers viewed and scored the tutors delivery of the Corrective Reading lesson using the Direct Instruction supervision system. Observations were split into five three-minute intervals and a frequency count was conducted on the rate of presentation, percent correct error correction, and rate of reinforcement. At the end of the observation the researcher calculated a point by point agreement on the percent correct error correction and an occurrence agreement for the rate of presentation and rate of reinforcement. 
Measures (Both Study 1 \& Study 2)

The primary dependent variable was oral reading fluency. The primary measure of oral reading fluency was the Oral Reading Fluency (ORF) subtest of the Dynamic Indicators of Basic Early Literacy Skills (DIBELS) reading battery (Good \& Kaminski, 2002). DIBELS-ORF is an individually administered test of accuracy and fluency in oral reading of connected text. The student reads a text passage aloud for $1 \mathrm{~min}$. The tester records the number of correct and error words. Errors are words omitted, substitutions, and hesitations of more than $3 \mathrm{~s}$. Errors that are self-corrected within $3 \mathrm{~s}$ are scored as accurate. The DIBELS-ORF includes two kinds of assessments: benchmark and progress monitoring. Benchmark assessment is given three times per year to track growth in overall reading skill. Each benchmark assessment consists of three reading passages with the student's score being the median correct words per min from the three passages. Progress monitoring assessment is intended to provide weekly measures of reading growth for students who are at risk of reading failure. It is similar to the benchmark assessment except that it consists of only one passage read aloud for $1 \mathrm{~min}$. To reduce the variability in oral reading fluency data seen in the pilot study, I administered three progress-monitoring probes at each data collection point and calculated the median correct words as the data point.

One problem with taking the median of three readings is that three probes are required to derive a single data point. The fourth-grade DIBELS assessment contains 29 reading probes - this was not enough for the anticipated duration of the study. I split each DIBELS probe in half, doubling the number of available probes to 58 . On average, each DIBELS reading probe has about 350 words. Thus, half of a probe was sufficiently long 
to accommodate our participants' needs. In addition, to control for passage differences, the administration of these probes was counterbalanced by participants and reading order. For example participant 1 read the first half of passage 1 , second half of passage 2, and first half of passage 3 for the first data point; and participants 2 read the second half of passage 1, first half of passage 2, and second half of passage 3 for the first data point. The concurrent validity of DIBELS-ORF measures with other standardized measures of early literacy skills (e.g., Metropolitan Readiness Test, Stanford Diagnostic Reading Test, Woodcock Johnson Psycho-Educational Battery) ranges from .36 in the beginning of Kindergarten to .81 for fourth graders.

A secondary dependent variable was general reading skill. This was conceptualized as including decoding accuracy, fluency, and comprehension. It was measured with the Letter-Word Identification, Reading Fluency, Passage Comprehension, Word Attack, and Picture Vocabulary subtests of the Woodcock Johnson Tests of Achievement $3^{\text {rd }}$ ed. (WJ-III) (McGrew \& Woodcock, 2001). Together, these subtests comprise the Broad Reading and Basic Reading cluster of the WJ-III. Letter-Word Identification items involve identifying isolated letters and words that appear in isolation (i.e., not connected text). Passage Comprehension requires the participant to read a short passage and identify a missing key word. The task requires the child to state a word that would be appropriate in the context of the passage. The participant exercises a variety of comprehension and vocabulary skills. Reading fluency subtest measures the participant's ability to quickly read simple sentences, decide if the statement is true, and then circle "Yes or No" (Mather \& Woodcock, 2001, p. 11). McGrew and Woodcock reported the complete WJ-III battery was correlated with the 
Wechsler Individual Achievement Test (Wechsler, 1992; $\mathrm{r}=.79$ ) and the Kaufman Test of Educational Achievement (Kaufman \& Kaufman 1985; r=.79). Forbush, Stenhoff, Vasquez, Furzland, and Alexander (2007) demonstrated that effective WJ-III assessments may be delivered online effectively. Administration of the WJ-III in this research systematically replicated Forbush et al. procedures.

Prior to delivering WJ-III and DIBELS assessments; tutors were trained and assessed on the administration each assessment. The DIBELS assessment has an administration checklist and each tutor was evaluated with the DIBELS administration checklist to ensure that all critical aspects were implemented (see Appendix C). Prior to delivering this assessment to students, tutors administered it to the researcher for feedback on correct administration. Finally, tutors were checked out administering the WJ-III using the Woodcock Johnson III checkout tool (see Appendix D).

The third set of dependent variables focused on issues of social validity. Wolf (1978) recommended that social validity should be assessed in three ways: the social significance of the target behavior, the appropriateness of the procedures, and the social importance of the results. In the present study, social validity data were collected via questionnaires on which teachers, tutors, students and parents responded to questions on each of the topics Wolf suggested. Respondents evaluated the acceptability of project goals, skill assessments, acceptability of tutoring procedures, ease of use of the online tutoring system, overall perception of effectiveness of the tutoring intervention, and whether the respondent would like to continue the intervention (see Appendix $E$ for all questions). 
Assessment of IOA and Assessment Fidelity

(Both Study 1 \& Study 2)

During online DIBELS and WJ-III assessments, 100\% of sessions (pre/posttests), and $30 \%$ of DIBELS progress monitoring sessions were recorded, then later observed and independently scored for fidelity of assessment procedures and Inter Observer Agreement (IOA). Tutors' delivery of the DIBELS assessment was evaluated with the DIBELS fidelity checklist (see Appendix C). Delivery of the WJ-III assessment was evaluated with a WJ-III checklist established by Forbush et al. (2007) (see Appendix D). IOA was calculated by dividing agreements by the sum of agreements and disagreements of each delivered item and multiplying by $100 \%$ (Kazdin, 1982). For ORF, the total number of words read per min and number of errors were compared word by word across two independent observers for $30 \%$ of all tutoring sessions. In addition, each stimulus presented from the WJ-III subtests was compared question by question across two independent observers.

Procedures, Experimental Design, and Conditions (Both Study 1 \& Study 2)

The primary research question - the extent to which online tutoring increases oral reading fluency - was addressed with a multiple baseline across participants design. Oral reading fluency was monitored frequently and online tutoring was implemented in a staggered fashion across participants. The secondary research question - the degree to which the tutoring improves general reading skills - was addressed with a nonexperimental pretest-posttest design based on pretests conducted before tutoring and posttests conducted at the conclusion of tutoring. The tertiary research questions - the social validity of online tutoring - was addressed through a posttest only design. Social 
validity measures were administered at the conclusion of the intervention

\section{Initial Assessment}

After potential student participants were identified, USU tutors administered three assessments (i.e., WJ-III, DIBLES Benchmark, and CR Placement Test). Students who met the selection criteria were invited to participate in this study.

\section{Baseline}

All participants began in the baseline condition. During baseline, each participant was administered three DIBELS ORF progress monitoring probes in a single session (resulting in a single data point) every three days by their assigned tutors. These assessments took place online; however, during baseline students did not receive online tutoring. For each participant, a minimum of four data points was collected in baseline condition.

\section{- Intervention}

Trained undergraduate preservice teachers delivered the Corrective Reading Decoding Level B1 program and repeated readings practice as described above. Assessment continued as in the baseline phase.

Phase changes

Prior to implementing online tutoring for participant 1 , the researcher inspected baseline trends of DIBELS-ORF for all participants and determined if data were stable and predictable. In general, a stable and predictable data trend was defined as five data points which did not vary more than an average of twenty words read per min. However, 
this criterion was used as a guideline rather than absolute rule. Level, trend, and variability of all legs of the multiple baseline was considered in making decisions on phase changes.

When treatment was initiated for participant 1 , the other participants remained in baseline until participant 1 demonstrated a distinct pattern of data. Generally, a distinct pattern of data was defined as at least 4 data points that show a change in slope and at least $75 \%$ of the data points exceeding those from the same participant in the baseline phase. Again, these criteria were used as guidelines rather than absolute rules. When a distinct pattern of data was demonstrated, a second participant was considered for intervention. Synchronous online tutoring was given to student participants in this staggered pattern until each participant was exposed to the treatment.

Posttests

At the conclusion of the study, Tutors administered posttests (i.e., DIBELS benchmark, WJ-III, and Social Validity Questionnaire) to all student participants.

Data Analysis (Both Study $1 \&$ Study 2)

\section{Analysis of Data in Multiple Baseline Design}

Visual analysis of DIBELS progress monitoring probes. Single-subject research results may be interpreted with the use of statistical analyses (Todman \& Dugard, 2001); however, the traditional approach to analysis of single-subject research data involves systematic visual comparison of responding within and across conditions of a study (Parsonson \& Baer, 1978). When visually analyzing data the researcher should note 
changes in: (a) mean level, (b) trend line slopes, and (c), variability or data "bounce" (Gorman \& Allison, 1996).

Percent of non-overlapping data points. To help researchers analyze single subject research, Scruggs, Mastropieri, and Castro (1987) developed a nonparametric method for the analysis of single subject data. Their method is based on computing the percent of non-overlapping data points (PND) between phases. Assuming the goal of treatment is to increase behavior, the PND is calculated as follows in the simple $A B$ design: First, the number of data points in the treatment phase that exceeds the highest data point in the previous baseline phase is divided by the total number of data points in the treatment phase. Second, the resulting number is multiplied by $100 \%$, yielding a percentage score.

The strongest feature of the PND method is its ease of computation and interpretability. Results can be generated with a simple hand calculator and can be calculated more quickly than most other methods. Furthermore, most readers readily understand a percentage score. Despite these strengths, the PND method has several drawbacks. First, PND is neither an effect size nor related to an accepted effect size, so it needs its own interpretation guidelines. Second, PND has unknown reliability, as it lacks a known sampling distribution, so $\mathrm{p}$ values and confidence intervals cannot be calculated. The third weakness is that PND ignores all baseline phase data except on the single highest data point. Lastly, PND lacks sensitivity or discrimination ability as it nears $100 \%$ for large changes in behavior. Given the limitations of PND, we also computed regression lines for each phase for all student participants to assist in the analysis of the data. 
Regression analysis. I calculated trend for each student in each phase by using ordinary least-squares regression (OLS) (Franklin, Allison, \& Gorman, 1997), a statistical formula that is often used in time-series graphs. The computation of OLS regression results in slope and intercept values. Using these values I can draw a line through the data series that shows the best "linear fit" of all values.

Effect size. As a further aid to analysis, effect sizes were calculated for each data series. I employed a formula for "standardized difference" recommended by Faith, Allison, and Gorman, (1997); and Shernoff, Kratochwill, and Stoiber (2002). The effect size is calculated by subtracting the mean in treatment from the mean in baseline divided by the standard deviation in the baseline phase. Cautions and limitations reported by Faith, Allison, and Gorman include a loss of information about slope or rate of change in the treatment data and the data may contain positive or negative autocorrelation, which can bias effect-size values. Finally, each participant's ORF change was compared to the amount of change expected of students at the appropriate grade level based on Hasbrouck and Tindall (2006) ORF norms.

Analysis of Pretest and Posttest Data

Woodcock Johnson-III. All participants were assessed with the WJ-III reading subtests at pretest and posttest. Raw scores were converted to standard scores with the WJ-III scoring software. From the standard scores I calculated difference scores (posttest - pretest) for each participant.

DIBELS benchmark assessment. Students were also assessed with the DIBELS benchmark assessment at pretest and posttest. Pre/post difference scores were calculated for each participants ORF median. 
Social validity. Data from the social validity questionnaires was summarized with descriptive statistics. 
CHAPTER IV

\section{RESULTS}

The purpose of this study was to examine the effects of online reading instruction on at-risk fourth-grade students. Specifically, three questions guided this research:

1. To what extent will synchronous supplemental reading instruction delivered online increase the oral reading fluency of students at risk of reading failure?

2. To what extent will synchronous supplemental reading instruction delivered online increase overall reading skills as measured by the Woodcock Johnson III Tests of Academic Achievement reading battery (Letter Word ID, Word Attack, Reading Fluency, Passage Comprehension, and Picture Vocabulary) for students at risk of reading failure?

3. What are students', tutors' parents', and teachers' perceptions of the effectiveness and desirability of the online tutoring program?

Two studies are reported in response to the questions. The primary study (Study 1) consisted of a multiple baseline across four participants in Philadelphia, PA, and a systematic replication (Study 2) consisted of the same treatment, design, and measures with four students in Kearns, UT. The multiple baseline graphs (see Figures 2 \& 6) presented throughout this chapter illustrate the number of words read per min. For confidentiality reasons pseudonyms are used throughout the text. 
Study 1 Philadelphia, PA

Interobserver Agreement

Table 2 provides data on the Interobserver agreement (IOA) across all dependent measures, fidelity of assessment delivery checklists, and treatment integrity measures for study 1 .

Overall, on the DIBELS Progress Monitoring assessments there was a mean agreement of $97.2 \%$ between two independent observers (range $91.7-100$ ). DIBELS

Table 2

Interobserver Agreement for All Dependent Measures in Philadelphia

\begin{tabular}{lcc}
\hline Measure & Mean & Range \\
\hline DIBELS progress monitoring & 97.2 & $95-100$ \\
DIBELS benchmark & 100 & 100 \\
WJ-III & & \\
$\quad$ Letter word ID & 97.2 & $96.4-100$ \\
$\quad$ Reading fluency & 100 & 100 \\
$\quad$ Passage comprehension & 97.9 & $96.3-100$ \\
$\quad$ Word attack & 95.2 & $95-100$ \\
$\quad$ Picture vocabulary & 99 & $96.9-100$ \\
WJ-III checklist & 100 & 100 \\
DIBELS integrity checklist & 100 & 100 \\
DI observation form (overall) & 96.2 & $95-100$ \\
\hline
\end{tabular}


benchmark assessment agreement was $100 \%$ based on word-by-word agreement. Overall WJ-III Interobserver agreement was 97.86\% (range 95.6-100) given an item-by-item method for calculating IOA. Table 2 provides mean and range IOA values for the individual WJ-III subtests.

Interobserver agreement was also assessed on fidelity of assessment checklists and treatment integrity measures. The WJ-III assessment checklist and DIBELS assessment integrity checklists had $100 \%$ agreement on all observations. The DI treatment integrity measure was assessed using the DI-Checklist (see Appendix B) on the rate of presentation, percent correct use of an error correction procedure, and rate of reinforcement. Overall IOA for the DI-Checklist was $96.2 \%$.

\section{Fidelity of Implementation}

Treatment integrity was assessed $24 \%$ (range $17 \%-30 \%$ ) of all tutoring sessions. Observers recorded the rate of stimulus presentation (i.e., the whole cue, pause, signal sequence), the percent correct delivery of error correction (i.e., model, test, retest), and the rate of reinforcement. Table 3 provides the mean performance for each tutor on each key component for delivering Direct Instruction tutoring. Overall, the mean rate of stimulus presentation was 9.83 responses per min. The percent correct delivery of error correction mean was $94 \%$, and the rate of reinforcement was 5.54 per min.

To assess the accurate and fluent presentation of WJ-III and DIBELS assessments we utilized fidelity checklists. Table 4 provides outcomes for each assessment (i.e., WJIII reading subtests, DIBELS Benchmarks, and DIBELS progress monitoring probes). Fidelity of assessment delivery for both the WJ-III and DIBELS benchmarks was 
Table 3

Assessment of Treatment Fidelity (Direct Instruction Observation Form)

\begin{tabular}{lccc}
\hline Tutor & $\begin{array}{c}\text { Number of } \\
\text { observations }\end{array}$ & Error & Rate of reinforcement \\
& 23 & $95 \%$ & $5.08 / \mathrm{min}$ \\
\hline Jennifer & 26 & $93 \%$ & $5.51 / \mathrm{min}$ \\
Melissa & 15 & $94 \%$ & $6.02 / \mathrm{min}$ \\
Pam & 21.3 & $94 \%$ & $5.54 / \mathrm{min}$ \\
\hline$M$ & & & \\
\hline
\end{tabular}

measured on $100 \%$ of all pretest and posttest assessments sessions. The mean percent correct for the accurate and fluent delivery of the WJ-III was $96.85 \%$. DIBELS Benchmark assessment mean percent correct was 100\%. Assessment of Fidelity for DIBELS progress monitoring was taken $30 \%$ of all assessment. The mean for the fluent delivery of DIBELS progress monitoring was $92.5 \%$ with a range of $83 \%-100 \%$.

\section{Multiple Baseline Across Participants}

Oral reading rate in each phase is displayed in Figure 2. Daniel's mean words read correctly per min (WCPM) during baseline was 24.6 with a decreasing slope of -1.1 words per week. Given 16 weeks of supplemental online instruction his WCPM change visibly in both level and slope.

Daniel had an intervention phase mean of 53.1 WCPM and slope of 1.47 words per week. The percent of non-overlapping data points (PND) was $100 \%$. To provide additional analysis two more PND calculations were made. First, we projected the slope 
Table 4

Fidelity of Assessment Delivery for Pre/Posttest Measures

\begin{tabular}{lccc}
\hline Measure & Mean & Range & Percent assessed \\
\hline WJ-III Checklist & $96.85 \%$ & $91.6-100$ & $100 \%$ \\
DIBELS Benchmark Checklist & $100.00 \%$ & 100 & $100 \%$ \\
DIBELS Progress Monitoring & $92.50 \%$ & $83-100$ & $30 \%$ \\
Checklist & & & \\
\hline
\end{tabular}

from the baseline phase through the intervention phase and calculated a PND based on this projected slope. With a decreasing slope in baseline, the PND was $100 \%$. Second, we projected another trend line through the treatment phase using oral reading fluency norms established by Hasbrouck and Tindall (2006). Hasbrouck and Tindall report fourth-grade students gain 1.15 words per week. We began with the highest point in baseline and projected a line based on weekly gain of 1.15 words per week (See Figure 2). Daniel was in treatment for 18 weeks. We multiplied 18 times 1.15 to identify a projected ending point. After the projected slope was drawn, we calculated a PND. For Daniel this PND was $100 \%$. Thus, every one of his intervention phase data points was above this line based on normative gain in WCPM.

Kendall's baseline mean was 38.1 WCPM with a slightly increasing slope of .98 words per week. After the phase change, there was a noted changed in level; however, there was no change in slope. The mean of the treatment phase for Kendall was 60.5 WCP with a slope of .99 words per week. The traditional PND was $100 \%$; however, this calculation may be misleading given the increasing trend in the baseline phase. Using 


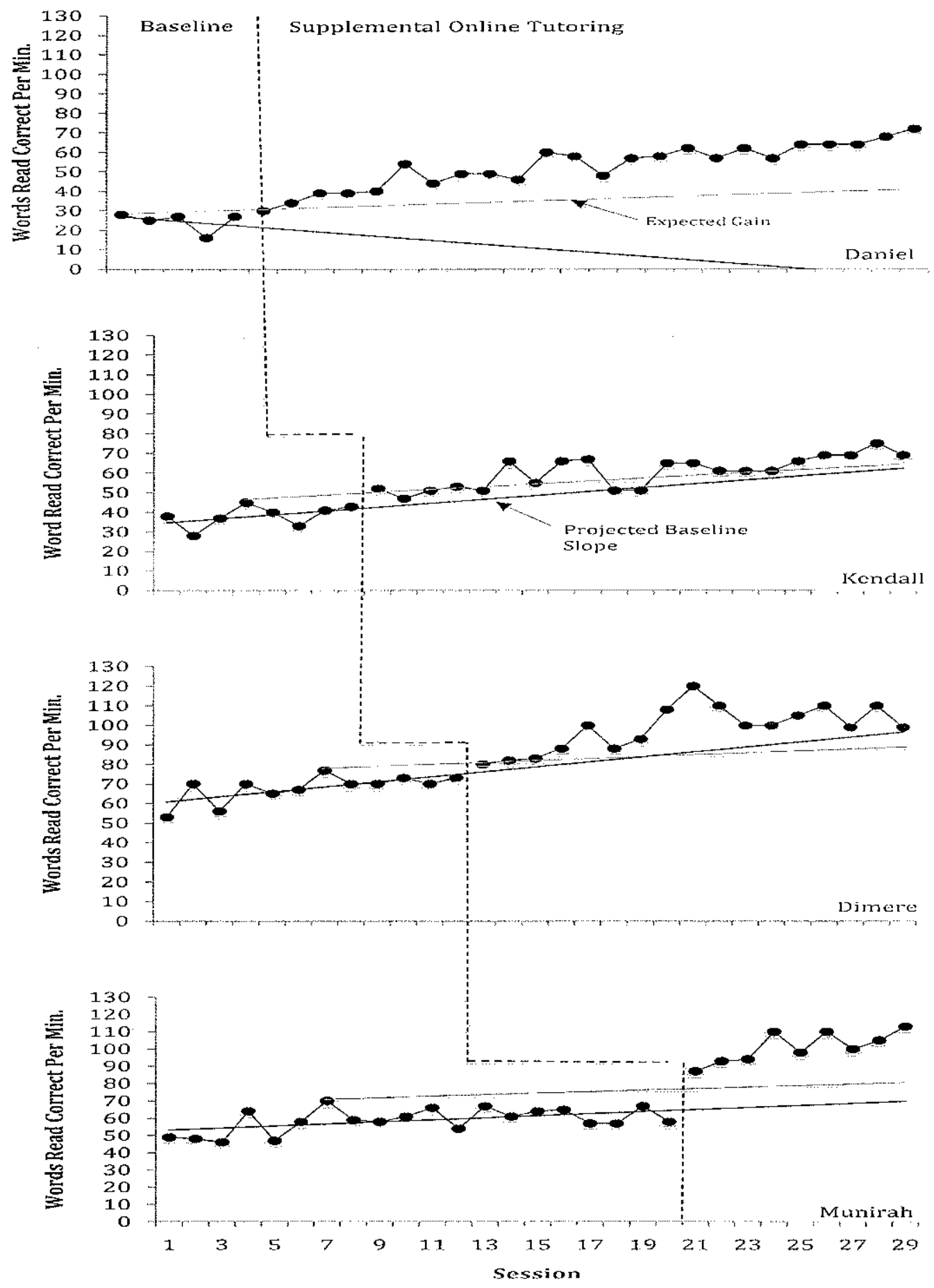

Figure 2. Results of online tutoring for students in Philadelphia. Data represent median number of words read correctly per min in a multiple baseline across participants design. 
the projected baseline slope to calculate a PND also yielded $100 \%$. And finally, using the projected line based on the normative gain of 1.15 words per week yielded a PND of $76.2 \%$

Dimere's baseline mean was 67.8 WCPM with an increasing slope of 1.27 words per week. This contrasts with the 13 week of intervention phase with a mean of 98.5 WCPM and an increasing slope of 1.53 words per week. Visual analysis confirms these changes in level and slope. There was 100\% PND for the traditional analysis, the projected baseline PND was $100 \%$, and the expected gain PND was $94.1 \%$.

Munirah's mean in baseline was 58.8 WCPM with a slightly increasing slope of .59 words per week. In the 8-week intervention phase her mean WCMP increased to 101.1 with a slope of 2.53 words per week. The figure shows that Munirah made marked changes in both level and slope. There was 100\% PND for all three analysis (i.e., traditional PND, projected baseline PND, and expected gain PND). Visual analysis of Figure 2 reflects overall marked improvement for two of the four students. The type of between-phase differences noted for all fours students appears to be in trend line slopes resulting in higher means for intervention phases when compared to baseline phases.

\section{Non Experimental Pre/Posttest}

The following section presents the non-experimental pre/post data for students in Philadelphia. Figure 3 presents data from the DIBELS Benchmark assessments. Overall, all 4 students in Philadelphia made marked improvements in WCPM from pretest to posttest on the DIBELS benchmark assessment. The mean gain in WCPM was 40.5 with a range of 27.6-55.6 (see Figure 3). Importantly, students varied in the duration of the 


\section{DIBELS}

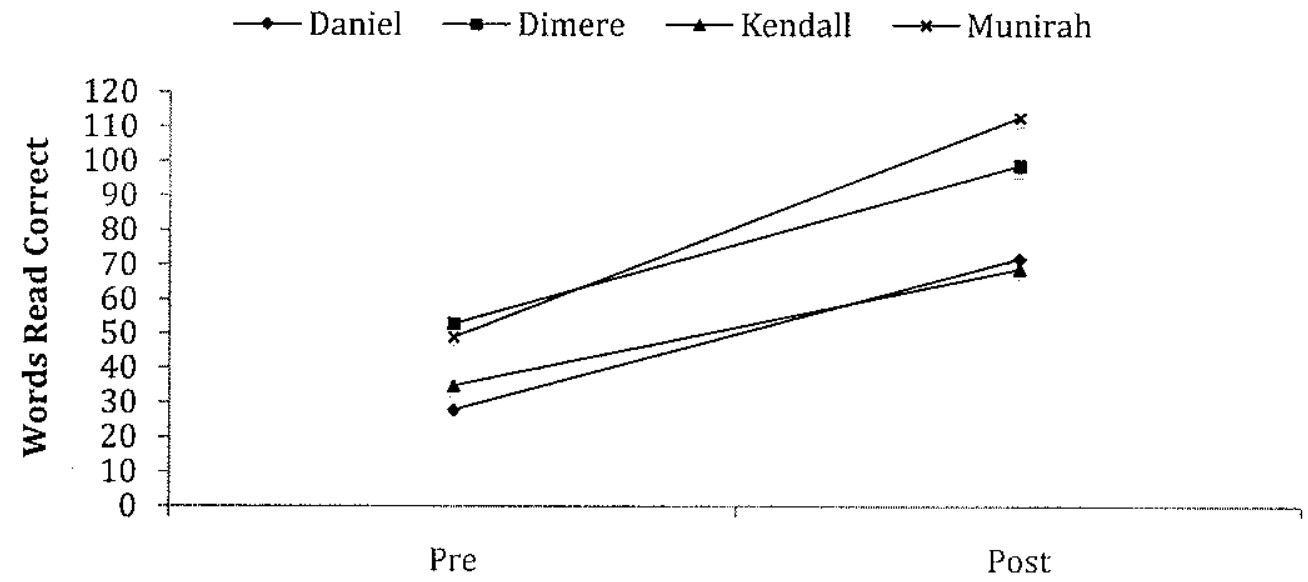

Figure 3. DIBELS benchmark pre- and posttest scores in words read correct per minute for students in Philadelphia.

treatment phase (i.e., amount of exposure to the independent variable); nevertheless, all students made gains.

Individually, Munirah made the greatest gains (increase of 55.6 WCPM) and Kendall made the least gain (increase of 27.6 WCPM). Figure 4 presents overall changes in standards scores (SS) on the WJ-III basic and broad reading clusters for pre and posttests. Overall, all four students made gains in SS for the Basic Reading cluster. Daniel had the smallest change in SS from pre to post with a gain of +1 point and Munirah had the largest gain of +12 SS points. Dimere gained six SS points and Kendall gained eight SS points from pre to post. On the WJ-III Broad Reading Skills cluster, all four students made gains in with a mean gain of six SS points (range 2 to 9). 

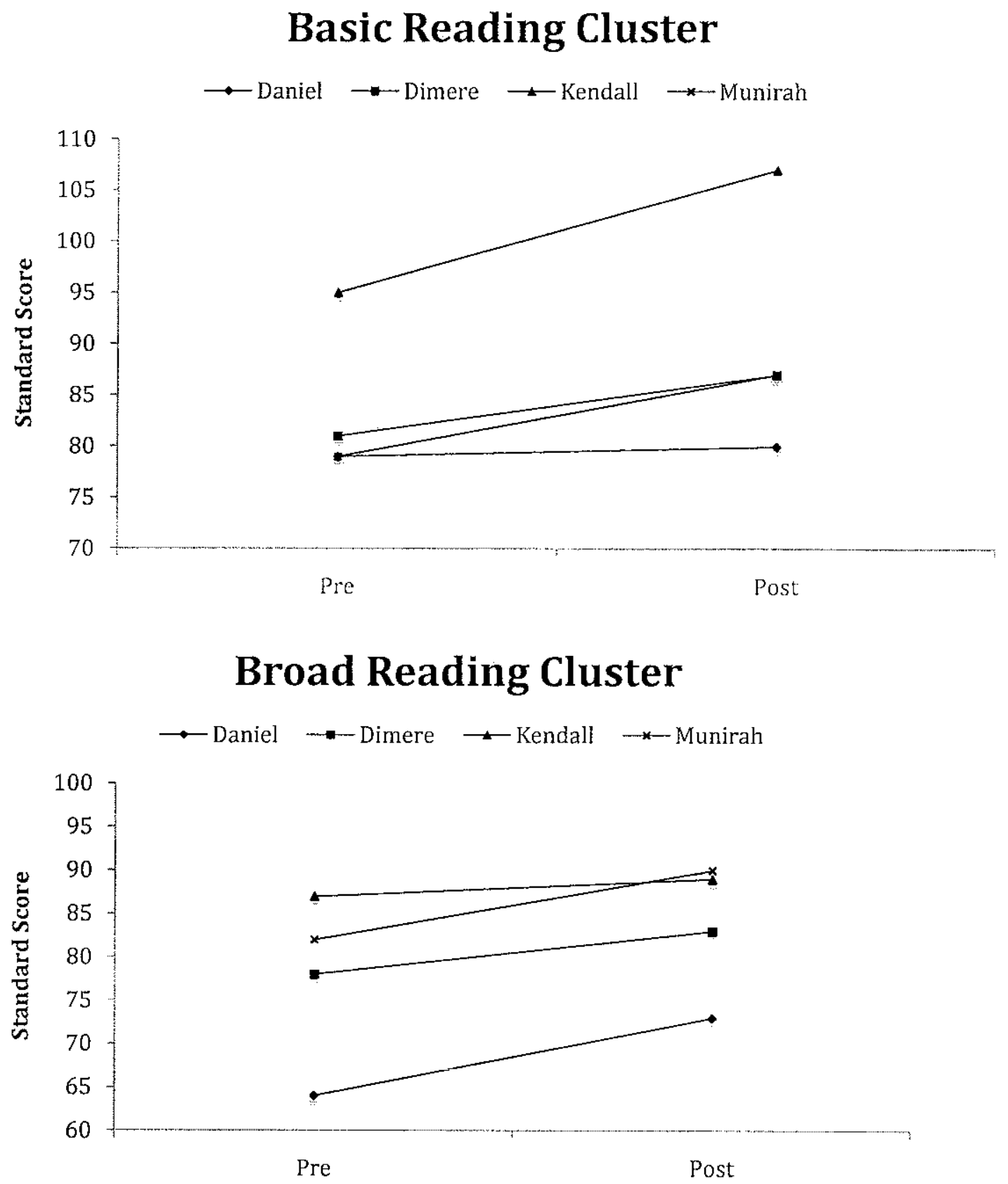

Figure 4. Woodcock Johnson III reading cluster scores. 
Figure 5 presents pretest and posttest outcomes on individual subtests. All four students made gains in SS from pretest to posttest on Letter Word ID, Reading Fluency, and Word Attack. On the Passage Comprehension subtest, two of the four students made gains in SS, one student made no gain, and one showed a decrease. On the Picture Vocabulary subtest, Dimere and Munirah both had decreases in SS ( -9 and -1 respectively) and both Daniel and Kendall made relatively small gains in SS from pre to posttest $(+7$ and +4 , respectively).

Table 5 provides information on each student's expected gain (based on Hasbrouck \& Tindall, 2006) and actual gain observed during the intervention. We multiplied the number of weeks each student was exposed to the treatment by 1.15 to

\section{Table 5}

Comparison of Expected ORF Gains Compared to Actual Gain Scores for Students in Philadelphia

\begin{tabular}{lcccc}
\hline \multicolumn{1}{r}{ Student } & Weeks in & Expected & Actual gain & Difference \\
& treatment & gain & & \\
\hline Daniel & 18 & 20.7 & 37.3 & +16.6 \\
Kendall & 16 & 18.4 & 27.6 & +9.2 \\
Dimere & 13 & 14.95 & 41.4 & +26.45 \\
Munirah & 8 & 9.2 & 55.6 & +46.4 \\
\hline
\end{tabular}


Letter Word ID

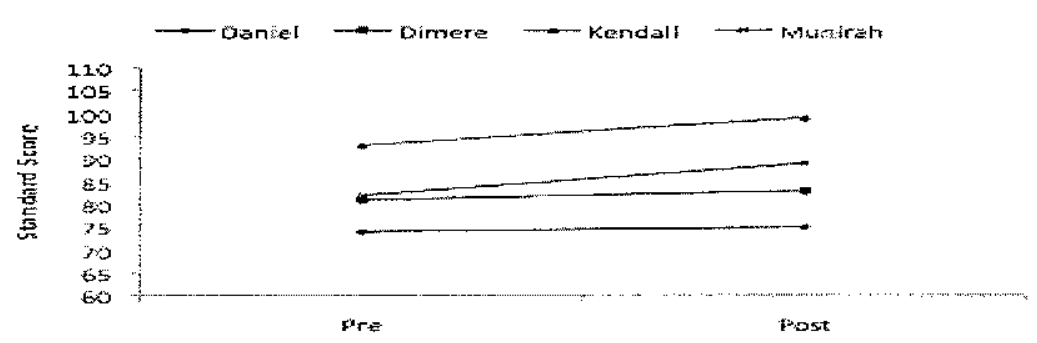

Reading Fluency

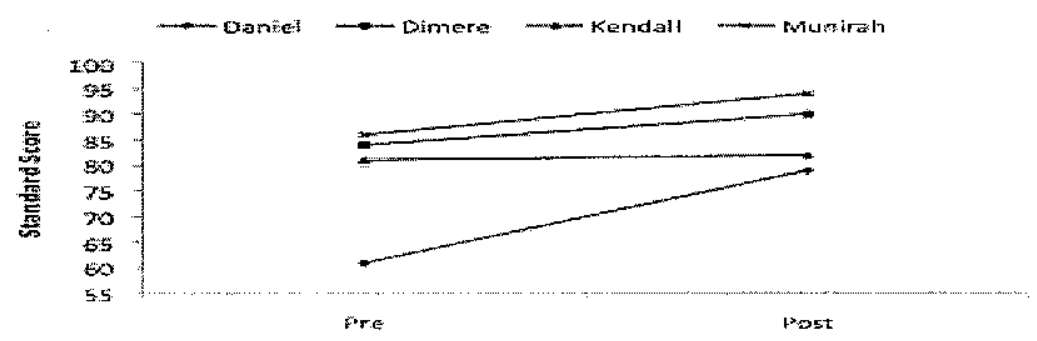

Passage Comprehension
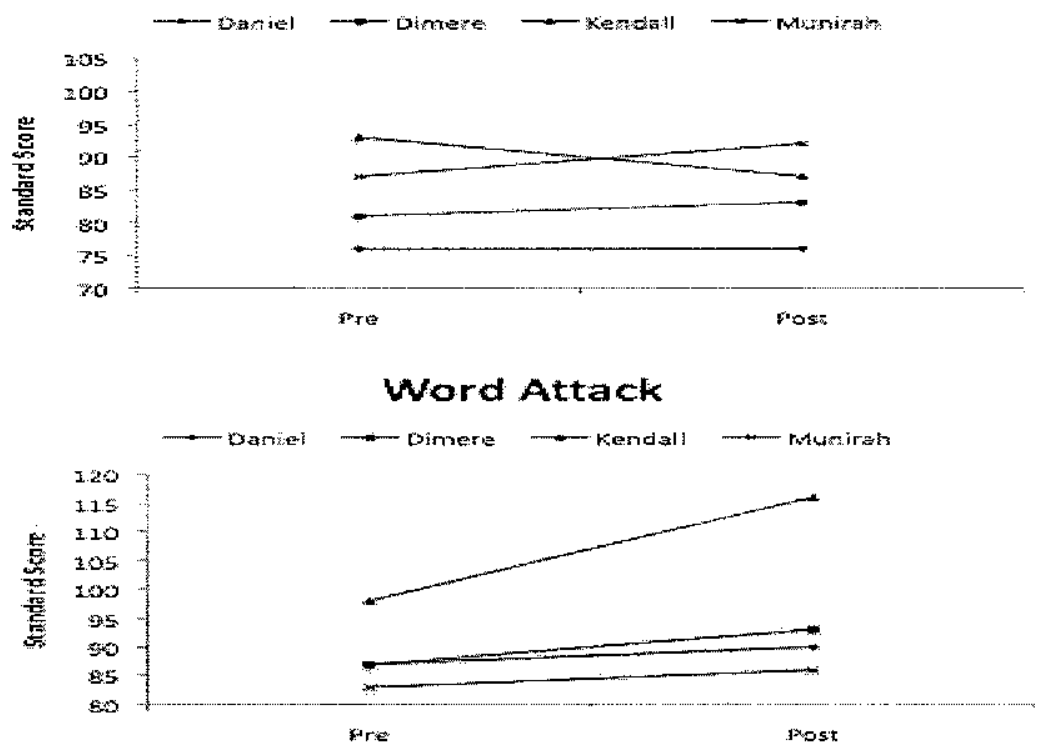

Picture vacabulary

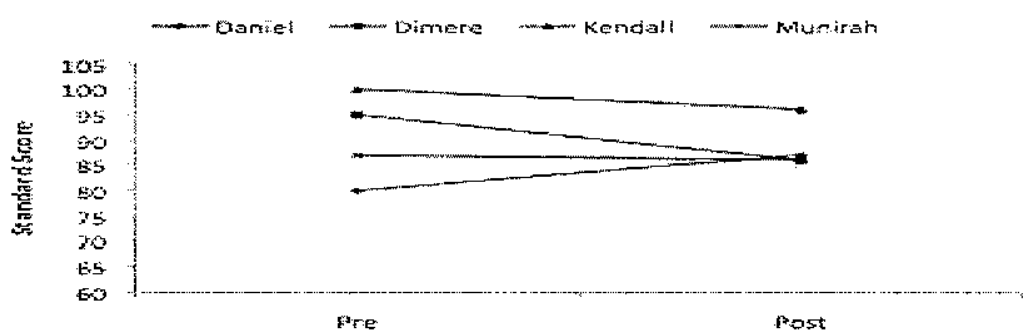

Figure 5. Results from individual Woodcock Johnson III reading subtests. 
establish the expected words gained across the treatment phase. To calculate the actual gain we subtracted the WCPM median in posttest from pretest. From the actual gain score we subtracted the expected gain to calculate the difference score. Overall, the four students gained 24.67 more WCPM (range 9.2-46.4) than would be expected based on these norms. Again, all four students surpassed the expected gain of 1.15 word per week.

\section{Social Validity Questionnaire}

This section provides the outcomes of a questionnaire delivered at the conclusion of the study in Philadelphia. Table 6 provides parent, teacher, student, and tutor ratings on the goals, procedures, and outcomes of online instruction. Two teachers, four tutors, four students, and two parents responded to the questions. Overall, all the parent, student, teacher, and tutor participants reported the goals, procedures and outcomes of online tutoring to be beneficial. Both Students and teachers reported favorable close working relationships with their tutors and also reported an increase in reading skill given the intervention. Specifically, $100 \%$ of teachers, parents, and tutors responded that online tutoring was a good way to deliver reading instruction and get favorable student outcomes. For the acceptability of online tutoring procedures, teachers and tutors all report that the set up was "easy," however, not "very easy." Teachers, students and tutors report that some student materials could be clearer; however, overall the clarity was acceptable. Teachers, tutors and students report occasional problems hearing each other. Finally, $100 \%$ of all teachers, parents, students, and tutors reported improved reading skills, generalization of reading skills into other areas (e.g., classroom or home environments) and would recommend online tutoring for other students. 
Table 6

Social Validity Outcomes for Participants in Philadelphia

\begin{tabular}{|c|c|c|c|c|}
\hline \multirow{2}{*}{$\begin{array}{l}\text { Measure } \\
\text { Goals }\end{array}$} & \multicolumn{4}{|c|}{ Percent who responded "yes" } \\
\hline & Parent & Teacher & Tutor & Student \\
\hline $\begin{array}{l}\text { Is online tutoring a good way to } \\
\text { deliver supplemental reading } \\
\text { instruction? }\end{array}$ & $100 \%$ & $100 \%$ & $100 \%$ & $100 \%$ \\
\hline $\begin{array}{l}\text { Was progress shown and } \\
\text { explained? }\end{array}$ & $100 \%$ & $100 \%$ & $100 \%$ & $100 \%$ \\
\hline $\begin{array}{l}\text { Did your student enjoy reading } \\
\text { over the system }\end{array}$ & $100 \%$ & $100 \%$ & $100 \%$ & $100 \%$ \\
\hline $\begin{array}{l}\text { Did the student build a trusting } \\
\text { relationship with tutor? }\end{array}$ & $100 \%$ & $100 \%$ & $100 \%$ & $100 \%$ \\
\hline Procedures & \multicolumn{4}{|c|}{ On a scale of $1-4$ (very easy-very difficult) } \\
\hline $\begin{array}{l}\text { Was it easy to setup online } \\
\text { tutoring? }\end{array}$ & $\mathrm{N} / \mathrm{A}$ & 2 & 1 & N/A \\
\hline $\begin{array}{l}\text { Was it easy to hear tutors over the } \\
\text { system? }\end{array}$ & N/A & 2.5 & 2.25 & 2 \\
\hline Was it easy to read the student & N/A & 2 & 2 & 1.5 \\
\hline Materials online? & & & & \\
\hline Outcomes & \multicolumn{4}{|c|}{ Percent who responded "yes" } \\
\hline $\begin{array}{l}\text { Did you see improvements in } \\
\text { student reading skills? }\end{array}$ & $100 \%$ & $100 \%$ & $100 \%$ & $100 \%$ \\
\hline $\begin{array}{l}\text { Were the changes noticeable in the } \\
\text { classroom or home? }\end{array}$ & $100 \%$ & $100 \%$ & $100 \%$ & $100 \%$ \\
\hline $\begin{array}{l}\text { Would you recommend online } \\
\text { tutoring to others? }\end{array}$ & $100 \%$ & $100 \%$ & $100 \%$ & $100 \%$ \\
\hline Would you pay for online tutoring? & $100 \%$ & $100 \%$ & N/A & N/A \\
\hline
\end{tabular}


Teacher and student participants were asked additional questions regarding what they liked and disliked about online tutoring. Teachers were asked what changes they would make to improve online tutoring. All (100\%) of the Philadelphia teachers reported that they would like to shorten the length of the lesson but increase tutoring to 5 days per week. All four students reported that they liked the stories, the you-me game, and meeting teachers from Utah. Two of the four students responded that they disliked having to sound out difficult words and having instruction early in the morning. The other two students reported that they disliked nothing about online tutoring.

\section{Discussion}

Overall, when given online tutoring, all students in Philadelphia made gains in oral reading fluency. Both Daniel and Munirah had clear changes in slope and level demonstrating clear experimental control. However, Kendal and Dimere both had slightly increasing trends in baseline making visual analysis difficult. Even with slightly increasing trends in baseline, three methods of PND analysis support the conclusion that performance in the treatment phase was substantially higher than performance in baseline. Interestingly, Dimere's projected baseline slope was better than the "expected gain" slope. This indicates that Dimere was learning more than the expected gain established by Hasbrouck and Tindall (2006) before online tutoring was implemented.

Despite the increasing baseline trend, Dimere's slope in the treatment phases was steeper than the baseline slope (regular classroom instruction only) and the expected gain slope. Additionally, all four students showed changes in SS scores on the basic and broad reading clusters of the WJ-III reading subtests. A gain in standard score indicates that the student learned more than those in the norm sample. The Corrective Reading Decoding 
curriculum focuses on specific skills. Given the range of reading skills assessed by the WJ-III we would expect gains in certain subtest and not in others.

The Letter Word ID and Reading Fluency subtests are well aligned with the intervention, so we would expect the largest gains on these subtests. In fact, all four students do show marked gains in these subtests. Next, Word Attack and Passage Comprehension subtests have moderate overlap with instruction. Specifically, Word Attack uses nonsense words to test generalization of decoding skills, thus it is a test of generalization of the skills taught in Corrective Reading program. Passage Comprehension requires decoding skills, but also extensive comprehension skills that are not the target of Corrective Reading Decoding. So we would expect some impact, but we would expect it to be moderate because some of the skills required for Passage Comprehension were not taught in the program.

All students made gains in SS for Word Attack. However, on Passage Comprehension, only two of the four students made gains in SS. Finally, the Picture Vocabulary subtest does not overlap at all with our intervention. We included this subtest to serve as a control to test the specificity of observed changes and to compute the broad reading cluster score. Gains in Picture Vocabulary would suggest that some factor that is broader than the intervention (maturation, other educational activities) may have caused the changes. In fact, three of the four students either made a decrease in SS or had no change. Only one student made a gain in SS (Daniel). Thus, the improvements seen on the subtests of the WJ-III are precisely those that would be predicted based on the nature of the intervention. 
Study 2 Kearns, UT

This section presents data on a systematic replication of study 1 at a different school with four new students. Table 7 provides outcome data on interobserver agreement across all dependent measures, fidelity checklists, and treatment integrity measures for study 2 . Overall, there was a mean agreement of $96.18 \%$ (range $94.5-100$ ) between two independent observers on the words read correctly. Overall WJ-III agreement was $96.19 \%$ (range $86.92-100$ ) in an item by item rating. Table 4 provides mean and range values for interobserver agreement on individual WJ-II subtests.

Table 7

Interobserver Agreement for all Dependent Measures in Kearns

\begin{tabular}{lcc}
\hline Measure & Mean & Rangc \\
\hline DIBELS progress monitoring & 96.18 & $94.50-100$ \\
Letter word ID & 97.34 & $96.5-100$ \\
Reading fluency & 100 & 100 \\
Passage comprehension & 98.03 & $95.35-100$ \\
Word attack & 86.92 & $85.18-87.5$ \\
Picture vocabulary & 98.69 & $97.37-100$ \\
DIBELS benchmark & 100 & 100 \\
WJ-III checklist & 100 & 100 \\
DIBELS integrity checklist & 100 & 100 \\
DI observation form & 94.39 & $93.50-100$ \\
\hline
\end{tabular}


Letter Word ID mean agreement was $97.34 \%$ (range 96.5-100), Reading Fluency mean agreement was 100\%, Passage Comprehension was 98\% (range 95.35-100), Word Attack 86.9\% (range 85.18-87.5), and Picture Vocabulary was 98.69\% (range 97.37100). DIBELS Benchmark assessment agreement was $100 \%$ based on word-by-word agreement.

Interobserver agreement was assessed on fidelity of assessment checklists and treatment integrity measures. The WJ-III assessment checklist and DIBELS assessment integrity checklists had a mean agreement of 100\%. Overall IOA for the DI-Checklist was $94.4 \%$.

Treatment integrity was assessed $27 \%$ (range $22 \%-30 \%$ ) of all tutoring sessions. At least one independent observer recorded to rate of stimulus presentation (i.e., cue, pause, signal), the percent correct delivery of error correction (i.e., model, lead, test, retest), and the rate of reinforcement. Table 8 provides the treatment integrity results for

Table 8

Assessment of Treatment Integrity (Direct Instruction Observation Form)

\begin{tabular}{lccc}
\hline Tutor & $\begin{array}{c}\text { Number of } \\
\text { observations }\end{array}$ & $\begin{array}{c}\text { Error } \\
\text { correction }\end{array}$ & $\begin{array}{c}\text { Rate of } \\
\text { reinforcement }\end{array}$ \\
\hline Jennifer & 8 & $96.52 \%$ & $6.33 / \mathrm{min}$ \\
Pam & 8 & $94.05 \%$ & $4.83 / \mathrm{min}$ \\
Cathy & 6 & $97.32 \%$ & $7.27 / \mathrm{min}$ \\
\hline$M$ & 7.33 & $95.96 \%$ & $6.14 / \mathrm{min}$
\end{tabular}


each tutor. Overall, the mean rate of stimulus presentation was 8.63 responses per min.

The mean percent of correct of error corrections was $95.96 \%$, and the rate of reinforcement was 6.14 per $\min$.

To assess the accurate and fluent presentation of WJ-III and DIBELS assessments we utilized the same fidelity checklists as in study 1 . Table 9 provides outcomes for each assessment (i.e., WJ-III reading subtests, DIBELS Benchmarks, and DIBELS progress monitoring probes). Fidelity assessment procedures were assessed for both the WJ-III and DIBELS benchmarks was on $100 \%$ of all assessments sessions (i.e., pre and posttest). Assessment of fidelity for DIBELS progress monitoring was taken $30 \%$ of all data collection sessions. The mean percent correct for the accurate and fluent delivery of the WJ-III was $97.08 \%$. DIBELS Benchmark assessment mean percent correct was $100 \%$ and DIBELS progress monitoring was $97.61 \%$.

Table 9

Assessment of Fidelity for Pre/Posttest Measures

\begin{tabular}{lccc}
\hline Measure & Mean & Range & Percent assessed \\
\hline WJ-III checklist & $97.08 \%$ & $92.33-100$ & $100 \%$ of all assessments \\
DIBELS benchmark checklist & $100 \%$ & 100 & $100 \%$ of all assessments \\
DIBELS progress monitoring & $97.61 \%$ & $93.5-100$ & $38 \%$ of all sessions \\
checklist & & & $(n=5)$ \\
\hline
\end{tabular}


Multiple Baseline Across Participants

The primary results of study 2 are presented in Figure 6. Kur's mean WCPM during baseline was 32.8 with a decreasing slope of -2.7 words per week. In this study two participants were inserted into treatment quickly due to time constraints. Importantly, Study 2 served as a replication of Study 1 and the additional participants in Study 2 served as experimental control

Given 6 weeks of supplemental online instruction his WCPM change visibly in both level and slope. He had an intervention phase mean of 60.2 and slope of +.42 words per week. The PND was 100\%. Projected baseline slope PND was $100 \%$ as was the PND based on expected gain. Kur's standardized mean difference effect size was 6.32 .

Francis's baseline mean was 26.5 WPM with a decreasing slope of -4.6 words per week. In the 6-week phase of supplemental online instruction, there was a noted increase in both level and slope. The mean WCPM in treatment was 46.7 for Francis and she had a slope of 1.48 words per week. The traditional PND score was $100 \%$; the projected baseline PND was $100 \%$ and the expected gain PND yielded a score of $100 \%$. The standardized mean difference effect size was 3.08 .

Chris and Sydney served as control for Francis and Kur. When online tutoring was administered to both Francis and Kur, Chris and Sydney made no gains in words read correct indicating independence across the legs of the multiple baseline. Chris's baseline mean was 78.9 WCPM with a slightly decreasing slope of -.5 words per week. In the four-week intervention phase the mean increased to 98.7 WCPM with a slope of +2.11 words per week. There was $100 \%$ PND for the traditional analysis, $100 \%$ projected 


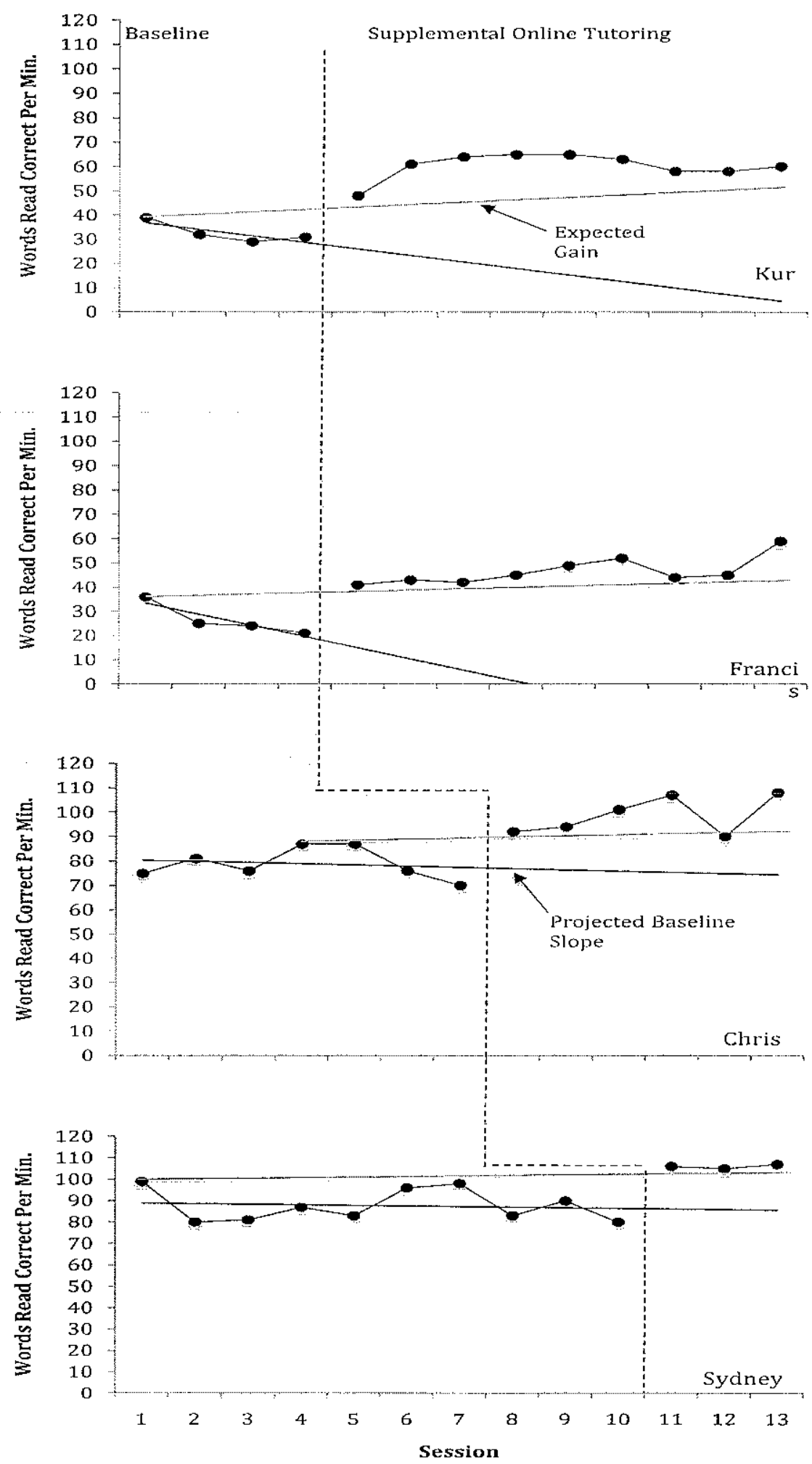

Figure 6. Effects of supplemental online instruction to students in Kearns, UT. 
baseline PND, and 100\% expected gain PND. The standardized difference effect size was 3.09 for Chris.

Finally, Sydney's mean in baseline was 97.7 WCPM with a slightly decreasing slope of -.27 words per week. Given 2 weeks of online tutoring her mean WCMP increased to 106 with an increasing slope of +.5 words per week. Visually, Sydney made small changes in both level and slope when given supplemental online instruction.

Sydney had the shortest intervention phase (i.e., 2 weeks); nevertheless she was able to make gains in ORF. Additionally, there was 100\% PND for all three analyses (i.e., traditional PND, projected baseline PND, and expected gain PND). The standardized difference effect size was 2.42 .

Visual analysis of Figure 6 indicates an overall increase in the words read correctly after the initiation of synchronous online tutoring. All four students showed increases in mean levels, jumps of trend line intercepts, and higher trend line slopes in the treatment phase than in baseline. The mean effect size for study 2 was 3.73 (range $2.42-$ 6.32). Given the short time period available for this study ( 9 weeks), we implemented online tutoring for two students at one time allowing legs 3 and 4 to act as controls for the first two legs.

Non Experimental Pre/Posttest

This section presents the non-experimental pre/post data for students in study 2 . Figure 7 presents data from the DIBELS Benchmark assessments. Overall, all 4 students made marked improvements in words correct on the DIBELS benchmark test. The mean gain was 22.5 WCPM with a range of 8-36 WCPM. The students varied in the amount of 


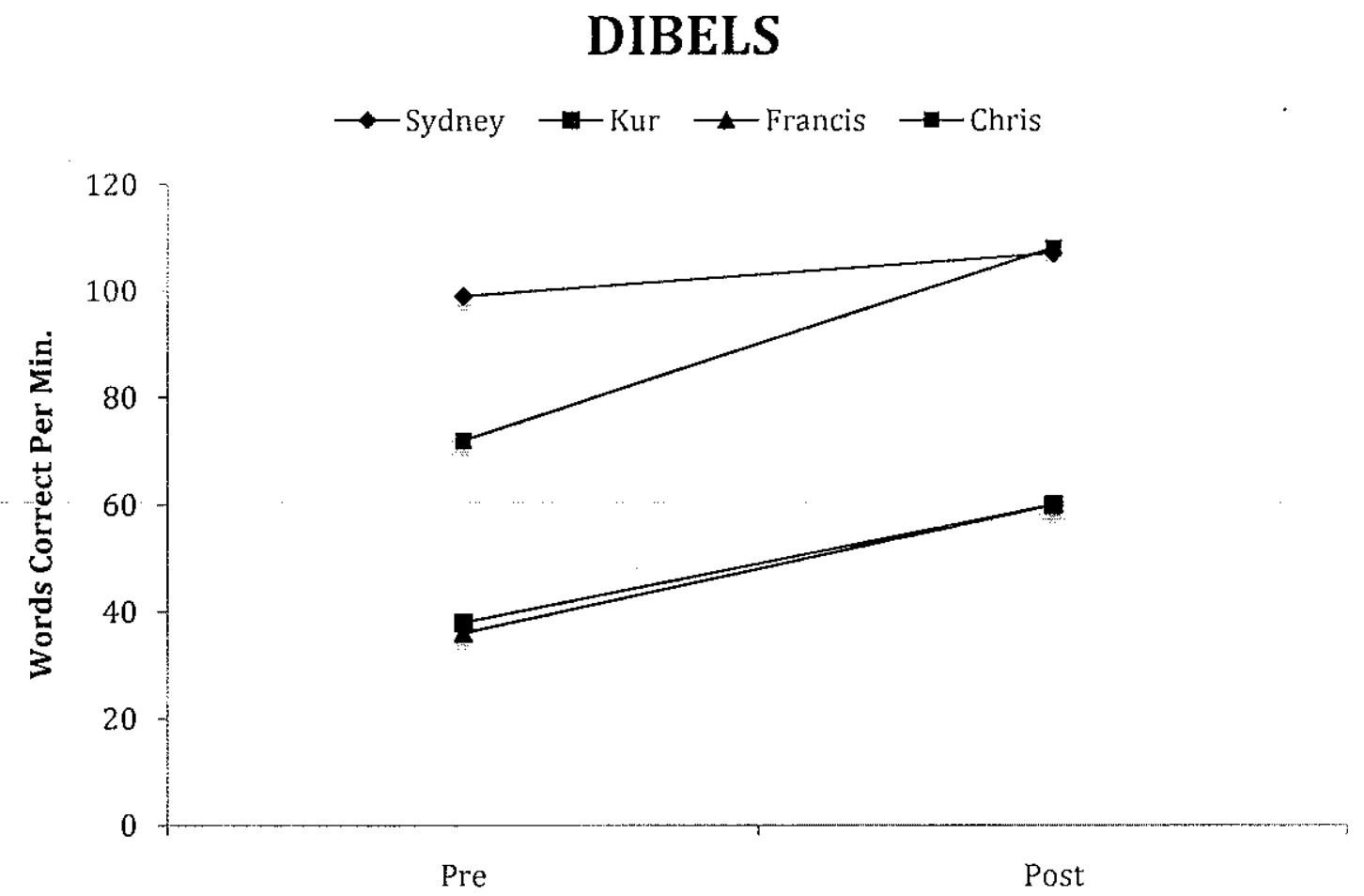

Figure 7. DIBELS oral reading fluency benchmark pre and posttest results.

time they received supplemental online instruction (range 2-6 weeks); however, all made gains in oral reading fluency. Individually, Chris made the greatest gains (increase of 36 WCPM) and Sydney made the smallest gain (increase of 8 WCPM), however she received treatment for only two weeks.

Figure 8 presents changes in SS on the WJ-III subtests. Three of the four students made gains on the Basic Reading cluster (range +6 to -3 ). In the Broad Reading cluster, three of the four students made gains and one student had no change in standard score (range +8 to 0 ). Figure 9 presents each student's outcomes on individual subtests. Overall, all four students made gains in standard score from pre to posttest for Picture 

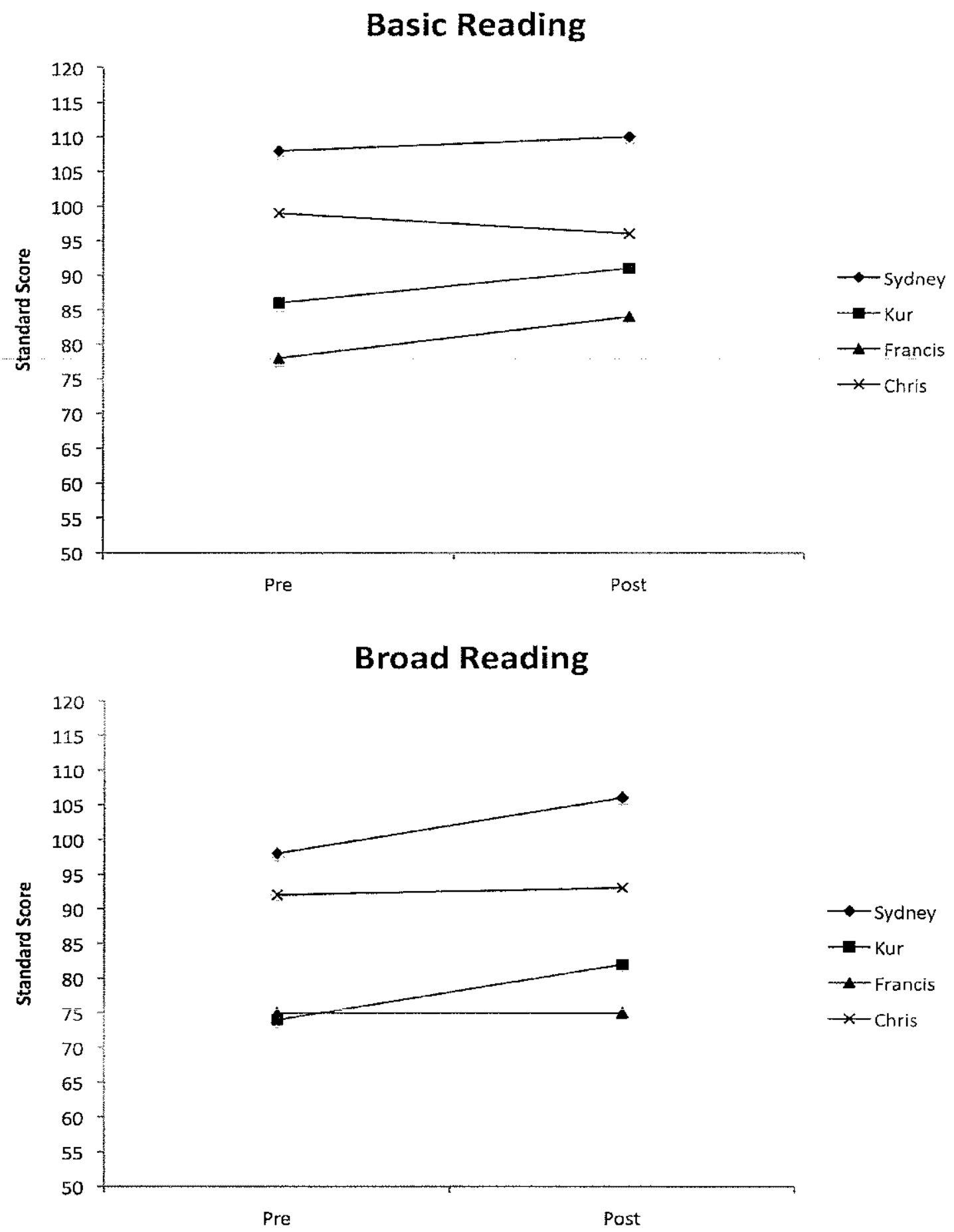

Figure 8. Woodcock Johnson III reading cluster scores. 


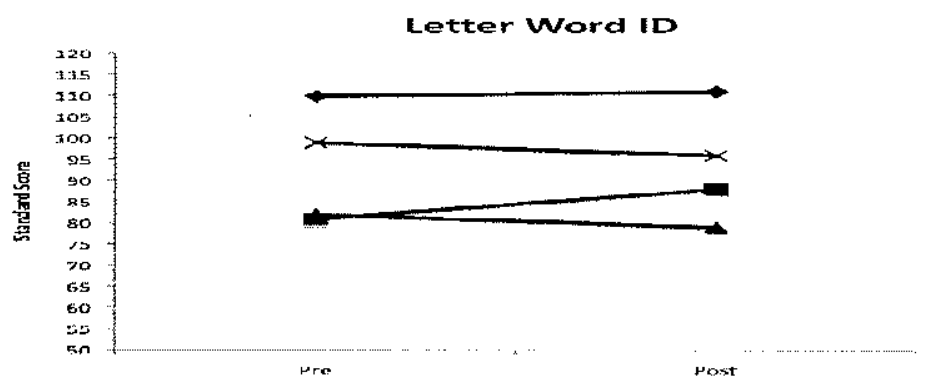

- sydrey

- Kur

Ziterancis

Readine fluency

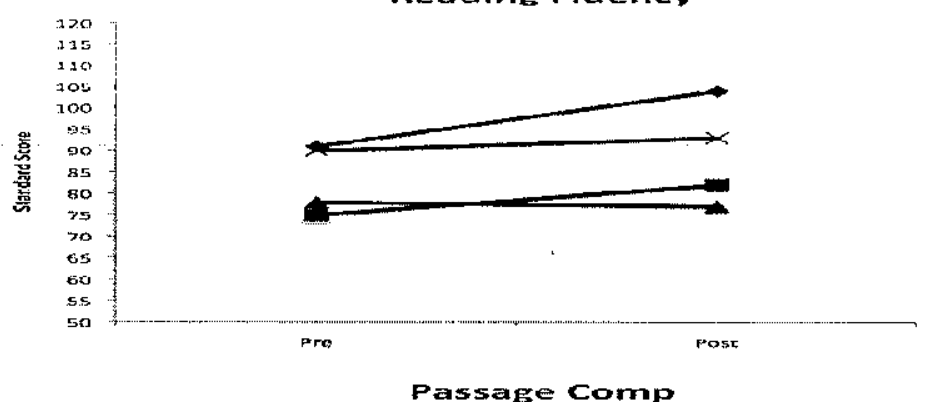

Dhesaner

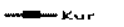

$\rightarrow$ Frankis

$\rightarrow$ Chris

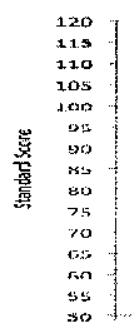

Passage Comp
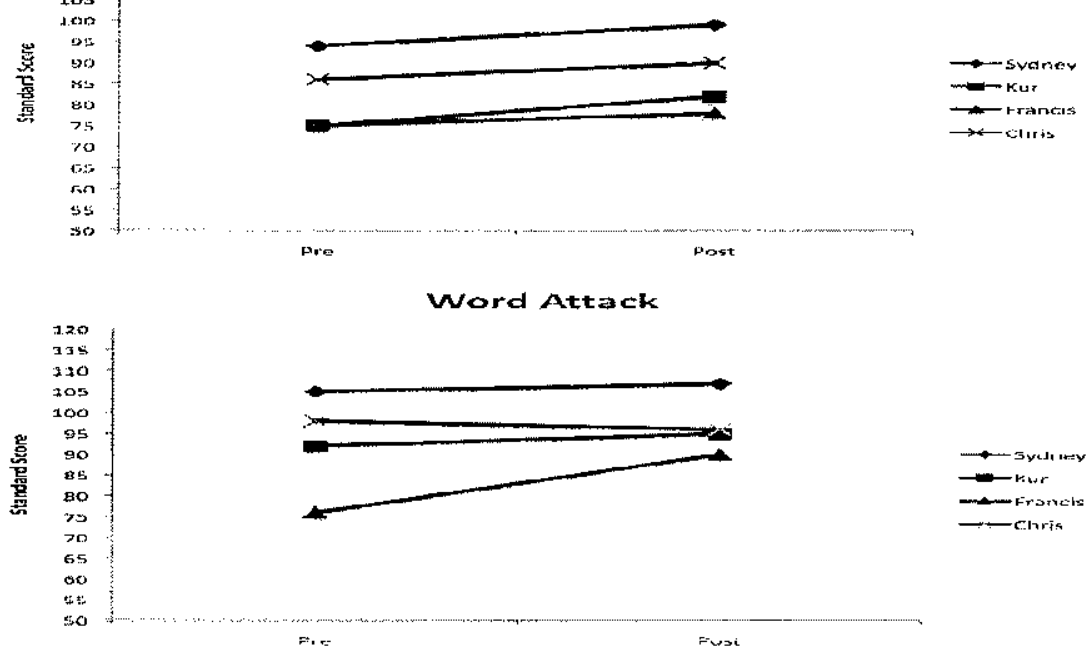

Picture Vocab

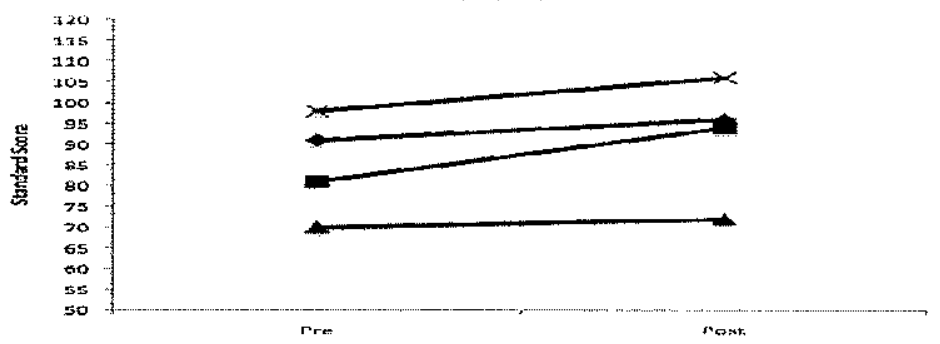

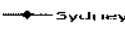
- mowr merarich

- - syuncy mour Ltranei nom

Figure 9. Results from individual Woodcock Johnson III reading subtests. 
Vocabulary and Passage Comprehension. Three of the four students made gains in standard score for Reading Fluency and Word Attack. Finally, two of the four students made gains in SS on the Letter Word Identification subtest (see Figure 9). Specifically, Sydney, and Kur made gains in SS for the Letter Word ID.

Both Francis and Chris decreased $3 \mathrm{SS}$ points from pre to posttest. The mean gain in SS for the Reading Fluency Subtest was 5.75 (range 0-13). The mean gain in SS for the Passage Comprehension subtest was 4.75 (range 3-7) and the mean gain for Word attack was 4.25 (range -2 to +14 ). Lastly, the mean gain in Picture Vocabulary was 7 (range 2-13).

Table 10 presents a comparison of expected gain scores contrasted against actual gain scores from the DIBELS pre and posttests. Again, all four students showed more than the expected gain of 1.15 words per week.

Table 10

Comparison of Expected ORF Gains Compared to Actual Gain Scores for Students in Kearns

\begin{tabular}{lcccc}
\hline Student & $\begin{array}{c}\text { Weeks in } \\
\text { treatment }\end{array}$ & Expected & Actual & Difference \\
& 6 & 6.9 & 22 & +15.1 \\
\hline Kur & 6 & 6.9 & 24 & +17.1 \\
Francis & 4 & 4.6 & 36 & +31.4 \\
Chris & 2 & 2.3 & 8 & +5.7 \\
Sydney & 2 & & & \\
\hline
\end{tabular}


Social Validity Questionnaire

Table 11 provides results on parent, teacher, student, and tutor perceptions of the goals, procedures, and outcomes of online instruction. Two teachers, four tutors, four students, and two parents responded to the questions.

Overall all parent, student, teacher, and tutor participants reported the goals, procedures and outcomes of online tutoring were beneficial. Similar to Study 1, both students and teachers reported favorable close working relationships with their tutors and also reported an increase in reading skill from the intervention. In fact, at the end of the study one student wrote a letter to his tutor thanking her for being a good mentor and teaching him how to read better.

Similar to Study 1, all teachers, parents and tutors reported favorable responses to the goals procedures, and outcomes of synchronous online tutoring. Unlike Study 1, one teacher and three students report occasional problems hearing each other. Most importantly $100 \%$ of all teachers, parents, students, and tutors reported improved reading skills. However, one teacher reported that she did not see the reading skills generalize into the classroom. Nevertheless, $100 \%$ of the parents and remaining teacher did report a noticeable and generalized gain in reading skill. Further, all teachers, students, parents, and tutors reported that they would recommend online tutoring for other students.

Teacher and student participants were asked additional questions regarding what they liked and disliked about online tutoring. Teachers in Kearns were asked what changes they would make to improve online tutoring. Both teachers reported that they would like a longer intervention as this study only lasted nine weeks. Additionally, they reported a preference for a more efficient login process to the Adobe Connect system. All 
Table 11

Social Validity Outcomes for Participants in Kearns

\begin{tabular}{lllll}
\hline Measure & Parent & Teacher & Tutor & Student \\
\hline Goals & & Percent who responded "yes" \\
Is online tutoring a good way to & $100 \%$ & $100 \%$ & $100 \%$ & $100 \%$ \\
$\begin{array}{l}\text { deliver supplemental reading } \\
\text { instruction? }\end{array}$ & & & & \\
Was progress shown and explained? & $100 \%$ & $100 \%$ & $100 \%$ & $100 \%$ \\
$\begin{array}{l}\text { Did your student enjoy reading over } \\
\text { the system }\end{array}$ & $100 \%$ & $100 \%$ & $100 \%$ & $100 \%$ \\
$\begin{array}{l}\text { Did the student build a trusting } \\
\text { relationship with tutor? }\end{array}$ & $100 \%$ & $100 \%$ & $100 \%$ & $100 \%$ \\
\hline $\begin{array}{l}\text { Procedures } \\
\text { Was it easy to setup online tutoring? }\end{array}$ & N/A & 2.5 & 1 & N/A \\
$\begin{array}{l}\text { Was it easy to hear tutors over the } \\
\text { system? }\end{array}$ & N/A & 2.5 & 2.25 & 2 \\
$\begin{array}{l}\text { Was it easy to read the student } \\
\text { Materials online? }\end{array}$ & N/A & & & \\
\hline
\end{tabular}

Outcomes

Did you see improvements in student reading skills?

Were the changes noticeable in the classroom or home?

Would you recommend online tutoring to others?

Would you pay for online tutoring?
Percent who responded "yes"

$100 \% \quad 100 \% \quad 100 \% \quad 100 \%$

$100 \% \quad 50 \% \quad 100 \% \quad 100 \%$

$100 \% \quad 100 \% \quad 100 \% \quad 100 \%$

$100 \% \quad 0 \% \quad$ N/A $\quad$ N/A 
four students reported that they liked the stories and learning how to read better. When asked what they would change to make online tutoring better, three of the four students recommended that the video pod be larger, make the sound a little bit louder, and spend more time reading stories. Lastly, students were asked to respond to what they liked and disliked about online tutoring. All of the students responded that they enjoyed the stories and working on the computer. Two of the four students reported that the word attack part of the lesson was very difficult and the remaining two students reported that they would change nothing.

Discussion

The results of this systematic replication support the outcomes from the primary study. When given online tutoring, all students in Kearns made gains in oral reading fluency. Although this study was brief and Sydney received only two weeks of intervention, all students made clear increases in slope and trend from baseline to intervention. Similar to study 1, three methods of PND analysis indicate a successful intervention across all students. Overall, participants increased an average of 17.35 WCPM (range 5.7-31.4) more than would be expected based on the Hasbrouck and Tindall's (2006) norms.

All four students made standard score (SS) gains in the Broad Reading Cluster scores of the WJ-III and three of the four students made gains in the Basic Reading Cluster. Given the high degree of alignment between the intervention and the LetterWord ID and Reading Fluency subtests, we would expect the largest effects on these subtests. Two of the four students (Kur and Sydney) did make marked gains in Letter Word ID; however, the other two students (Chris and Francis) showed decreases in SS. 
On the Reading Fluency subtest, Kur, Sydney, and Chris made marked gains in SS; however, Francis had a slight decrease in SS. Word Attack and Passage Comprehension subtests have moderate overlap with Corrective Reading. For Word Attack, Kur, Francis, and Sydney made gains in SS; however, Chris had a slight decrease. Interestingly all four students had gains in SS for Passage Comprehension. Finally, the Picture Vocabulary subtest does not overlap at all with our intervention. Surprisingly, all four students made gains on this subtest. One possible explanation for the increase in standard score for this subtest may be that all students continued to receive daily instruction from their general education class. This intervention was focused as a supplemental reading intervention. The changes we see in SS for the Picture Vocabulary may be attributed to instruction delivered in the classroom since tutors using the Corrective Reading program did not provide instruction on picture vocabulary. 


\section{CHAPTER V}

\section{DISCUSSION}

This study investigated the effects of online supplemental reading instruction on students at risk of reading failure in Philadelphia, PA and Kearns, UT. Despite occasional technical difficulties (e.g., dropped audio packets and intermittent network problems) students made marked gains in oral reading fluency when given supplemental online tutoring. Overall, students in both locations made gains in basic and broad reading skills as assessed by the WJ-III.

\section{Technical Demands and Challenges}

Several technical demands were identified in early system development and more were encountered during the field test. During the study we received feedback from teachers, students, and tutors regarding the online system as a whole. First, teachers at both locations reported that the overall setup was easy to use. Teacher responsibilities included setting up the tutoring session at the school site and asking participating students to $\log$ in. Teachers at Western Hills Elementary in Utah had more difficulty logging into the Adobe Connect system than teachers at Stanton Elementary in Philadelphia. The computers in Kearns, UT were set up utilizing Novell-networking systems. As part of the logoff process for Novell, each computer was returned to a default state; that is, any changes in web browser and operating system settings were deleted. This system is very secure and normally enables students to work online with little interference. However, when we attempted to update programs such as Internet Explorer and install drivers required to efficiently run the Adobe Connect system, those settings were erased 
whenever the user logged off. We attempted to work with the network administrators to allow us to save our settings; however, we were not successful and were not allowed to compromise their security by updating and installing these programs. To continue this study, a task analysis was conducted to identify all the steps needed to quickly install and update the drivers prior to each tutoring session. Teachers were then taught how to update the computer's programs and login each day before students arrived for tutoring. The demand on the teachers was moderate; however, teachers did note that they would prefer the system to be more user friendly. At M Stanton. Hall elementary in Philadelphiawhere these login problems were not present - teachers reported that the system was very user friendly. Variation in network security and rules associated with individual schools may be an obstacle to online instruction using systems such as Adobe Connect.

Another important adaptation needed to successfully employ online instruction was the use of binaural headsets. Students were in computer labs with frequent audio distractions (e.g., students in the hallway, teachers delivering instruction, etc.). Noisecanceling binaural headsets allowed students to hear tutors more efficiently and noisecanceling microphones eliminated unwanted background noise. The feedback we received from tutors, teachers, and students was that the headsets made a significant improvement in audio quality when compared to the pilot study.

In addition to audio, we used Adobe Connect to provide live 2-way video. All computers were outfitted with Logitech web cameras. The feedback we received from teachers and students indicated that they liked the live video feature; however, they wished the video window was slightly bigger on the screen. We deliberately kept the video window small in order to provide more room on the screen for the curriculum and 
assessments (see Figure 1 for screen shot of Adobe Connect environment). Additionally, video was considered an important instructional component. For example, video allowed tutors to monitor student behaviors and environmental events that could influence instruction. Instruction was delivered in a classroom setting so other students sometimes tried to get participants off task. When this was seen by the tutor we asked the teacher to remove the problem student.

Finally, feedback on student materials indicated that occasionally, students and tutors had difficulty reading the text. We used high quality scans of all curriculum and assessments; however, the conversion of files from one format to another may have decreased the resolution of some of the scans. To address the resolution issue in the future we may have to retype each lesson or assessment and convert the typed document into a flash file. Working with a true text document (rather than a scanned image) would increase resolution.

Controlling student behavior at a distance was another challenge we had to address. We utilized a you-me game. At the beginning of each lesson, tutors would give directions on being ready for instruction (e.g., sit up straight, hands in lap, eyes on screen, etc.) and specific behavior expectations (respond when you hear the snap, park your mouse, etc). Students received points for following instructions and for correct responses on difficult items. The teacher received points when students violated the rules. Students tended to follow instructions well given the you-me game coupled with quick academic pacing. For some students, however, these two systems were not sufficient to maintain high rates of academic responding. To increase motivation, we implemented a token reinforcement system in which students earned reading certificates to take home and 
show parents their progress. Reading certificates were awarded to students who beat their ORF scores from previous lessons. If a student beat his or her score three times in a row, we sent an electronic copy of the certificate to the teacher and requested that the student receive the certificate for a parent's signature and approval. Importantly, reading certificates were not associated with DIBELS progress monitoring or benchmark assessments. The certificates were solely part of the daily reading instruction and fluency practice. Students, parents, and teachers agreed that the certificates were a good idea and students appeared to be excited to take home good news.

\section{Treatment Fidelity}

An important question in these two studies was whether or not supervised tutors could effectively provide supplemental reading instruction to students at risk of reading failure at a distance. The data indicate that, although occasional technical problems occurred, the instruction was implemented at a high level. None of the tutors needed to be retrained in data collection during the course of the two studies. However, tutors did get frequent feedback on the pace of instruction, the percent correct error correction procedure, and rate of reinforcement (both general and specific). Feedback was given to ensure high levels of treatment integrity and to maintain tutor skills. Once trained, all four tutors performed well. For example, all tutors across both studies average rate of stimulus presentation was $9.23 / \mathrm{min}$, averaged $94.98 \%$ correct delivery of error correction, and averaged 5.84 reinforcing statements per min. In fact, tutors in both studies matched or beat the pace of instruction, percent correct delivery of error correction, and rate of reinforcement when compared to Lignugaris-Kraft and Marchand-Martella (1993) target 
teaching behaviors and criteria. These data support our conclusion that tutors can effectively deliver reading instruction to students at risk of reading failure using the Adobe Connect software and the Corrective Reading program.

\section{Fidelity of Assessment}

Tutors were also responsible for collecting data from three assessments with high fidelity. Once trained, all four tutors delivered the DIBELS, and Woodcock Johnson III assessments correctly and fluently. Tutors delivered each assessment according to directions at a high level. For both studies DIBELS benchmarks tutors averaged 100\% correct delivery, WJ-III reading subtests delivery averaged $96.97 \%$ correct, and DIBELS progress monitoring averaged $95.06 \%$ correct. Interestingly, all four tutors reported that it was easier to deliver the WJ-III online than it was face-to-face. Specifically, tutors reported that the online assessment was easier to deliver because finding the correct starting and ending place was more efficient and they could easily magnify a specific stimulus or sentence.

\section{Social Validity}

We investigated social validity of the methods and outcomes of this study as perceived by teachers, parents, and students. All four teachers in both locations reported that online tutoring was effective at increasing the reading skills for their students. Further, three of the four teachers reported noticeable increases in reading skill from participating students in their classroom. One teacher noted that she did not see her 
students reading skills transfer to the classroom. All teachers agreed, however, that this was an efficient way to deliver 1:1 instruction to students needing remedial instruction.

Parents said they appreciated the change in their students' reading skills. For instance, one parent reported that they had never received good news about their child's reading progress. When asked if teachers and parents would pay for online tutoring if it was not free, $100 \%$ stated that they would likely pay for the service.

Another aspect of determining the social validity of these studies is the impact on the students. Every student reported that his or her reading skill had improved after they had access to online tutoring. Generally, students stated that they liked the stories they read and tutors were good teachers.

\section{Relationship to Prior Research}

The positive effects of the Corrective Reading Program reported in this research are consistent with the findings reported by Przychodzin-Havis et al. (2005), Benner, Kinder, Beaudoin, Stein, \& Hirschmann (2005), and Gunn et al. (2000). In fact, Przychodzin-Havies and colleagues' review of literature on the Corrective Reading curriculum revealed 28 published studies examining the effectiveness of Corrective Reading delivered by teachers in general education, special education, and alterative education settings. Our findings correlate well with these articles showing marked gains in oral reading fluency and other reading skills using the Corrective Reading program. Further, Hasbrouck and Tindall (2006) oral reading fluency norms were established with general education students. We would expect students in our study to gain less than the 
normative group. Interestingly, our students gained more words correct per minute than the norm group.

These results also correspond with Clark's (1983) argument that media are neutral and are simply means to deliver the instruction. Although not perfect, the system used in this study allowed instructional delivery to students at a distance given an internet connected computer, webcam and headset. The most important aspect of these data are the favorable student outcomes given a research-based curriculum combined with increased access to supplemental instruction using the Adobe Connect system. Gutknecht and Gutknecht (2001) reported a plan to implement instruction very similar to this study -their goal was to provide one-on-one reading instruction to fourth-grade students over an internet-based interactive video conferencing program. Unfortunately, the authors never completed the study due to technical difficulties suggesting further improvement in technology prior to implementing this type of system.

\section{Limitations}

Despite the strong findings from both of these studies, there are several limitations that warrant attention. First, most students in both studies showed gradual changes in performance after implementation of the independent variable. Single case designs including the multiple baseline design demonstrate experimental control most clearly when target behaviors show a dramatic increase or decrease immediately after implementation of the independent variable. For the multiple baseline design the intervention is first applied to leg 1 , and the results in leg 1 are compared to the other legs in the design. An increase or decrease in the target behavior in leg 1 and little or no 
change in the remaining legs (still in baseline phase) suggests experimental control. The remaining legs in the design are then exposed to treatment one at a time and in each case an immediate and dramatic change most clearly demonstrates experimental control. However, we would not expect oral reading fluency to increase dramatically given its complexity. Oral reading is a complex skill encompassing numerous component skills. Over time, students gain skill through sustained instruction, practice and reinforcement. The gradual change expected of oral reading fluency makes visual inspection of the data more difficult. Thus, one limitation of this study is that the apparent effects of the treatment are somewhat subtle and gradual, and therefore experimental control is not as dramatic as one might like.

Second, two students in study 1 (Kendall and Dimere), showed slightly increasing trends in baseline making analysis difficult. The slightly increasing trend in baseline indicates that these students were gaining skills before the intervention was implemented. This is not terribly surprising given that they were receiving daily in-class reading instruction throughout all phases of the study. Nevertheless, close inspection of the data indicate that once online tutoring was implemented, each student's oral reading fluency slope increased above baseline levels.

Finally, the last leg in study 1 (Munirah) showed the largest gains in oral reading fluency in spite of the fact that she received the least amount of treatment. Munirah's gains in ORF were also larger than any student in study 2. It is unclear why she made such large gains compared to other students. When identifying students to participate in this study, we used the DI placement tests as well as DIBELS and WJ-III pretests. Overall, all students had similar skills according to the outcomes of these assessments; 
however, it is impossible to identify all prerequisite skills using these assessments. Compared to the other students, Munirah may have had stronger prerequisite skills that made her more sensitive to the effects of the intervention.

\section{Implications}

The findings of this study offer several potential benefits to students, schools, parents and teachers. First, using this type of instruction students gain access to $1: 1$ tutoring. Normally, students rarely get access to this type of intensive instruction in a general education setting due to costs and availability of trained tutors. Second, reading skills can be assessed effectively using this online system. The ability to deliver assessments and instruction on the same system increases the efficiency and usefulness of this system. Finally, students developed meaningful relationships with preservice teachers from Utah State University. In fact, these relationships were so meaningful that two students took the time to write thank you letters to their tutors at the conclusion of the study without teacher or parent prompting.

Schools can also gain benefits participating in online tutoring. First, this kind of system offers schools in urban and rural locations access to supplemental reading instruction for students at risk of reading failure. With university collaboration these tutoring services can be provided at reasonable cost. NCLB mandates schools to pay for supplemental instruction given a failure to meet AYP. This program may be one effective way to provide these services at reasonable cost. Third, schools can ensure that trained and supervised tutors will deliver supplemental instruction. Researchers report a lack of data available on the qualifications and treatment integrity of other supplemental 
instruction providers (Anderson \& Laguarda, 2005). Our program utilized preservice teachers who were supervised and who received daily feedback on their performance. Fourth, this program used the Corrective Reading program, which has a large research base. Schools can report to parents that the curriculum is effective citing numerous research articles and reviews (e.g., Przychodzin-Havis et al., 2005). Finally, although there may be additional costs for technology (depending on technology currently available in schools), these costs are spread across many students, and compared to the cost of local training and supervision of tutors, they are minimal. In addition, the hardware required to use this system is increasingly available in schools and may also be used for many other educational purposes. For example, in both Philadelphia and Kearns the schools already had computer labs equipped with either PC or Macintosh computers that were connected to the Internet. The only equipment needed to deliver supplemental online tutoring over Adobe Connect was webcameras, electronic writing boards, and binaural headsets. With these technologies in place, teachers, students, and other school personnel can use the computers for grading, writing papers or assignments, and accessing information on the World Wide Web.

The implications for parents are also important. First, tutoring services can be conveniently accessed from home with adequate technology. For example, busy parents can establish the connection with the online tutoring, make dinner while their child is receiving live $1: 1$ tutoring, then return after a designated time to close the session. Second, there is a reduction in transportation costs and time demands. With traditional tutoring parents may have to take their students to a tutoring clinic from school adding to the daily commute. Additionally, parents may have to wait or return to the clinic to pick 
up their children to take them home adding a large time commitment for parents as well as their students. Third, online tutoring may reduce scheduling conflicts - tutoring services can be scheduled to meet the needs of the clients. The only limitation is time constraints of the tutors. With a large number of tutors, services could be delivered at any reasonable hour. Finally, parents may have increased involvement in their students' reading instruction. Having parents both $\log$ on and log off their child's session allows tutors to give parents frequent and detailed feedback on their student's progress in the program. This may be one way to increase the participation of parents with their children's' reading skills.

Lastly, the implications for tutors are also great. First, tutors get access to frequent and meaningful feedback from their supervisors on the delivery of instruction and assessments. Frequent feedback allows tutors to make subtle changes in their instruction so that they may be more efficient and effective. Finally, our tutors were preservice undergraduate students who gained valuable experience teaching real kids in a real world situation. In many undergraduate programs, preservice teachers do not get this type of experience until they enter student teaching in their last year of their program.

\section{Generalizability}

The ways in which results of a research study might be generalized to somewhat different independent variables, populations, and content is always a difficult issue. Table 12 describes the degree of generalization that appears to be reasonable across each of six variables: technology, population, grade level, behavior issues, culture and linguistic diversity, and content. 
Table 12

Possible Generalization of Research Findings

\begin{tabular}{|c|c|c|c|}
\hline Variable & High & Medium & Low \\
\hline Technology & $\begin{array}{l}\text { Other Web } \\
\text { Browsers }\end{array}$ & $\begin{array}{l}\text { Older computers } \\
\text { Slower Internet Connections } \\
\text { New technology (e.g., PDA, } \\
\text { Cell Phone, etc.) }\end{array}$ & $\begin{array}{l}\text { Eliminating } \\
\text { technology such } \\
\text { as webcam }\end{array}$ \\
\hline Population & $\begin{array}{l}\text { G\&T, Gen Ed, } \\
\text { Similar } 4^{\text {th }} \text { grade } \\
\text { students }\end{array}$ & $\begin{array}{l}\text { Lower functioning readers } \\
\text { (e.g., LD) }\end{array}$ & $\begin{array}{l}\text { Severe } \\
\text { Disabilities } \\
\text { Multiple } \\
\text { disabilities }\end{array}$ \\
\hline Grade & $4-12$ & $3^{\text {rd }}$ & $\mathrm{K}-2^{\mathrm{nd}}$ \\
\hline CLD & $\begin{array}{l}\text { Similar Language } \\
\text { skills as our } \\
\text { participants }\end{array}$ & Instruction in native language & $\begin{array}{l}\text { ESL, Second } \\
\text { Language } \\
\text { Acquisition }\end{array}$ \\
\hline Content & $\begin{array}{l}\text { Other reading } \\
\text { programs }\end{array}$ & $\begin{array}{l}\text { Different subjects (math, } \\
\text { Writing, etc.) }\end{array}$ & \\
\hline
\end{tabular}

For each of these variables, the table delineates variations that would allow for low, medium, and high levels of generalization. For example, a high level of generalization might be inferred from Internet Explorer or Safari to other web browsers. In contrast, a lower local of generalization is suggested to older computers or lower speed Internet access because they will not efficiently run the Adobe Connect system.

New technology such as Internet connected PDA's or cell phones may efficiently run the system. However, it is uncertain whether these new smaller technologies will allow the student to see the content as well as a full-size computer screen. Lastly, 
eliminating functional technology such as webcams would reduce the need for high Internet bandwidth; however, it is unclear whether this kind of change would hinder the overall delivery of online tutoring.

Given similar or higher functioning students, results from this system would be expected to generalize quite well. It is unclear if this system would be as effective to meet the needs of lower functioning readers who have more intense academic and behavioral needs. Individuals with severe and multiple disabilities are likely to have difficulty using this system without additional technology adaptations and support. Similarly, students in grades 4-12 have a high likelihood of gaining similar outcomes as the present study. Younger students may have more difficulty with attention span or behavior that may require more support from on-site teachers. There is no reason to expect different responses from students of various ethnic backgrounds. Students in this study were all from low socioeconomic and cultural or linguistically diverse populations (i.e., all received either free or reduced lunch and were either African American $n=5$, Hispanic $n=2$, or Caucasian $n=1$ ). Direct Instruction has a long history of working well for students from different cultural and linguistic backgrounds (Meyer, 1984; Watkins \& Slocum, 2004).

Instruction in language acquisition (whether first or second language) may be problematic. Dropped audio packets were a continuous problem that limited audio quality over both VOIP and Adobe Connect. This could have a profound effect on language instruction. Finally, this delivery system may generalize to research based reading programs other than Corrective Reading. Instructional formats are broadly similar across programs and Direct Instruction tends to require more technical precision 
than other programs. Similarly, it is likely there would be a high degree of generalizability to different content areas. Reading instruction is relatively demanding with frequent oral responses that must be heard clearly by the teacher (e.g., to detect errors that differ from the correct response by only one phoneme). In mathematics instruction, for example, audio quality might not be quite as critical.

\section{Conclusion}

The evidence is clear that there are significant numbers of students who are not making adequate yearly progress in reading. It is also clear that effective supplemental programs need to be made more accessible to students at risk of reading failure. In this study we effectively delivered instruction using the Adobe Connect system and produced positive student outcomes. Although the results are promising, the research base in this area is so sparse that much more research is needed before conclusive evidence can be cited as to which reading intervention, or combination of interventions, may be most effective in improving the reading skills of students at risk of reading failure when delivered from a synchronous online technology.

As a result of this study the need for research in several related areas become apparent. First, how well does this kind of system mediate other reading programs, and instruction in other content areas such as math and writing? Similar reading programs may be as effective as Corrective Reading in producing increases in words read correct per min, however this is an empirical question. Second, to what extent will supplemental online reading instruction increase the words read correct for students at risk of reading failure given a larger sample. Clearly, the present study provides evidence that increases 
in reading fluency are possible given online supplemental instruction for two studies with a sample of four students each. Importantly, this study adds to the research on access to high quality tier two or three services for students in rural and urban areas. Given these results, what is needed to scale-up this technology to serve larger numbers of students? Possible issues with scaling-up this study include increased technology costs (i.e., more computers, and peripheral technology), finding and training more tutors, building relations with more than two schools or parents, and scheduling tutoring sessions to meet the needs of both students and undergraduate tutors. Finally, researchers and teachers have an obligation to use effective practices for ethnic minority students given NCLB mandates. To address these mandates, future research should seek student participants from minority backgrounds and disaggregate their results by subgroup to identify the extent to which synchronous supplemental reading instruction is effective for various types of learners.

\section{Summary}

This study suggests a promising means of delivering supplemental reading instruction to increase oral reading fluency and basic reading skills for students at risk of reading failure. First, all students in both studies made gains in oral reading fluency when placed into the synchronous online tutoring program. Second, all participants made standard score gains on basic reading skills as assessed by the Woodcock Johnson Test of Achievement and DIBELS benchmark assessments. Participating students and tutors reported an awareness of increased reading skills and value of synchronous online instruction. Further, teachers and parents generally reported that students demonstrated 
increased reading skills after receiving instruction. In all, teaching students over this system may greatly promote their overall reading skills allowing students to participate in more complex reading tasks. Finally, these results provide a foundation for future component analysis and other more differentiated research questions. 


\section{REFERENCES}

Adams, G. L., \& Engelmann, S. (1996). Research on Direct Instruction: 25 years beyond DISTAR. Seattle, WA: Educational Achievement Systems.

Adobe Acrobat (2005) Breeze Guide [computer software and manual]. Retrieved March 23, 2008 from http://www.adobe.com/education/resources.htm

Adobe Acrobat (2008) Adobe Acrobat Connect Pro Guide [computer software and manual]. Retrieved March 23, 2008 from http:/www.adobe.com/education/ resources/hed/instructional/connect/collaborative_teaching/pdfs/overview _ connect.pdf

Allen, M., Bourhis, J., Burrell, N., \& Mabry, E. (2002). Comparing student satisfaction with distance education to traditional classrooms in higher education: A meta analysis. American Journal of Distance Education, 16(2), 83-97.

Altman, D. (1996). Evidence-based medicine: Use of confidence intervals to indicate uncertainty in research findings. Retrieved March 1, 2008, from the World Wide Web: http:/www.acponline.org/journals/ebm/mayjun96/ebconfid.htm American Federation of Teachers (AFT). (1999). Building one the best, learning from what works: Five promising remedial reading intervention programs. Washington, DC: Author.

Anderson, L. M., \& Laguarda, K. G. (2005). Case studies of supplemental services under the No Child Left Behind Act: Findings from 2003-2004. Washington, DC: U.S. Department of Education.

Armbruster, B. B., Lehr, F., \& Osborn, J. (2003). Put reading first: The research building blocks of reading instruction. Jessup, MD: National Institute for Literacy. 
Benner, G. J., Kinder, D., Beaudoin, K. M., Stein, M., \& Hirschmann, K. (2005). The effects of the Corrective Reading Decoding program on the basic reading skills and social adjustments of students with high incidence disabilities. Journal of Direct Instruction, 5(1), 67-80.

Bernard, R. M., Abrami, P. C., Lou, Y., Borokhovski, E., Wade, A., Wozney, L., et al. (2004). How does distance education compare with classroom instruction? A meta-analysis of the empirical literature. Review of Educational Research, 74, $379-439$.

Beth-Marom, R., Saporta, K., \& Caspi, A. (2005). Synchronous vs. asynchronous tutorials: Factors affecting students' preferences and choices. Journal of Research on Technology in Education, 37(3), 245-262.

Blackman, B. (1996). Preventing early reading failure. In S.C. Cramer \& W. Ellis (Eds.), Learning disability: Lifelong issues (pp.113-118). Baltimore: Paul C. Brookes.

Blackman, B. (1997). Early intervention and phonological awareness: A cautionary tale. In Blackman (Ed.), Foundations of reading acquisition and dyslexia: Implications for early intervention (pp. 347-379). Mahwah, NJ: Lawrence Erlbaum.

Branzburg, J. (2004). A tour of online tutors. Retrieved September 1, 2006, from http://www.teachlearning.com/story/march2004

Campbell, J. R., Hombo, C. M., \& Mazzeo, J. (2000). NAEP 1999 trends in academic progress: Three decades of student performance. Washington, DC: U.S. Department of Education.

Campbell, M. L. (1988). Corrective Reading program evaluated with secondary students in San Diego. ADINews, 7(4), 15-17. 
Catts, H. W., Fey, M. E., Tomblin, J. B., \& Zhang, Z. (2002). A longitudinal investigation of reading outcomes in children with language impairments. Journal of Speech, Language, and Hearing Research, 45, 1142-1157

Cavanaugh, C. S. (2001). The effectiveness of interactive distance education technologies in K-12 learning: a meta-analysis. International Journal of Educational Telecommunications, $7(1), 73-88$

Cavanaugh, C., Gillan, K. J., Kromrey, J., Hess, M., \& Blomeyer, R. (2004). The effects of distance education on $K-12$ student outcomes: A meta analysis. Naperville, IL: Learning Point Associates.

Clark, C., \& Gorski, P. (2002). Multicultural education and the digital divide: Focus on socioeconomic class background. Multicultural Perspectives, 4(3), 25-36.

Clark, R. E. (1983). Reconsidering research on learning from media. Review of Educational Research, 53(3), 445-459.

Clark, R. E. (1994). Media will never influence learning. Educational Technology Research and Development, 43(2), 21-29.

Cole, J. M., \& Hilliard, V. R. (2006). The effects of web-based reading curriculum on children's reading performance motivation. Journal of Education Computing Research, 34(4), 353-380.

Conger, S. B. (2005). If there is no significant difference, why should we care? The Journal of Educators Online, 2(2), 1-4.

Cooper, H. L., \& Nichols, S. K. (2007). Technology and early Braille literacy: Using the Mountbatten Pro Brailler in primary-grade classrooms. Journal of Visual Impairments \& Blindness, 101, 22-31. 
Creswell, J. (2002). Educational research: Planning, conducting, and evaluating quantitative and qualitative research. Upper Saddle River, NJ: Pearson Education.

Daly, E. J., Martens, B. K., Dool, E. J., \& Hintze, J. M. (1998). Using brief functional analysis to select interventions for oral reading. Journal of Behavioral Education, $8,203-218$

Diaz, D., \& Cartnal, R. (1999). Students' learning styles in two classes: Online distance learning and equivalent on-campus. College Teaching, 45(4), 21-35.

Dowhower, S. L. (1994). Repeated readings revisited: Research into practice. Reading \& Writing Quarterly, 10(4), 343-358.

Ehrmann, S. C. (1995). Asking the right questions. Change, 27(2), 20-28.

Elementary and Secondary Education Act (ESEA) of 1965, Public Law 89.10.

Elliott, D. (1998) National Youth Survey: Wave III, 1978. First ICPSR Version: Boulder, CO: Behavioral Research Institute, University of Colorado, [producer]. Ann Arbor, MI: Interuniversity Consortium for Political and Social Research, 1994 [distributor].

Engelman, S., Carnine, L., \& Johnson, G. (1999). Corrective reading decoding level A: Word attack basics. Columbus, OH: Science Research Associates (SRA).

Engelmann, S., Meyer, L., Carnine, L., Becker, W., Eisele, J., \& Johnson, G. (1999). Corrective reading decoding level $B$ : Decoding strategies. Columbus, $\mathrm{OH}$ : Science Research Associates (SRA). 
Engelmann, S., Meyer, L., Johnson, G., \& Carnine, L. (1999). Corrective reading decoding level C: Skill applications. Columbus, $\mathrm{OH}$ : Science Research Associates (SRA).

Englert, C. S., Zhao, Y., Collings, N., \& Romig, N. (2005). Leaming to read words: The effects of internet based software on the improvement of reading performance. Remedial and Special Education, 26(6), 357-371.

Faith, M. S., Allison, D. B., \& Gorman, B. S., (1997). Meta-analysis of single-case research. In D.R. Franklin, D. B., Allison, \& B. S. Gorman (Eds.), Design and analysis of single-case research (pp. 245-277). Mahwah, NJ: Lawrence Erlbaum.

Felton, R. H. (1993). Effects of instruction on the decoding skills of children with phonological-processing problems. Journal of Learning Disabilities, 26, 583-89.

Fletcher, J. M., \& Lyon, G. R. (1998). Reading: A research-based approach. In W.M. Evers (Ed.), What's wrong in America's classrooms (pp. 49-90). Stanford, CA: Hoover Institution Press.

Forbush, D. E., Stenhoff, D. M., Vasquez, E., Furzland, M. Alexander, M., \& Stein, J. (2007). Evaluation of an online tool to facilitate distant assessment of pre-service special education teachers' delivery of the Woodcock-Johnson Test of academic achievement. Teacher Education and Special Education, 30(3), 142-154.

Franklin, R. D., Allison, D. B., \& Gorman, B. S. (1997). Design and analysis of single case research. Hillsdale, NJ: Lawrence Erlbaum.

Fuchs, D., Mock, D., Morgan, P. L., \& Young, C. L. (2003). Responsiveness-tointervention: Definitions, evidence, and implications for the learning disabilities construct. Learning Disabilities Research \& Practice, 18(3), 157-171. 
Gall, J. P., Gall, M. D., \& Borg, W. R. (1999). Applying educational research (4 ${ }^{\text {th }} \mathrm{ed}$.). New York: Addison Wesley Longman.

Good, R. H., \& Kaminski, R. A. (Eds.). (2002). Dynamic indicators of basic early literacy skills $\left(6^{\text {th }}\right.$ ed.). Eugene, OR: Institute for the Development of Educational Achievement. Available: http://dibels.uoregon.edu/

Gorman, B. S., \& Allison, D. B. (1996). Statistical alternatives for single case designs. In R. D. Franklin, D. B. Allison, \& B.S. Gorman (Eds.), Design and analysis of single case research (pp. 159-214). Mahwah, NJ: Lawrence Erlbaum.

Greenberg, G. (1998). Distance education technologies: Best practices for K-12 settings. IEEE Technology and Society Magazine, (Winter), 36-40.

Gregory, R. P., Hackney, C., \& Gregory, N. M. (1982) Corrective reading programmed: An evaluation. British Journal of Educational Psychology, 52(1), 33-50.

Gunn, B., Biglan, A., Smolkowski, K., \& Ary, D. (2000). The efficacy of supplemental instruction in decoding skills for Hispanic and non-Hispanic students in early elementary school. The Journal of Special Education, 34(2), 90-103.

Gunn, B., Smolkowski, K., Biglan, A., \& Black, C. (2002). Supplemental instruction in decoding skills for Hispanic and non-Hispanic students in early elementary school: A follow up. The Journal of Special Education, 36(2), 69-79.

Gutknecht, B. A., \& Gutknecht, C. D. (2001). Connecting at risk children \& teacher prep students virtually: Applications of synchronous distance education technologies. Reading Improvement, 38(3), 99-105. 
Haisley, F. B., Tell, C. A., \& Andrews, J. A. (1981). Peers as tutors in the mainstream: Trained "teachers" of handicapped adolescents. Journal of Learning Disabilities, $14,224-226$.

Hanusheck, E. A. (1994). Making school work. Washington, DC: Brookings.

Hasbrouck, J., \& Tindall, G. A. (2006), Oral reading fluency norms: A valuable assessment tool for reading teachers. The Reading Teacher, 59(7), 636-644.

Holdsworth, P. (1984-85). Corrective Reading tested in U.K. ADI News, 4(2), 1, 4-5.

Homan, S. P., Klesius, J. P., \& Hite, C. (1993). Effects of repeated readings and nonrepetitive strategies on students' fluency and comprehension. Journal of Educational Research, 87(2), 94-99.

Individuals with Disabilities Education Improvement Act, 20 U.S.C. $§ 1400-1487$ (1997, 2004).

Kamps, D. M., Greenwood, C., Arreaga-Mayer, C., Veerkamp, M. P., Utley, C., Tapia, Y., et al. (2008). The efficacy of classwide peer tutoring in middle schools. Education and Treatment of Children, 31(2), 119-152.

Kasendorf, S. J., \& McQuaid, P. (1987). Corrective Reading evaluation study. ADI News, $7(1), 9$.

Kaufman, A. S., \& Kaufman, N. L. (1985). Kaufman Test of Educational Achievement. Circle Pines, MN: American Guidance Service.

Kazdin, A. E. (1982). Single-case research designs: Methods for clinical and applied settings. New York: Oxford University Press. 
Keegan, D. (1996). Distance education technology for the new millennium: compressed video teaching. ZIFF Papiere. Hagen, Germany: Institute for Research into Distance Education. (Eric Document Reproduction Service No. ED 389 931)

Kinash, S. (2002). Empirical research on implementation of person centered planning and supports. Presentation at International conference. Blazing the trail: Inclusion, Opportunity \& Equity. TASH. Reno, NV

Kinash, S. (2003). Computer Literacy and Online Learning of Blind Adults. Presentation at the International Conference. Getting in Touch with Literacy. University of British Columbia, Vancouver, BC.

Kinash, S., Crichton, S., \& Kim-Rupnow, W. S. (2004). A review of 2000-2003 literature at the intersection of online learning and disability. The American Journal of Distance Education, 18(1), 5-19.

Kornhauser, L. H., \& Brooke, P. (1968). Enrichment through radio: A proposal to use radio as a tool of instruction from pre-kindergarten through grade 12. Washington, DC: American University.

Kozma, R. (1994). Will media influence learning? Reframing the debate. Educational Technology Research and Development, 42(2), 7-19.

Lignugaris-Kraft, B., \& Marchand-Martella, N. (1993). Evaluation of preservice teachers' interactive teaching skills in a direct instruction practicum using student teachers as supervisors. Teacher Education and Special Education, 16, 309-318.

Lockee, B., Moore, M., \& Burton, K. (2001). Old concerns with new distance education research. Education Quarterly, 2, 60-65. 
Lyon, G. R. (2001). Measuring success: Using assessments and accountability to raise student achievement. Subcommittee on education reform committee on education and the workforce U.S. House of Representatives Washington, DC [Online]. Available: http://www.nrrf.org/lyon_statement3-01.htm

Machtmes, K., \& Asher, J. W. (2000). A meta-analysis of the effectiveness of telecourses in distance education. The American Journal of Distance Education, 14(1), 27-46.

Malmgren, K. W., \& Leone, P. E. (2000). Effects of a short-term auxiliary reading program on the reading skills of incarcerated youth. Education and Treatment of Children, 23, 239-247.

Mather, N., \& Woodcock, R. (2001). The identification of gifted underachievers using the Woodcock Johnson Psychoeducational Battery. Roeper Review, 8, 54-56

McCook, K. (2006). A place at the table: Participating in community building. Chicago: American Library Association.

McGrew, K.S., \& Woodcock, R. W. (2001). Technical manual. Woodcock-Johnson-IYI. Itasca, IL: Riverside.

Meyer, L. A. (1984). Long-term academic effects of the direct instruction project followthough. Elementary School Journal, 84, 380-394.

Meyer, B. J. F., Brezinski, T K., Middlemiss, J., \& McDougall, J. (2002). Effects of structure strategy instruction delivered to fifth grade children using the internet with and without the aid of older adult tutors. Journal of Educational Psychology, $94(3), 486-519$. 
Moore, M. G., \& Thompson, M. M. (1997). The effects of distance learning Rev. Ed. (ACSDE Research monograph \# 15). University Park, PA: Amcrican Center for the Study of Distance Education, Pennsylvania State University.

Morrison, G. R. (1994). The media effects question: Unresolveable or asking the right question. Educational Technology Research \& Development, 42(2), 41-44.

National Assessment of Educational Progress. (2007). The nations report card. Washington, DC: U.S. Department of Education.

National Association of State Directors of Special Education (NASDSE). (2005) [Online]. Response to Intervention: Policy considerations and Implementation. Available at http://www.nasdse.org

National Education Association \& National Association of State Directors of Special Education Incorporated. (2004). The Intersection of IDEA and NCLB. Washington DC: National Education Association.

National Reading Panel. (2000). Report of the National Reading Panel: Teaching children to read: An evidence-based assessment of the scientific research literature on reading and its implications for reading instruction. Jessup, MD: National Institute for Literacy.

National Research Council (NRC). (1999). Preventing reading difficulties in young children (C. E. Snow, M. S. Burns, \& P. Griffin, Eds.). Washington DC: National Research Council.

No Child Left Behind Act of 2001. P.L. 107-110. 115 STAT. 1425. U.S. Department of Education, Washington, DC.

Parsonson, B. S., \& Baer, D. M. (1978). The analysis and presentation of graphic data. 
Journal of Applied Behavior Analysis, 11(3), 363-380.

Phipps, R., \& Merisotis, J. (1999). What's the difference? A review of contemporary research on the effectiveness of distance learning in higher education.

Washington, DC: Institute for Higher Education Policy.

Przychodzin Havis, A. M., Marchand-Martella, N. E., Martella, R. C., Miller, D. A., Warner, L., Leonard, B., et al. (2005). An analysis of "corrective reading" research. Journal of Direct Instruction, 51(1), 37-65.

Reeves, C. (2003). Implementing the No Child Left Behind Act: Implications for rural schools and districts. Naperville, IL: North Central Regional Education Laboratory.

Richard, A. (2005). Supplemental help can be hard to find for rural students. Education Week, 25(14), 1-3.

Rosenshine, B. V. (1987). Explicit teaching. In D.C. Berliner \& B. Rosenshine (Eds.), Talks to teachers (pp. 75-92). New York: Lane Akers.

Russell, T. L. (1999). The no significant difference phenomenon. Raleigh, NC: North Carolina State University, Office of Educational Telecommunications.

Russell, T. L. (2008). The no significant difference phenomenon. Available at http://www.nosignificantdifference.org/

Saba, F. (1999). Is distance education comparable to "traditional education?" Retrieved August 10, 2007 from the World Wide Web: http://distanceeducator.com/der/comparable.html

Samuels, S. J. (1978). The method of repeated reading. The Reading Teacher, 32, 403420. 
Sax, B. (2002). Brief report: New roles for tutors in an online classroom. Journal of College Reading and Learning, 33(1), 62-67.

Scruggs, T. E., Mastropieri, M. A., \& Castro, G. (1987). The quantitative synthesis of single subject research: Methodology and validation. Remedial and Special Education, 8(2), 24-33

Setzer, L., \& Lewis, B. (2005). Distance education courses for public elementary and secondary school students: 2002-2003. Washington, DC: U.S. Department of Education, National Center for Education Statistics.

Shachar, M., \& Newmann, Y. (2003). Differences between traditional and distance education academic performance: A meta-analytic approach. The International Review of Research in Open and Distance Learning, 4(2), 1-20.

Shadish, W. R., Cook, T. D., \& Campbell, D. T. (2002). Experimental and quasiexperimental designs for generalized casual inference. Boston, New York: Houghton Mifflin.

Shernoff, E. S., Kratochwill, T. R., \& Stoiber, K. C. (2002). Evidence based interventions in school psychology: An illustration of task force coding criteria using single participant research design. School Psychology Quarterly, 17(4), 390-422.

Sindelar, P.T., Monda, L.E., \& O’Shea, L. J. (1990). Effects of repeated readings on instructional-and mastery-level readers. Journal of Education Research, 83, 220226.

Snow, C., Burns, S., \& Griffen, P. (Eds.). (1998). Preventing reading difficulties in young children. Washington, DC: National Academy Press. 
Spellings, M. (2007). Building on results: A blueprint for strengthening the No Child Left Behind Act. Washington, DC: U.S. Department of Education. Retrieved June 15, 2007 from http://www.ed.gov/policy/elsec/leg/nclb/buildingonresults.pdf

Sprick, R. S., \& Howard, L. M. (1995-1997). The teacher's encyclopedia of behavior management. Longmont, CO: Sopris West.

Stoddard, K., Valcante, G., Sindelar, P. O’Shea, L., \& Algozzine, B. (1993). Increasing reading rate and comprehension: 'The effects of repeated readings, Sentence segmentation, and intonation training. Reading Research and Instruction, 32(4), 53-65.

Teaster, P. B., \& Blieszner, R. (1999) Promises and pitfalls of the interactive television approach to teaching adult development and aging. Educational Gerontology, 25(8), 741-753.

Tennyson, R. D. (1994). The big wrench vs. integrated approaches: The great media debate. Educational Technology Research and Development, 42(3), 15-28

Thompson, B. (1992). A field report: Specific learning disabilities corrective reading pilot study 1989-90. ADI News, 11(2), 11-13.

Thorne, M. T. (1978). Payment for reading: The use of the corrective reading scheme' with junior maladjusted boys. Remedial Education, 13(2), 87-90.

Todman, J. B., \& Dugard, P. (2001). Single case and small n experimental design: $A$ practical guide to randomization tests. Mahwah, NJ: Lawrence Erlbaum.

Torgesen, J. K. (1997). The prevention and remediation of reading disabilities: Evaluating what we know from research. Journal of Academic Language Therapy, 1, 11-47. 
Ullmer, E. J. (1994). Media and learning: Are there two kinds of truth? Educational Technology Research and Development, 42(1), 21-32.

Ungerleider, C., \& Burns, T. (2003). A systematic review of the effectiveness and efficiency of networked ICT in Education: A state of the art report to the council of ministers Canada and industry Canada. Industry Canada, Ontario.

United States Department of Education. (2002). No Child Left Behind Act. Washington, DC: Author.

United States Department of Education. (2005) Supplemental Educational Services NonRegulatory Guidance. Washington, DC: U.S. Department of Education.

Utah State Office of Education. (n.d.). Supplemental Service Providers. Retrieved August 27, 2008, from, http://schools.utah.gov/nclb/supplemental_serviccs.htm

Van Norman, R. K., \& Wood, C. L. (2008). Effects of prerecorded sight words and the accuracy of tutor feedback. Remedial and Special Education, 29(2), 96-107.

Watkins, C. L., \& Slocum, T. A. (2004). The components of direct instruction. In N. E. Marchand-Martella, T. A. Slocum, \& R. C. Martella (Eds.), Introduction to Direct instruction (pp. 28-65). Boston: Pearson.

Weinstein, G., \& Cooke, N. L. (1992). The effects of two repeated readings interventions on generalization of fluency. Learning Disability Quarterly, 15, 21-28

Wechsler, D. (1992). Wechsler Individual Achievement Test. San Antonio, TX: Psychological Corporation.

Wolf, M. M. (1978). Social validity: The case for subjective measurement or how applied behavior analysis is finding it's heart. Journal of Applied Behavior Analysis, I1(2), 203-214. 
APPENDICES 
Appendix A

Pilot Study 


\section{Online Tutoring System Pilot Study}

\section{PILOT STUDY}

During the Summer and Fall of 2006, Utah State University (USU) and University of Kentucky (UK) partnered to begin developing an online distance tutoring system. The system included two-two way audio and video, and was used to deliver instruction to students located in the states of Utah, Kentucky, and Pennsylvania. A tutor located in Kentucky delivered reading tutoring to a student in Utah, and three tutors located in Utah delivered reading instruction to students in Utah, Kentucky, and Pennsylvania. Tutors delivered 50 minutes of direct instruction utilizing the $C R$ Program. Two tutoring sessions were delivered twice per week for 6 to 8 weeks. Extensive data on the instructional process (i.e., instructional delivery, error correction, instructional pace and praise rate) was collected to judge the degree to which the instructional delivery practices of DI could be conducted over this system. In addition, a multiple baseline design was used to evaluate student outcomes.

Process data revealed that tutors were able to deliver DI with reasonable fidelity over this system. In addition, interobserver reliability checks confirmed that observations of teacher behavior conducted via the distance education system corresponded closely with live observations. However, specific technical difficulties and behavior management challenges were noted. In addition, student outcomes were somewhat ambiguous (see figure 1). First, there was a great deal of variability within each phase. Second, any treatment effects were relatively subtle in comparison to the background variability. Thus, the pilot study suggested that the technical system was basically sound and apparently sufficient to convey DI across a distance; however methodological improvements would have to be made before clear student outcome results would be expected.

Responses to the Pilot Study

Results of the pilot study suggest changes in research methods, in the intervention, and in specific technical aspects of the system. The main methodological problem was variability in the measure of oral reading rate. One well-established method for reducing this variability is to administer three one-min timings and use the median score of the three. Another limitation in the pilot study was the small effect size. In the pilot study we delivered instruction two times a week. To enhance the effect size for the present study, we plan to conduct tutoring sessions four times per week. In addition we will add repeated readings to the overall intervention package.

In the pilot test we encountered challenges with minor misbehavior. The fact that the tutor was not in physical proximity to the student apparently allowed for a variety of minor misbehaviors including off-task behavior (moving mouse, shutting down the webcamera, or moving items on the computer desktop), noncompliance (not responding to tutor instruction within 30 seconds) and quiet responding (responses which were not audible to the tutor). Through the pilot test we learned to manage these behaviors in several ways. First, we used high quality, high paced instruction with several opportunities for student responding, reinforcement, and error correction. Second, we used a "you/me" game along with a token economy to manage both noncompliance and off-task behavior. Third, prior to tutoring sessions students were given explicit instruction on appropriate learning behaviors. For example a tutor may tell a student to adjust the 
camera for full viewing, "park the mouse" (place the mouse behind the monitor), sit up tall with hands in lap.

The second obstacle faced was the quality of sound. In beginning reading instruction, clear audio is essential to hear the discreet sounds students make when learning to read. We found that any background noise (e.g., teacher delivering instruction, other computers, hallway noise, etc.) would degrade the quality of sound picked up from the microphone. In addition to microphone sensitivity, students found it hard to hear on their end using only a single ear headset. We found a duel ear headset with noise-canceling microphone was the solution for clear sound both on the tutor's end and student's end.

The third obstacle was voice tone. Occasionally we tutored a student who was shy and did not talk with strong tone or volume. In this case we already had the appropriate microphone and headset. The next step was to train the student to talk with stronger tone or increased volume. We shaped the students response by modeling appropriate tone and volume. After we modeled the correct response we asked the student to respond until we were able to get appropriate levels of volume and tone. We worked with this student prior to each tutoring session to make sure we were able to hear her clearly.

Forth, the transition from face-to-face tutoring to online tutoring was difficult for inexperienced tutors. The online system we use is user friendly, however, the setup is different from a face-to-face session. Tutors have to manipulate the screen environment rather than turning a page to deliver the appropriate student stimuli. Further, tutors only see what is on a camera. For example, identifying behaviors that could lead to problems is difficult if the tutor is manipulating the stimuli visible to the student, providing reinforcement or correcting an error. Tutors reported that the learning curve was high since the teaching environment was so different. However, data comparing online and face-to-face tutoring, showed very similar overall rates of reinforcement, error correction, and instructional pace across both conditions. Tutors who were well trained in delivering Direct Instruction had less of a problem transitioning to online tutoring than those who had never been trained previously in DI. Thus, the pilot test led to numerous adjustments to research methods, instructional procedures, tutor training procedures, and technology. 
Appendix B

Direct Instruction Supervision System 
Rav, \&23/07

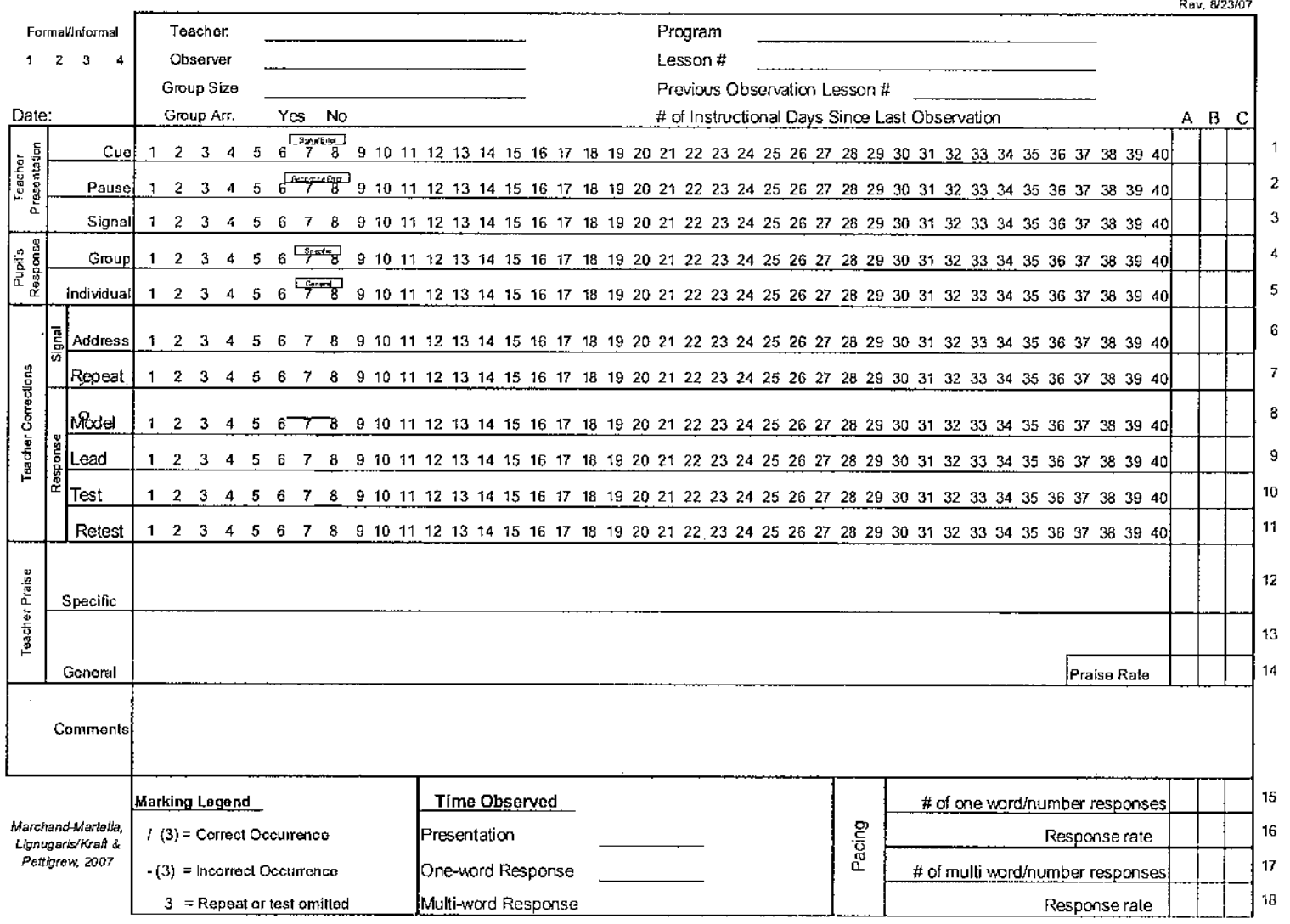


Appendix C

Dynamic Indicator Battery of Early Literacy Skills Integrity Checklist 
DIBELS ${ }^{\mathrm{NA}}-\mathrm{ORY}$

Page 38

\section{OMBELS' Orsil Residing Fluency} Assissment Integrity Checklist

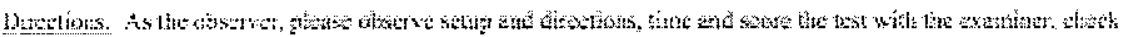

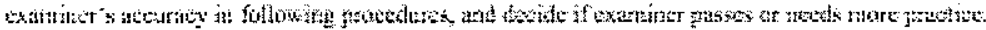

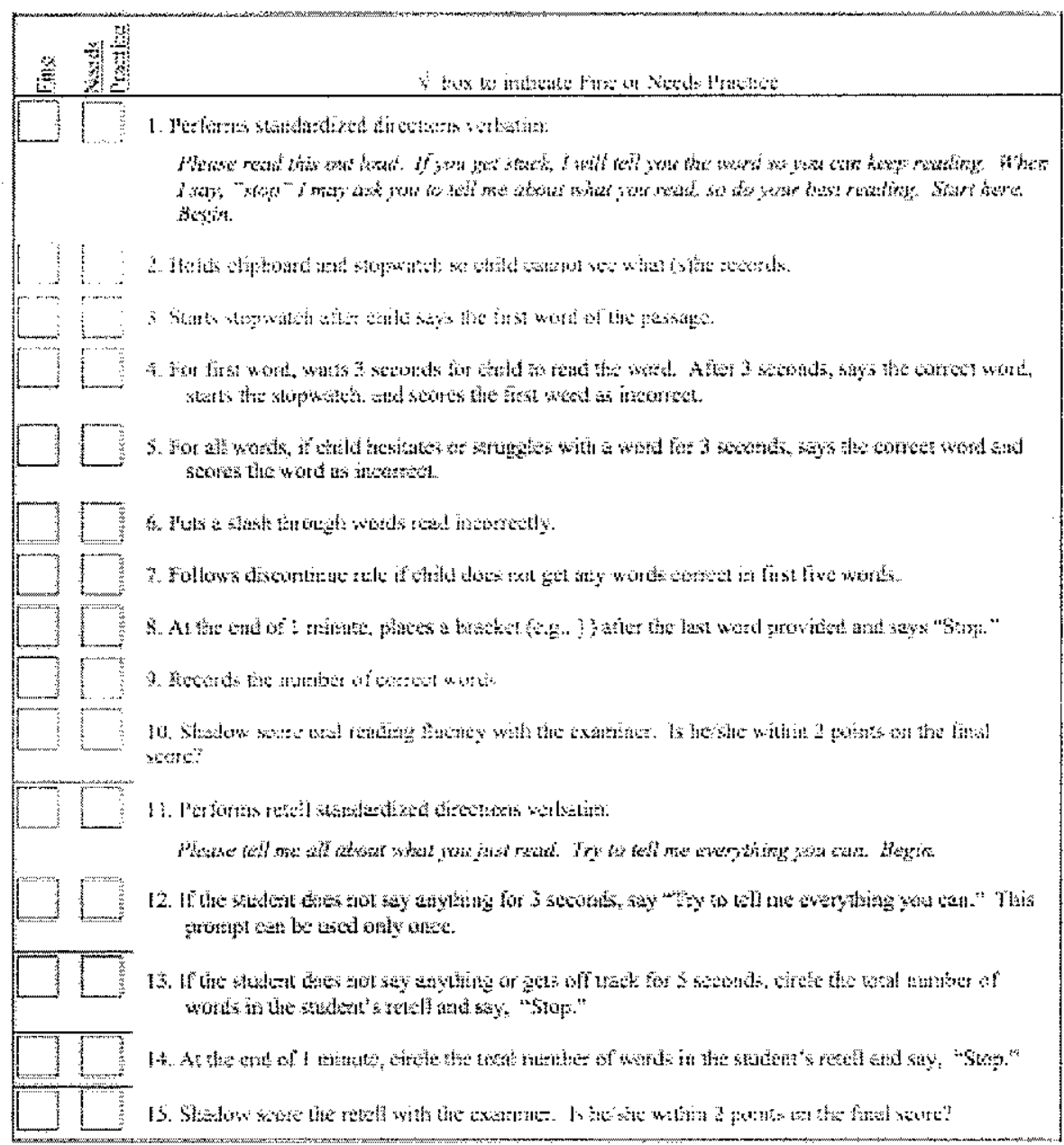


Appendix D

Woodcock Johnson-III Test of Academic Achievement Fidelity Checklist 


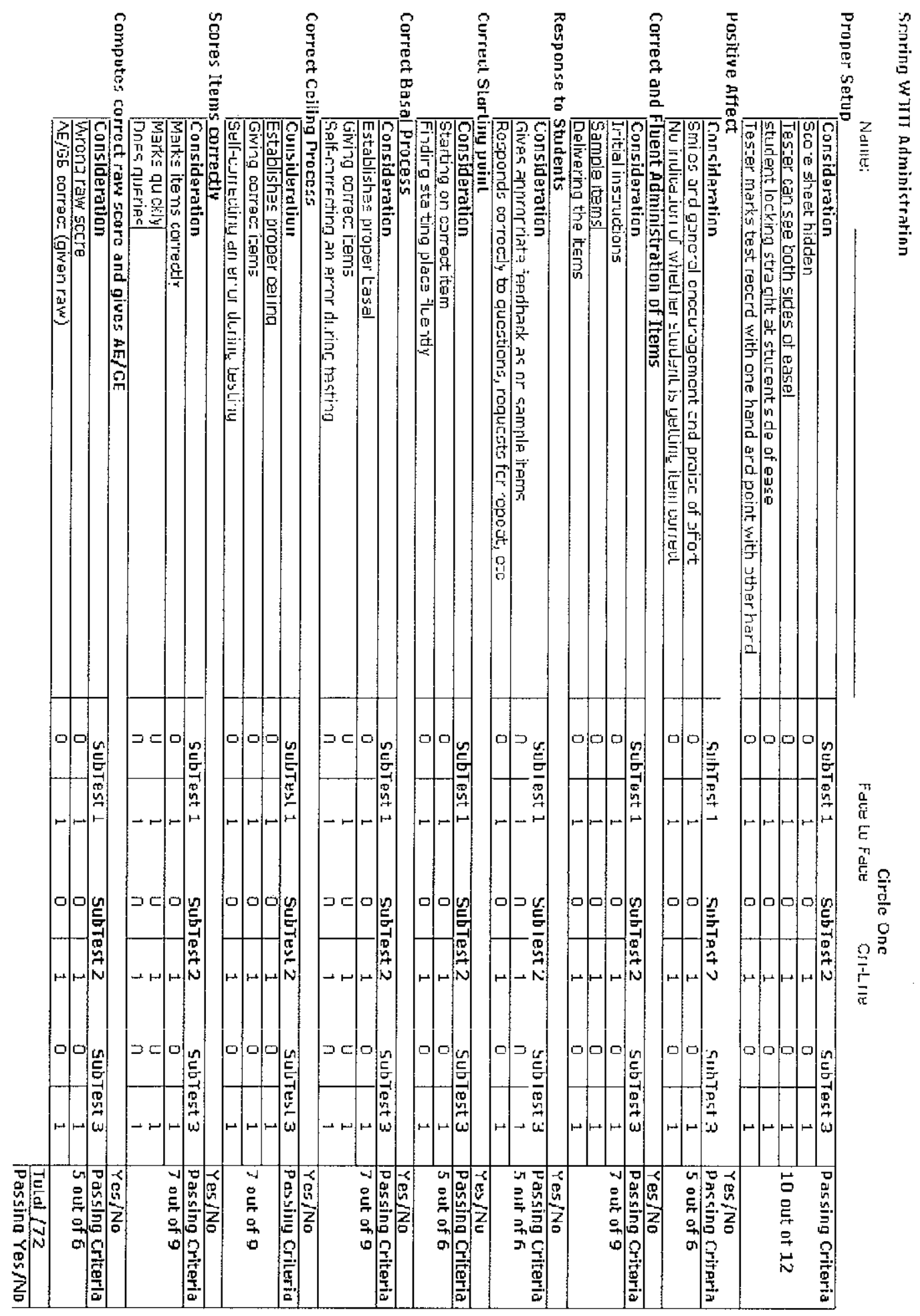


Appendix E

Social Validity Questionnaires 
Social Validity Rating Scale

(Tutors)

1) Rate the ease of the online tutoring environment Very Easy (VE) Easy (E) Difficult

(D) or Very Difficult (VD)

\begin{tabular}{|l|l|c|c|c|c|}
\hline $\begin{array}{l}\text { Q. } \\
\text { No }\end{array}$ & Question & VE & E & D & VD \\
\hline 1.1 & Uploading software & & & & \\
\hline 1.2 & Legibility of student materials & & & & \\
\hline 1.3 & Hearing student responses & & & & \\
\hline 1.4 & Navigating the Breeze system & & & & \\
\hline 1.5 & Managing student behavior & & & & \\
\hline 1.6 & Keeping students' attention & & & & \\
\hline
\end{tabular}

2) Do you have additional comments or concerns regarding the online environment?

3) Would you recommend online tutoring to friends or parents with young children?

$$
\text { Yes No }
$$

4) Would you continue tutoring online?

Yes No

5) Did you see improvement in the students during the online tutoring intervention?

Yes No Some 
Social Validity Rating Scale

(Students)

1.1) Do you play on the computer?

Yes No

1.2 If yes, how often?

Once a month

1.3) Where?

Once a week More than once a week

Daily

At home At school

2) What was something you liked about online tutoring?

3) What was something you disliked about online tutoring?

4) Was it easy to hear and understand the tutor?

Yes No Sometimes

5) Was it easy to read the stories?

Yes No Sometimes

6) Do you think your friends would like to use this program to learn to read?

Yes No Sometimes

7) Did online tutoring help you learn to read better?

Yes No Sometimes

If yes, how?

8) What would you change about online tutoring to make it better? 
Social Validity Rating Scale

Parent/Teacher

1) Did you notice improvement in your student's reading after he/she received online tutoring?

$\begin{array}{lll} & \text { Yes } \quad \text { No I don't know } \\ \text { Comments } & \end{array}$

2) Did your student show enjoyment for the online tutoring program?

$$
\text { Yes } \quad \text { I don't know }
$$

Comments

3) Would you recommend online tutoring to other parents with children who need help with reading?
Yes
No
I don't know

Comments 
Appendix F

Informed Consent 


\section{INFORMED CONSENT-Parents and Children Philadelphia, PA}

This letter explains you and your child's participation as a research participant in an experiment. It is important that you read this material carefully to determine if you wish to volunteer.

Purpose: Dr. Tim Slocum in the Department of Special Education and Rehabilitation at Utah State University (USU) is conducting a research study on the effects of online tutoring for children's acquisition of key reading skills. Your child has been asked to take part because they have been identified by their teacher as needing supplemental reading instruction. In addition, we would like to know your perception of our online tutoring program at the end of services. There will be approximately four student participants at Stanton Hall Elementary School in Philadelphia, PA, and four parents. Procedures: The procedures will involve your child as a research participant, include an initial training, preparing students to use an online teleconferencing program (seeing and talking to a tutor over the computer). Participating children will receive online tutoring. Students will be directly tutored in reading by undergraduate teachers using the Corrective Reading program 50 minutes a day, 4 days a week for 12 weeks. Project trainers will observe students and tutors as students work on their reading skills utilizing the online system to ensure that tutors deliver instruction reliably and consistently. Audio/video recordings may be made of your child and the tutors during the course of this study. Your child will be tested using the DIBELS and Woodcock Johnson III (WJ-III) reading assessment before and after the tutoring is delivered. At the end of the study your child will also be asked to rate how well they liked the goals, procedures, and effects of the reading program and how well they thought it worked.

Parents will also be asked to fill out a questionnaire to rate the goals, procedures, and effects of the reading program their child participated in. This questionnaire will take about 5 to 10 minutes to complete and will be delivered at the end of the study. Results from the questionnaire will help researchers determine if delivering online tutoring to children in an inner city location is of social importance.

New Findings: During the course of this study, you will be informed of any significant new findings (either good or bad), such as changes in the risks or benefits resulting from participation in the research, or new alternatives to participation that might cause you to change your mind about continuing the study. If new information is obtained that is relevant or useful to you, or if the procedures and/or methods change at any time throughout the study, your consent to continue participating in this study will be obtained again.

Risks: There is minimal risk in participating in this research study. 
Benefits: There may not be any direct benefit to your child from participating in this study. However, suspected benefits to your child include increases in their reading skills. In addition, we hope to learn more about how to tutor children effectively over a computer system like this one.

Explanation \& Offer to answer questions: Dr. Tim Slocum or his staff has explained this study for you and answered your questions. If you have other questions or research related problems, you may reach Dr. Tim Slocum at 435-7973212.

Extra Cost(s) There will not be any costs for participating. Tutoring services and equipment will be supplied free of charge.

Voluntary nature of participation and right to withdraw without consequence:

Participation in this research experiment is voluntary. You may decline to participate and you may quit at any time during the course of this study. If you choose not to participate in this study other participation alternatives are not available. If you quit, or decline to participate, the benefits to which you are otherwise entitled will not be affected. You may discontinue participation by calling Dr. Slocum at (435) 797-3212.

Confidentiality: Research records and audio/video recordings will be kept confidential, consistent with federal and state regulations. Only the investigator and project personnel will have access to the data. All records will be stored in office 314 in the College of Education and Human Services at USU. Research records and audio recordings will be kept for no more than five years following the conclusion of this study. Participants will be assigned a code which will be used in place of names, to all research records and audio/video recordings. Participants' names and their associated codes will be stored in separate locations to ensure the confidentiality of participants. Participants' names and their assigned code will be kept for no more than five years after the study is completed. The results of this study may be published and/or presented at meetings without naming your child as a participant. Your rights and privacy will be maintained; however, Department of Special Education and Rehabilitation Counseling, the USU review board, and personnel particular to this research will have access to study records.

IRB Approval Statement: The Institutional Review Board for the protection of human subjects at USU has reviewed and approved this research project. If you have any questions you may contact them at (435) 797-1821.

Copy of consent: You have been given two copies of this Informed Consent. Please sign both copies and keep one copy for your files.

Investigator Statement: "I certify that the research study has been explained to the individual, by me or my research staff, and that the individual understands the nature and purpose, the possible risks and benefits associated with taking part in this research study. Any questions that have been raised have been answered."

Dr. Tim Slocum 
Principal Investigator

(435) 797-3212

Signature of Parent(s) By signing below, I agree for my child and I to participate in this research.

Parent/guardian

Date

Child/Youth Assent: I understand that my parent(s)/guardian is/are aware of this research study and that permission has been given for me to participate. I

understand that it is up to me to participate even if my parents say yes. If I do not want to be in this study, I do not have to and no one will be upset if I don't want to participate or if I change my mind later and want to stop. By signing below, I agree to participate.

Participant

Date 


\section{INFORMED CONSENT-Teachers \\ Philadelphia, PA}

This letter explains your participation as a research participant in an experiment. It is important that you read this material carefully to determine if you wish to volunteer.

Purpose: Dr. Tim Slocum in the Department of Special Education and Rehabilitation at Utah State University (USU) is conducting a research study on the effects of online tutoring for student's acquisition of key reading skills. You have been asked to take part because one of your students will receive online tutoring. We would like to know your perception of our online tutoring program at the end of services. We will ask you to rate the importance of the study by filling out a brief questionnaire. There will be approximately two teacher participants at Stanton Hall Elementary School in Philadelphia, PA, and two USU tutor participants.

Procedures: The procedures will involve answering a brief social validity questionnaire by rating the goals, procedures, and effects of the reading program your student participated in. This questionnaire will take about 5 to 10 minutes to complete and will be delivered at the end of the study. Results from the questionnaire will help researchers determine if delivering online tutoring to children in an inner city location is of social importance.

New Findings: During the course of this study, you will be informed of any significant new findings (either good or bad), such as changes in the risks or benefits resulting from participation in the research, or new alternatives to participation that might cause you to change your mind about continuing the study. If new information is obtained that is relevant or useful to you, or if the procedures and/or methods change at any time throughout the study, your consent to continue participating in this study will be obtained again.

Risks: There is minimal risk in participating in this research study.

Benefits: There may not be any direct benefit to you from participating in this study. We hope to learn more about how to tutor children effectively over a computer system like this one.

Explanation \& Offer to answer questions: Dr. Tim Slocum or his staff has explained this study for you and answered your questions. If you have other questions or research related problems, you may reach Dr. Tim Slocum at (435) 797-3212.

Voluntary nature of participation and right to withdraw without consequence:

Participation in this research experiment is voluntary. You may decline to participate and you may quit at any time during the course of this study. If you choose not to participate in this study other participation alternatives are not available. If you quit, or decline to participate, the benefits to which you are otherwise entitled will not be affected. You may discontinue participation by calling Dr. Slocum at (435) 797-3212. 
IRB Approval Statement: The Institutional Review Board for the protection of human subjects at USU has approved this research project. If you have any questions you may contact them at (435) 797-1821.

Copy of consent: You have been given two copies of this Informed Consent. Please sign both copies and keep one copy for your files.

Investigator Statement: "I certify that the research study has been explained to the individual, by me or my research staff, and that the individual understands the nature and purpose, the possible risks and benefits associated with taking part in this research study. Any questions that have been raised have been answered."

Dr. Tim Slocum

Date

Principal Investigator

(435) 797-3212

Signature of Participant (s) By signing below, I to participate in this research.

Participant

Date 


\section{INFORMED CONSENT-Parents and Children}

\section{Kearns, UT}

This letter explains you and your child's participation in a research study. It is important that you read this letter carefully to decide if you wish to take part.

Purpose: Dr. Tim Slocum in the Department of Special Education and Rehabilitation at Utah State University (USU) and Eleazar Vasquez, Research Assistant, are starting a research study on the effects of online tutoring. Your child has been asked to take part because they have been identified by their teacher as needing extra reading help. There will be approximately four student participants at Western Hills Elementary School in Kearns, UT, and four parents.

Procedures: If you and your child agree to participate, your child will receive training in how to use the computer system. Then they will receive tutoring over the computer system. Students will be tutored in reading by student teachers using the Corrective Reading program 50 minutes a day, 4 days a week for 11 weeks and DIBELS oral reading fluency probes will be delivered every 3 days. Tutors will be observed to ensure that they deliver instruction correctly. Audio/video recordings may be made of your child and the tutors during this study.

Your child will be tested using the DIBELS and Woodcock Johnson III (WJ-III) reading tests before and after the tutoring is delivered. At the end of the study your child will also be asked to rate how well they liked the goals, tutoring, and effects of the reading program and how well they thought it worked.

You will also be asked to fill out a survey to rate the goals, procedures, and effects of the reading program. This survey will take about 5 to 10 minutes and will be given to you at the end of the study. Results from the survey will help us decide if online tutoring is useful and valuable.

New Findings: You will be informed of any significant new findings (either good or bad) that might cause you to change your mind about continuing the study. If new information is found or if our methods change at any time during the study, your consent to continue taking part in this study will be obtained again.

Risks: There is minimal risk in participating in this research study.

Benefits: There may not be any direct benefit to your child from taking part in this study. However, suspected benefits to your child include increases in their reading skills. In addition, we hope to learn more about how to tutor children effectively over a computer system like this one.

Explanation \& Offer to answer questions: Dr. Tim Slocum or his staff has explained this study for you and answered your questions. If you have other questions or research related problems, you may reach Dr. Tim Slocum at 435-7973212.

Extra Cost(s) There will not be any costs for participating. Tutoring services and equipment will be supplied free of charge. 
Voluntary nature of participation and right to withdraw without consequence: Taking part in this research study is voluntary. You may decline to participate and you may quit at any time during the course of this study. If you quit, or decline to take part, the benefits to which you are otherwise entitled will not be affected. You may discontinue participation by calling Dr. Slocum at (435) 797-3212.

Confidentiality: Research records and audio/video recordings will be kept confidential, consistent with federal and state regulations. Only Dr. Slocum and project personnel will have access to the data. All records will be stored in office 305 in the College of Education and Human Services at USU. Research records and audio recordings will be kept for no more than ten years following the conclusion of this study. Participants will be assigned a code which will be used in place of names, to all research records and audio/video recordings. Participants' names and their associated codes will be stored in separate locations to ensure the confidentiality of participants. Participants' names and their assigned code will be kept for no more than ten years after the study is completed. The results of this study may be published and/or presented at meetings without naming your child as a participant. Your rights and privacy will be maintained; however, Department of Special Education and Rehabilitation, the USU review board, and personnel particular to this research will have access to study records.

IRB Approval Statement: The Institutional Review Board for the protection of human subjects at USU has reviewed and approved this research project. If you have any questions you may contact them at (435) 797-1821.

Copy of consent: You have been given two copies of this Informed Consent. Please sign both copies and keep one copy for your files.

Investigator Statement: "I certify that the research study has been explained to the individual, by me or my research staff, and that the individual understands the nature and purpose, the possible risks and benefits associated with taking part in this research study. Any questions that have been raised have been answered."

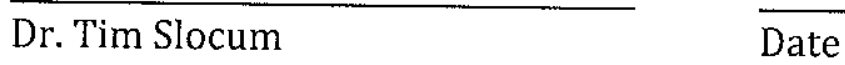

Principal Investigator

(435) 797-3212

Signature of Parent(s) By signing below I agree for me and my child to participate in this research.

Parent/guardian

Date 
Youth Assent (for those 7-17yrs or age): I understand that my parent(s)/guardian are aware of this research study and that permission has been given for me to take part. I understand that it is up to me to take part even if my parents say yes. If I do not want to be in this study, I do not have to. No one will be upset if I don't want to be in the study or if I change my mind later and want to stop. By signing below, I agree to start the study. 
INFORMED CONSENT-Teachers

Kearns, UT

This letter explains your participation in an experiment. It is important that you read this material carefully to decide if you wish to take part.

Purpose/Introduction: Dr. Tim Slocum in the Department of Special Education and Rehabilitation at Utah State University (USU) and Eleazar Vasquez, Research Assistant, are conducting a research study on the effects of online tutoring. You have been asked to take part because one of your students will receive online tutoring. We would like to know your opinion of our online tutoring program at the end of tutoring services. We will ask you to rate the value of the online tutoring by filling out a brief survey. There will be approximately two teacher participants at Western Hills Elementary School in Kearns, UT.

Procedures: You will be asked to complete a brief survey by rating the goals, procedures, and effects of the reading program you delivered. This survey will take about 5 to 10 minutes to complete and will be given at the end of the study. Results from the survey will help us decide if online tutoring is valuable to the students. New Findings: During the course of this study, you will be informed of any significant new findings (either good or bad), such as changes in the risks or benefits resulting from participation in the research, or new alternatives to participation that might cause you to change your mind about continuing the study. If new information is obtained that is relevant or useful to you, or if the procedures and/or methods change at any time throughout the study, your consent to continue participating in this study will be obtained again.

Risks: There is minimal risk in participating in this research study.

Benefits: There may not be any direct benefit to you from participating in this study. We hope to learn more about how to tutor children effectively over a computer system like this one.

Explanation \& Offer to answer questions: Dr. Tim Slocum or his staff has explained this study for you and answered your questions. If you have other questions or research related problems, you may reach Dr. Tim Slocum at (435) 797-3212.

Voluntary nature of participation and right to withdraw without consequence: Participation in this research experiment is voluntary. You may decline to participate and you may withdraw at any time during the course of this study. If you withdraw or decline to participate, the benefits to which you are otherwise entitled will not be affected. You may discontinue participation by calling Dr. Slocum at (435) 797-3212.

IRB Approval Statement: The Institutional Review Board for the protection of human subjects at USU has approved this research project. If you have any questions you may contact them at (435) 797-1821.

Copy of consent: You have been given two copies of this Informed Consent. Please sign both copies and keep one copy for your files. 
Investigator Statement: "I certify that the research study has been explained to the individual, by me or my research staff, and that the individual understands the nature and purpose, the possible risks and benefits associated with taking part in this research study. Any questions that have been raised have been answered."

Dr. Tim Slocum

Date

Eleazar Vasquez

Date

Principal Investigator

(435) 797-3212

Signature of Participant (s) By signing below I agree to participate in this research.

Participant's Signature

Date 


\section{INFORMED CONSENT-Tutors Logan, UT}

This letter explains your participation in an experiment. It is important that you read this letter carefully to decide if you wish to take part.

Purpose: Dr. Tim Slocum in the Department of Special Education and Rehabilitation at Utah State University (USU) and Eleazar Vasquez, Research Assistant, are conducting a research study on the effects of online tutoring. You have been asked to take part because you are providing these services. We would like to know your opinion of our online tutoring program at the end of tutoring services. We will ask you to rate the value of the online tutoring by filling out a brief survey. There will be approximately four student participants at Western Hills Elementary School in Kearns, UT, and two USU tutor participants.

Procedures: You will be asked to complete a brief survey by rating the goals, procedures, and effects of the reading program you delivered. This survey will take about 5 to 10 minutes to complete and will be given at the end of the study. Results from the survey will help us decide if online tutoring is valuable to the students. In addition, you will receive training to deliver the Corrective Reading program, Woodcock Johnson III Tests of Academic Achievement, and DIBELS oral reading probes. Training will take approximately two days and will be part of the 11-week study. You will receive feedback on your tutoring skills.

Tutor responsibilities include:

- Receiving training in the delivery of Corrective Reading, Woodcock Johnson III, and DIBELS.

- Delivering assessments and reading instruction 4 days a week to students in Utah.

- Collecting data on oral reading fluency

- Completing survey at end of study.

New Findings: During the course of this study, you will be informed of any significant new findings (either good or bad), such as changes in the risks or benefits resulting from participation in the research, or new alternatives to participation that might cause you to change your mind about continuing the study. If new information is obtained that is relevant or useful to you, or if the procedures and/or methods change at any time throughout the study, your consent to continue participating in this study will be obtained again.

Risks: There is minimal risk in participating in this research study.

Benefits: There may not be any direct benefit to you from participating in this study. However, we hope to learn more about how to tutor children effectively over a computer system like this one.

Explanation \& Offer to answer questions: Dr. Tim Slocum or his staff has explained this study for you and answered your questions. If you have other questions or research related problems, you may reach Dr. Tim Slocum at (435) 797-3212. 
Voluntary nature of participation and right to withdraw without consequence: Participation in this research is voluntary. You may decline to participate and you may quit at any time during the course of this study. If you quit, or decline to participate, the benefits to which you are otherwise entitled will not be affected. You may discontinue participation by calling Dr. Slocum at (435) 797-3212. Confidentiality: Research records and audio/video recordings will be kept confidential, consistent with federal and state regulations. Only Dr. Slocum and project personnel will have access to the data. All records will be stored in office 305 in the College of Education and Human Services at USU. Research records and audio recordings will be kept for no more than ten years following the conclusion of this study. Participants will be assigned a code which will be used in place of names, to all research records and audio/video recordings. Participants' names and their associated codes will be stored in separate locations to ensure the confidentiality of participants. Participants' names and their assigned code will be kept for no more than five years after the study is completed. The results of this study may be published and/or presented at meetings without naming you as a participant. Your rights and privacy will be maintained; however, Department of Special Education and Rehabilitation Counseling, the USU review board, and personnel particular to this research will have access to study records.

IRB Approval Statement: The Institutional Review Board for the protection of human subjects at USU has approved this research project. If you have any questions you may contact them at (435) 797-1821.

Copy of consent: You have been given two copies of this Informed Consent. Please sign both copies and keep one copy for your files.

Investigator Statement: "I certify that the research study has been explained to the individual, by me or my research staff, and that the individual understands the nature and purpose, the possible risks and benefits associated with taking part in this research study. Any questions that have been raised have been answered."

\begin{tabular}{llll}
\hline Dr. Tim Slocum & Date & Eleazar Vasquez & Date \\
Principal Investigator & & &
\end{tabular}
(435) $797-3212$

Signature of Participant: By signing below I agree to participate in this research. 


\section{Appendix $\mathrm{G}$}

Permission to use Adobe Connect Screen Shot 
Thank you for your request. This constitutes the addendum to the full terms set form in the Permissions and trademark guidelines referenced below for reproduction of partial screen shots.

Permission to use specific portions of a screen shot.

You must first review and accept the terms of the Permissions and trademark guidelines found at http://www adobe.com/misc/agreement.html and review and agree to the specific guidelines for Screen Shots.

Your use may not include screen shots from any other third party material so there is no confusion as to which screen shots belong to Adobe vs. any other third party.

You must include the following copyright attribution statement: "Adobe product screen shot(s) reprinted with permission from Adobe Systems Incorporated."

If your use includes references to an Adobe product, the full name of the product must be referenced at the first and most prominent mention (Adobe $($ Photoshop $($ ). When referencing any Adobe trademarks, please mark with a ${ }^{\mathrm{TM}}$ or ${ }^{\circledR}$ as indicated in the Adobe trademark database for general distribution. If you are distributing materials exclusively in Japan, please contact Adobe for a copy of the appropriate Adobe Trademark information for Japan.

If your use includes references to any Adobe trademarks, you should include the following trademark attribution statement: "[List of marks used, with "Adobe" first, if used, followed by other Adobe marks used, in alphabetical order] are either registered trademarks or trademarks of Adobe Systems Incorporated in the United States and/or other countries." If relevant, please also review "Use of Adobe trademarks in titles of books."

If your use is in compliance with these guidelines, no further written permission is required. We sincerely appreciate and thank you for your support of Adobe products. Please let me know if you have further questions.

Sincerely, Joyce Fowler 
CURICULUM VITAE

\author{
Eleazar Vasquez III \\ evasquez@mail.ucf.edu
}

\begin{abstract}
CONTACT INFORMAITON
Office: $\quad$ ED 315-F

Phone: $\quad 407-823-2898$

Fax: $\quad 407-823-3859$

Address: $\quad 4000$ Central Florida Blvd.
\end{abstract}

EDUCATION

December 2008 Ph.D. candidate, Disability Disciplines (Specialized in Special Education)

Utah State University, Logan, UT

Chair: Timothy Slocum, PhD

Dissertation: Evaluation of The Effectiveness of Online Tutoring for Students At- Risk of Reading Failure

*Dissertation Research Proposal Award from the American Council on Rural Special Education (ACRES) 2008 (\$500).

May 2003

M.A., School Psychology

Stephen F. Austin State University, Nacogdoches, TX

Chair: H. A. Chris Ninness, Ph.D.

Thesis: A Comparison of Parametric and Randomized Multivariate Statistics using Monte Carlo Methods: A Computer Generated Approach

June 1997 B.S., Special Education

Stephen F. Austin State University, Nacogdoches, TX

Advisor: Glen McCullar, Ph.D.

CERTIFICATIONS

United States: Nationally Certified School Psychologist (NCSP)

United States National Institute for Urban School Improvement (NIUSI)

United States National Center for Culturally Responsive Education Systems

Texas (NCCRESt)

CURRENT POSITION

Public School Teacher (Kinesiology and Special Education K-12)

Present Visiting Instructor

PROFESSIONAL EXPERIENCE: Employment

August 2004-

2008

Spring 2006 2008 Logan, UT
Doctoral Fellow Department of Special Education and rehabilitation, Utah State University, Logan, UT

Graduate Research Assistant, Utah State University,

Current project: Synchronous tutoring delivered online to students in rural and inner city locations.

- Develop and validate online tutoring instrument and methodology to comparatively evaluate teacher and student performance in reading and math.

- Empirically evaluate the feasibility of
Oriando, FL Logan, UT Logan, UT 
Summer and Fall 2005

2003-2005

2002- 2003

$2001-$

2003

2000-2001 delivering online tutoring.

- Conduct and supervise data collector training, data collection and analysis

- Supervisors: David Forbush, PhD; Timothy A. Slocum, Ph.D.; Robert Morgan, Ph.D.; and Benjamin Lignugaris/ Kraft, Ph.D.

Project Assistant, Your Job Selections (YES program), Utah State University. Online Job Preference Selection program.

- Development of online transition from CDROM program to web based program with additional search tools.

- Digital video editing, audio editing, script editing, production assistance, script writing, manual development and design, teleprompt setup and operation.

Supervisor: Robert Morgan, Ph.D.

School Psychologist

- Psychological Testing

Georgetown,

- Consultation and collaboration with school personnel

- Development of behavioral and educational programs for students with disabilities

- Functional Assessments

- Facilitated IEP meetings

- Direct service provider to students and parents

- Parent training

School Psychologist Intern

- 1200 hour internship with Nacogdoches ISD

- Development and implementation of behavioral intervention plans

- Functional Assessment

- Psychological Testing

- Consultation and collaboration with school personnel

- Parent training

Graduate Assistant

- Assisted Chris Ninness, Ph.D., Robin Rumph, Ph.D., and Anna Bradfield, Ph.D. on research and grant programs in the department of human services.

- Projects included RFT technology advancement of math facts and delivered via computer

- Supervision of Behavior clinic Assistive Technologist, Nacogdoches Independent School District Nacogdoches,

Nacogdoches,

TX

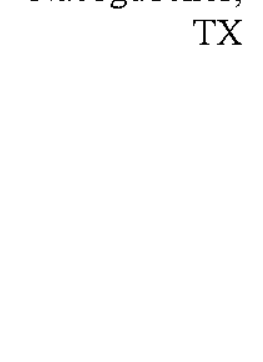
TX

Nacogdoches, TX 
$1999-2000$

Public School Teacher

Nacogdoches,

- Resource Math Special Education Grades 5-8.

TX

- Summer School English as a Second Language Teacher Grades 5-8.

PROFESSIONAL EXPERIENCE: Supervision \& Activities

$2006-2007$

Jan - May 2007

March 2005

Student Teaching Supervisor (SPED 5610), Utah State University

- Supervised preservice teachers ability to deliver effective instruction

- Provided feedback and error correction regarding instructional delivery

Supervisor; Kimberly Snow

Math Practicum Supervisor, Utah State University

Supervisor: Pam Hudson, Ph.D.

Guest Lecturer, Applied Behavior Analysis 2: Applications (SPED 5050), Utah State University

Topic: Timeout; ethical guidelines on use of punishment, and overcorrection

March 2005

Guest Lecturer, Applied Behavior Analysis 2: Applications (SPED 5050), Utah State University

Topic: Generalization and Maintenance

\section{PUBLICATIONS}

\section{Refereed}

Davis, R. L., Ninness, C., Rumph, R., McCuller, G., Stahl, K., Ward, T., \& Vasquez, E. (2008). Functional assessment of self-initiated maladaptive behaviors: A case study. Behavior and Social Issues, 17, 66-85.

Hudson, P., Shupe, M., Vasquez, E., \& Miller, S. (2008). Teaching data analysis to elementary students with mild disabilities. Teaching Exceptional Children.

Forbush, D., Stenhoff, D., Vasquez, E., Furzland, M. (2008). On line checkout of the WJ-III, A distance education approach. Journal of Teacher Education and Special Education.

Ninness, C., Rumph, R., McCuller, G., Vasquex, E., Bradfield, A., \& Ninness, S., (Winter 2005). A Relational frame and artificial neural network approach to computer-interactive 
mathematics. The Psychological Record., 55, 561-570.

Ninness, H. A. C., Newton, R., Saxon, J., Rumph, R., Bradfield, A., Harrison, C., Vasquez, E., \& Ninness, S. (2002). Small group statistics: A monte carlo comparison of parametric and randomization tests. Behavior and Social Issues. 12 (1), 53-63

Ninness, H. A. C., Rumph, R., Vasquez, E., Bradfield, A., (Dec. 2002) Multivariate

randomization tests for small- $\mathrm{n}$ behavioral research. Behavior and Social Issues. 12 (1), 64 74

\section{Non-Refereed}

Morgan, R. L., Morgan, R. B., Vasquez, E. (2006). I can search for jobs on the internet! A web site that helps youth in transition identify preferred employment. Teaching Exceptional Children, 38, 6-11

Morgan, R. L., \& Vasquez, E. (2006). Teaching functionally equivalent replacement behaviors to students with problem behavior: What? How? Why? The Utah Special Educator 26(4) p. 34

\section{Manuscripts in Review}

Ozenne, L. D., Ward, Vasquez, E., Ninness, C., McCuller, G., \& Rumph, R. (in review) Computer interactive functional analysis in planning and assessing the effectiveness of a behavioral intervention. Journal of Applied Behavior Analysis

\section{GRANTS}

\section{FUNDED}

Vasquez, E., (2007, May) Student Association for Behavior Analysis Student Presenter Grant provided by the International Association for Behavior Analysis. $(\$ 50)$

Vasquez, E., (2003, May) Student Association for Behavior Analysis Student Presenter Grant provided by the International Association for Behavior Analysis. $(\$ 50)$

Vasquez, E. (2002, October) Mini Grant provided by Stephen F. Austin State University Department of Graduate School. A comparison of parametric and randomized multivariate statistics using Monte Carlo methods: A computer generated approach $(\$ 800)$

\section{NON-FUNDED}

Stepping Stones Grant from the Department of Education. Project Reach to Teach: Evaluation of Live Video/Audio Online Tutoring to Students in Rural and Inner City Homes and schools. (2006). Department of Special Education and Rehabilitation, Utah State University $(\$ 400,000,2007-2009)$.

Score: 79 out of 100 Accepted without funding 
Role: Graduate Assistant

Role in Preparation: Co-author with Forbush, D. E., and Stenhoff, D, M.

Stepping Stones Grant from the Department of Education. Access to Choice of Employment

online program facilitating job choice/awareness and job curriculum. (2005 May)

Department of Special Education and Rehabilitation, Utah State University

Score: 98 out of 100 Accepted without funding

Role: Co-director of Research and Analysis

PRESENTATIONS

Role in Preparation: Co-author with Robert Morgan

\section{Professional Conferences}

Vasquez, E (2008). Evaluation of synchronous online tutoring to students in rural and inner city public school. Paper presented at the $34^{\text {th }}$ Annual Convention of the International Association for behavior Analysis, Chicago, IL.

Vasquez, E., Forbush, D., Gleed, L., Lockwood, A. (2007). An evaluation of the effectiveness, efficiency, and feasibility of live on-line reading tutoring for at risk students in an inner city location. Paper presented at the $5^{\text {th }}$ Annual Utah Conference on Effective Practices in Special Education and Rehabilitation: Interventions Across the Life Span, Logan, UT.

Vasquez, E., Stenhoff, D., (2007) Research on ethnic minority students: An analysis of 11 years of studies published in JABA. 33rd Annual Convention of the International Association for Behavior Analysis, San Diego, CA.

Vasquez, E., Forbush, D., Stenhoff, D., Lockwood, A., Gleed, L. (2007). An evaluation of the effectiveness, efficiency, and feasibility of live on-line tutoring for remediating students skill deficits. $33^{\text {rd }}$ Annual Convention of the International Association for Behavior Analysis, San Diego, CA

Morgan, R. L., Vasquez, E. (2007). Teaching applied behavior analysis to pre-service teachers. 33rd Annual Convention of the International Association for Behavior Analysis, San Diego, CA

Vasquez, E. (2007). Assessing tutees reading skills at a distance via a live online system. $10^{\text {th }}$ Annual Graduate Research Symposium. Logan, UT.

Forbush, D., Vasquez, E., Salzberg, C., Lockwood, A., Gleed, L. (2007). Delivery and evaluation of live audio/video internet based reading tutoring. 27 th $A n n u a l$ Conference of the American Council on Rural Special Education. Billings, MT. 
Forbush, D., Vasquez, E., Mason, L. (2007) Assessing tutees reading skills at a distance via a live audio/video internet based system. 27th Annual Conference of the American Council on Rural Special Education. Billings, MT.

Stenhoff, D. \& Forbush, D., Vasquez, E. (2006). Assessing undergraduates' delivery of an achievement test with an internet-based tool. 29th Annual Convention of the Teacher Education Division of the Council for Exceptional Children. San Diego, CA.

Morgan, R. L., \& Vasquez, E. (2006, June). Teaching functionally equivalent replacement behaviors: don't agitate. Communicate! Paper presented at the 4th Annual Utah Conference on Effective Practices in Special Education and Rehabilitation: Interventions Across the Life Span. Logan, UT.

Morgan, R. L., \& Vasquez, E. (2005, June). Teaching functionally equivalent replacement behaviors to students with problem behaviors: What, how, and why. Paper presented at the 3rd Annual Utah Conference on Effective Practices in Special Education and Rehabilitation: Interventions Across the Life Span. Logan, UT.

Ninness, C., Rumph, R., McCuller, G., Harrison, C., Vasquez, E., Bradfield, A., Ninness, S., (2003, May) Artificial neural network analysis of derived relational frames. Presentation at the International Association for Behavior Analysis, San Francisco, California

Vasquez, E., Ninness, C., Rumph, R., McCuller, G. (2003, May) Error Pattern recognition: artificial neural network analysis of transformation of functions. Poster session presented at International Association for Behavior Analysis, San Francisco, California.

Vasquez, E. (2002, November) A comparison of parametric and randomized muitivariate statistics using Monte Carlo methods: A computer generated approach. Poster session presented at Texas Association of School Psychologists, Dallas, Texas.

Vasquez, E. (2002, March) Small group statistics: A Monte Carlo comparison of parametric and randomization tests. Poster session presented at the Texas Association of Applied Behavior Analysis, Houston, Texas.

Calliou, M., Vasquez, E., (2002, March) The effects of using differential reinforcement of alternative (DRA) on self-stimulatory behaviors. Poster session presented at the Texas Association of Applied Behavior Analysis, Houston, Texas. 
INSERVICES \& WORKSHOPS

Davey, B., Stenhoff, D., Vasquez, E. (2008). Efficient Use of Microsoft Excel for Behavior Analysis and Practitioners to Graphically Communicate Outcomes. Workshop at the $34^{\text {th }}$ Annual Convention of the International Association for Behavior Analysis, Chicago, IL

Stenhoff, D., Davey, B., Vasquez, E. (2007). Efficient use of Excel for behavior analysis and practitioners to graphically communicate outcomes. Workshop at the $33^{\text {rd }}$ Annual Convention of the International Association for Behavior Analysis, San Diego, CA

Davey, B., Stenhoff, D., Vasquez, E. (2006). Using Excel spreadsheets and graphs for visual display of individual behavior and academic performance in applied settings. Workshop at the $32^{\text {nd }}$ Annual Convention of the International Association for Behavior Analysis, Atlanta, GA

\section{COURCES TAUGHT/ASSISTED}

\section{University of Central Florida}

EEX 4601 Introduction to Behavior Management: This undergraduate class is a study of management techniques based on applied behavior analysis principles for modifying inappropriate behaviors and maintaining appropriate behaviors of exceptional students. It will include practical application, of these principles that will increase skill in working with large groups and multiple groups of students with diverse learning, behavioral,

EEX 6612 Methods for Behavior Management: The course content includes analysis of the principles of behavior management and application of these principles to the solving of classroom management problems. It is a 3 semester hours course intended for graduate students pursuing a master's degree in varying exceptionalities or those seeking certification in varying exceptionalities.

\section{Utah State University}

SPED 5010

Applied Behavior Analysis I: Principles, Assessment and Analysis Undergraduate/graduate class presenting methods of collecting data, making data-based decisions, and applying principles of behavior management and instruction to children and youth in class and school wide settings

SPED $5050 \quad$ Applied Behavior Analysis II: Applications Undergraduate/graduate class providing in-depth examination of functional assessment, functional analysis, behavioral intervention based on functional analysis, punishment and ethical issues related to implementation, policies governing use of punishment and other behavior interventions, and assessment/intervention for students with autism and emotional disturbance/behavior disorders.

SPED 5610 Practicum: Instruction for Persons with Severe Disabilities 
Undergraduate field experience in working with students with severe disabilities in secondary settings.

SPED Advanced Behavior Analysis (Distance Online Class)

6620/7720 Teaching Assistantship Masters/doctoral level class discussing advanced

Stephen F. Austin State University topics and issues in behavior analysis

SPE 539

Introduction to applied behavior analysis

Undergraduate level class discussing behavior management for classroom and community use with students with disabilities.

SPE $550 \quad$ Research Methods

Masters level class discussing advanced study of research procedures

CONSULTATION, COMMUNITY \& UNIVERSITY SERVICES

August Faculty Search Committee member, Department of Special Education and

2006 - May Rehabilitation, Utah State University

2007

August

Graduate Student Representative, Doctoral Committee. Department of

2006 - May

2007

August

2006 - May

2007

July 2005

Nov. 2001-

May 2002

May 2002-

Aug 2002

Aug 2001-

2003

REVIEWS

May 2006

October 2006

July 2006

February

2007

February

2007

Special Education and Rehabilitation, Utah State University

Senator, Graduate Student Senate. Utah State University

Guest Panelist: CLD in Department of SPED

Student representative for search committee for the Dean of Education at Stephen F. Austin State University. Nacogdoches, TX.

Student representative for search committee for Faculty in the Department of Human Services, Stephen F. Austin State University. Nacogdoches, TX. President of Student Association for Behavior Analysis. Stephen F. Austin State University. Nacogdoches, Texas

Guest Reviewer, Rural Special Education Quarterly

Guest Reviewer, Education and Treatment of Children

AWARDS AND FELLOWSHIP

- Dissertation Research Proposal Award from the American Council on Rural Special Education (ACRES) 2008.

- Graduate Student Presentation Award from $10^{\text {th }}$ Annual Graduate Research Symposium 2007. Logan, UT

- Doctoral Fellowship, 2004 - 2008, Department of Special Education, Utah State University.

- 2004 Thesis Award nominee, Stephen F. Austin State University.

- Student Presentation Award from the International Association for Behavior Analysis. 2003 Conference, San Francisco, CA. 
- Recognized as student researcher of the year at the Texas Association of School Psychologists 2002 Conference.

- Accepted into the Who's Who Among Students in American Universities \& Colleges 2002.

\section{PROFESSIONAL MEMBERSHIPS}

Association for Behavior Analysis

National Association for School Psychologists

Council for Exceptional Children

Council for Children with Behavioral Disorders

Division for Learning Disabilities

Teacher Education Division 